\title{
FABRICATION AND OPTIMIZATION OF DYE-SENSITIZED SOLAR CELLS
}

\author{
by \\ Benjamin Fischer
}

BSc., Ryerson University, 2015

\author{
A thesis presented to Ryerson University \\ in partial fulfillment of the requirements for the degree of \\ Master of Applied Science in the program of \\ Environmental Applied Science and Management
}

Toronto Ontario, Canada, 2017

(C)Benjamin Fischer 2017 


\section{Author's Declaration}

I hereby declare that I am the sole author of this thesis. This is a true copy of the thesis, including any required final revisions, as accepted by my examiners. I authorize Ryerson University to lend this thesis to other institutions or individuals for the purpose of scholarly research. I further authorize Ryerson University to reproduce this thesis by photocopying or by other means, in total or in part, at the request

of other institutions or individuals for the purpose of scholarly research. I understand that my thesis may be made electronically available to the public. 


\title{
Abstract
}

\author{
Fabrication and Optimization of Dye-sensitized Solar Cells \\ Master of Applied Science \\ 2017 \\ Benjamin Fischer \\ Environmental Applied Science and Management \\ Ryerson University
}

Dye-Sensitized Solar Cells (DSSCs) have garnered considerable attention given their desirable design properties including, transparency and flexibility. A considerable amount of research has been done in all facets of the DSSC permitting significant progress in device development. However, there is still much improvement needed to make DSSCs a viable alternative energy option. The $\mathrm{I}^{-} / \mathrm{I}_{3}{ }^{-}$electrolyte has been used extensively in DSSCs but has inherent drawbacks including its absorption range and corrosiveness to DSSC components. Recently, cobalt based electrolytes and hole transport materials (HTMs) have shown promise of improved performance, especially in combination with metal free dyes. This thesis aims to develop a mastery of device fabrication and then study and compare various electrolytes paired with triphenylamine (TPA) and BODIPY based dyes with the aim of improving DSSC efficiency and long-term stability. 


\section{Acknowledgments}

First, I would like to thank my supervisor Bryan. In the five years I've known Bryan, he's been my instructor and supervisor, but most importantly he's been a mentor. Bryan has been a model for what hard work, generosity, and dedication can accomplish. I can't thank him enough for the profound impact his influence and example have had, and will continue to have on my life.

All my lab-mates, past and present, deserve an enormous thank you not just for their help and for what they have taught me, but for making the lab a fun and supportive environment to be a part of. I will always look back fondly on the time I spent in KHE 211. I especially want to thank Omar Abdi, Catherine Bonnier, Francis Buguis, Hardeep Devgan, Muntaser Farooque, Devin Machin, and Selvyn Simoes for their synthetic efforts towards dyes and electrolytes, and I couldn't forget to thank Sahana Sritharan for her support throughout the course of my masters either.

Beyond our lab I must thank everyone else in the department for always being there. Whether it be working through chemistry questions or borrowing reagents, no one ever hesitates to extend their help when it is needed. Special shout-outs to KHN 202 and KHE 322C.

I also want to thank my committee members Dr. Foucher and Dr. McWilliams for their time and effort reviewing my thesis and Dr. Oswald for chairing my defence. Their efforts helped make this thesis the best it could be. Additionally, I want to thank the Berlinguette group at UBC for their training with DSSC fabrication and the Bender group at U of T, especially Anjuli Szawiola, for supplying materials.

I want to thank my fellow EnSciMan students and my friends and family, especially my parents for their encouragement during the long path that has led to this thesis. Lastly, I want to thank my fiancé Allie. I can't begin to articulate how much she has contributed to me reaching this point. She has always been there for me and I am truly grateful. 


\section{Table of Contents}

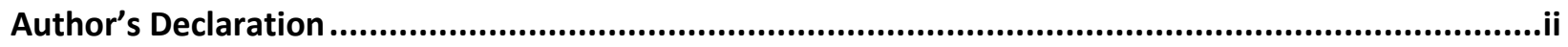

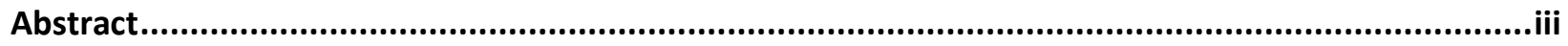

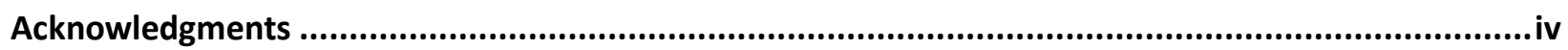

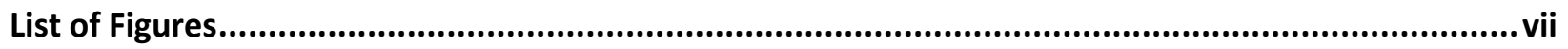

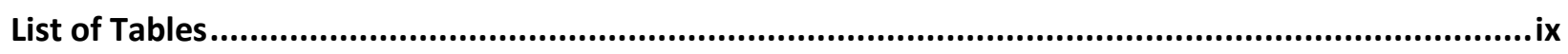

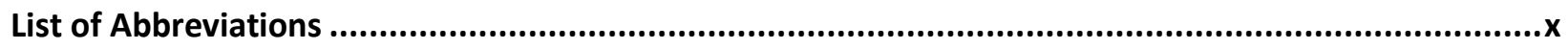

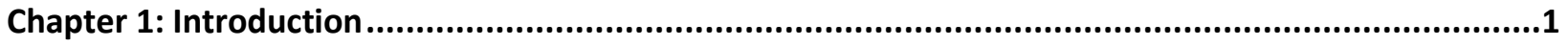

1.1 Current State of Energy Production and Consumption ........................................................ 1

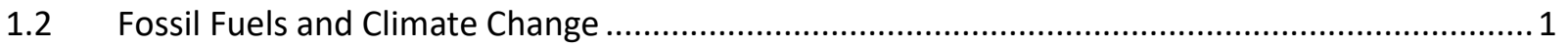

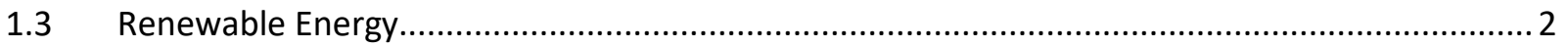

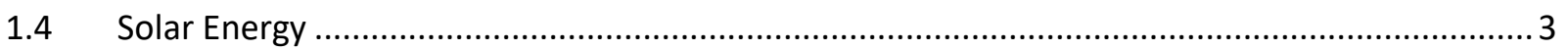

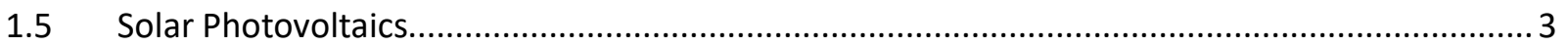

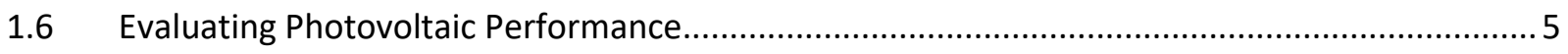

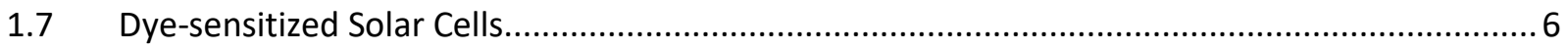

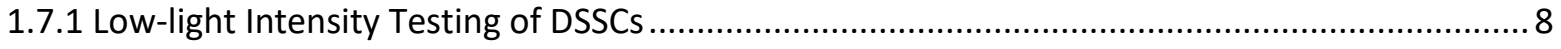

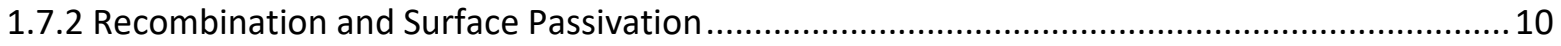

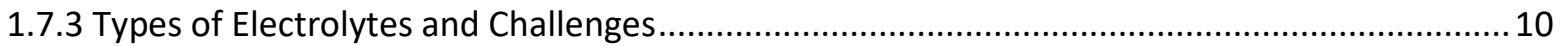

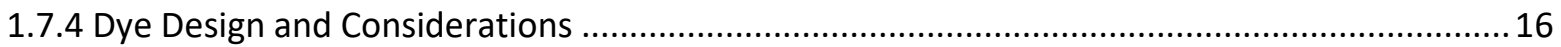

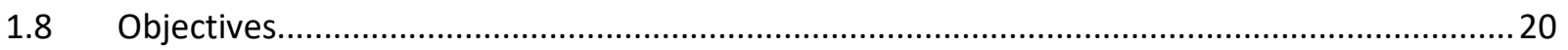

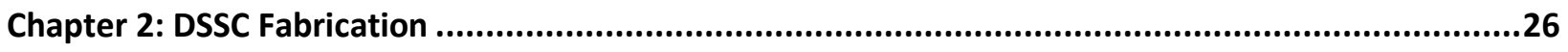

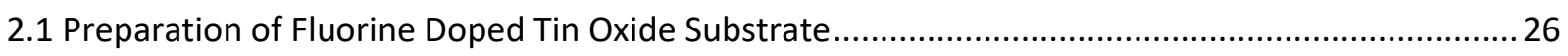

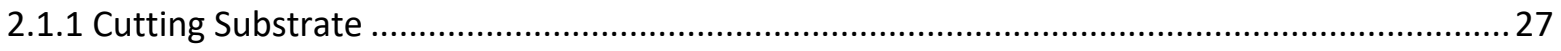

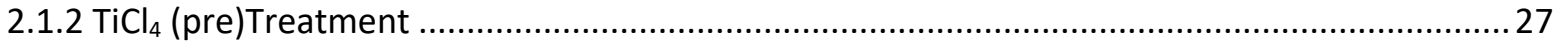

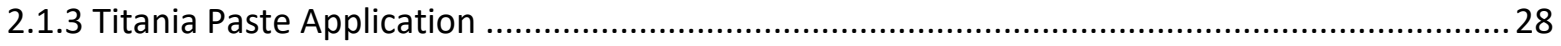

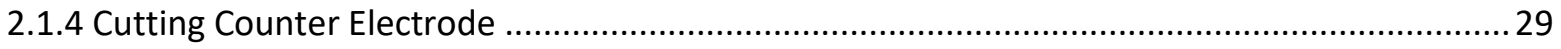

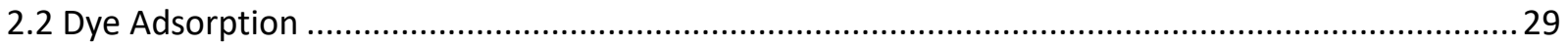

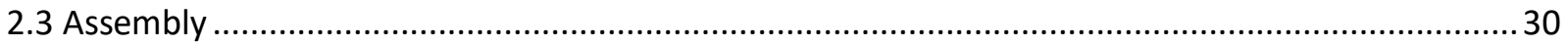

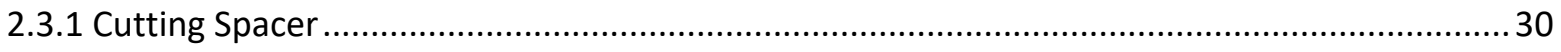

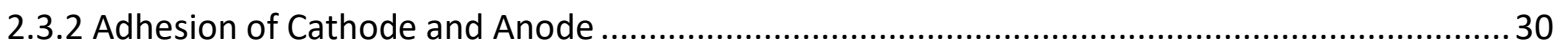

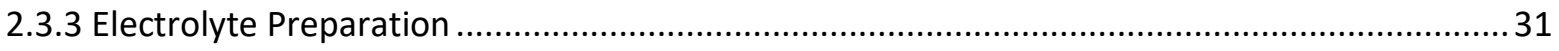

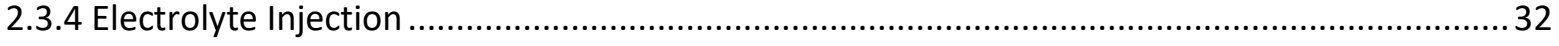




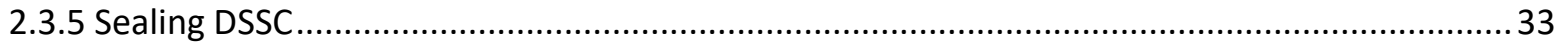

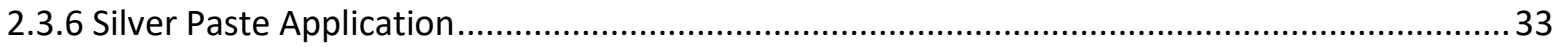

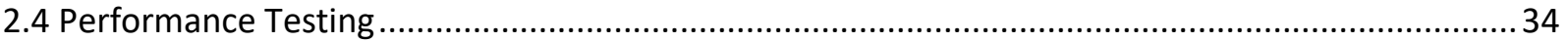

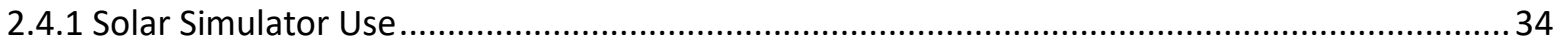

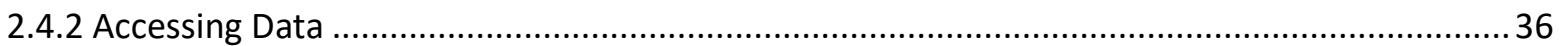

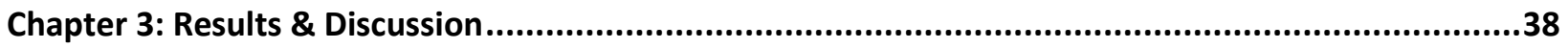

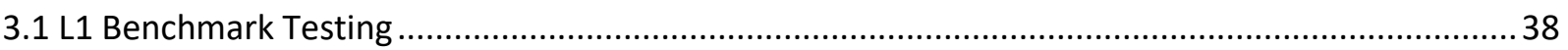

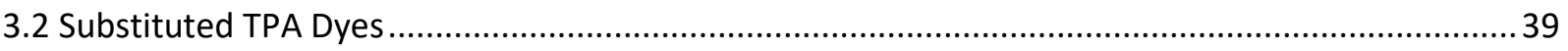

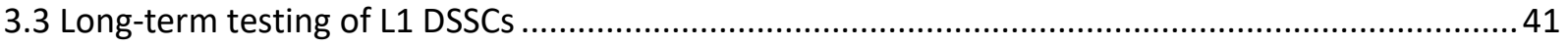

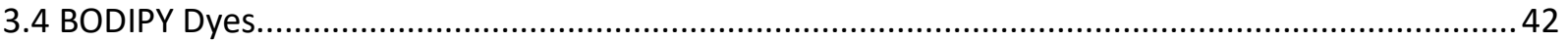

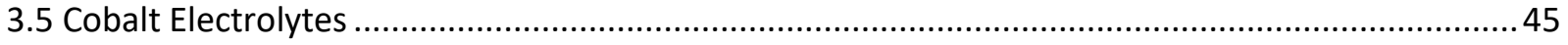

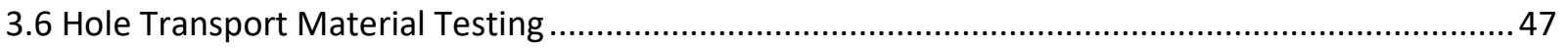

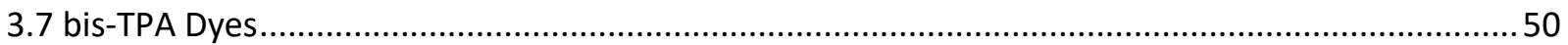

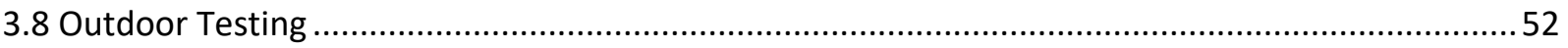

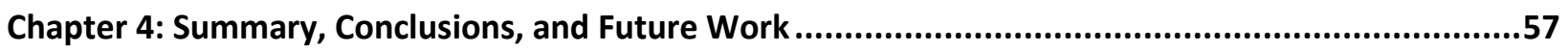

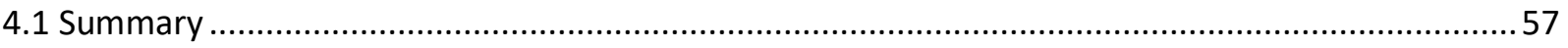

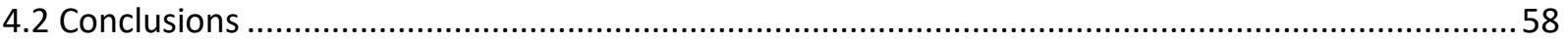

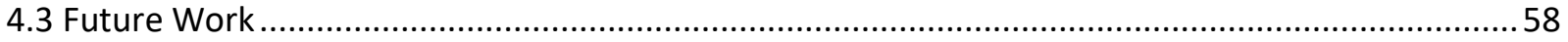

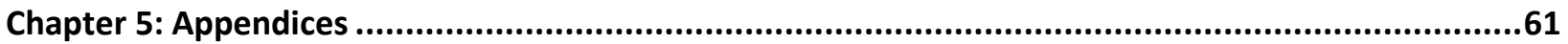

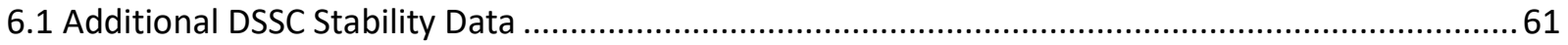

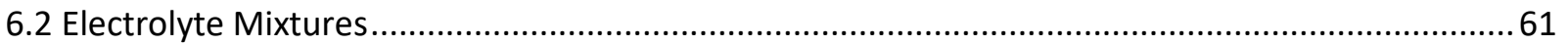

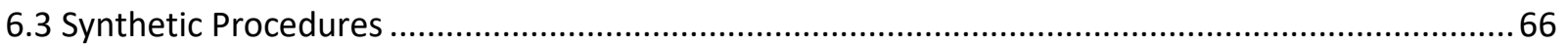

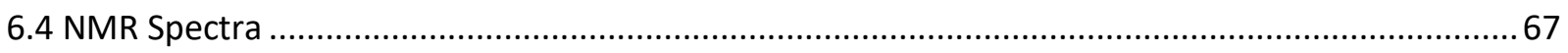

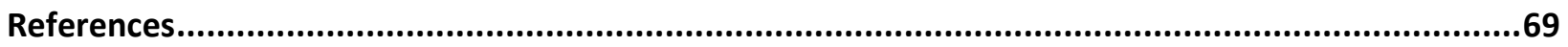




\section{List of Figures}

Figure 1 Annual solar irradiation compared to demand and fossil fuel reserves..................................... 3

Figure 2 First generation (monocrystalline silicon) solar cells (Woodbridge, ON) ................................... 4

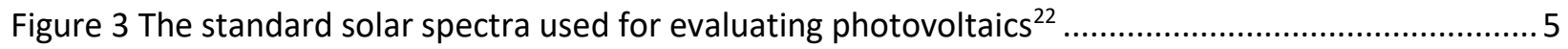

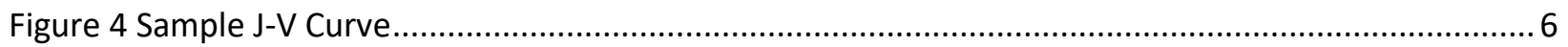

Figure 5 Left - The structure and working principle of the DSSC, Right - A three-dimensional

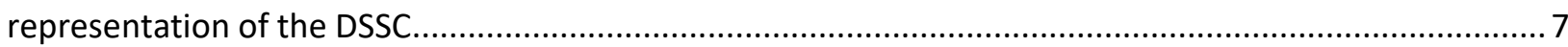

Figure 6 Co-adsorbents deoxycholic acid (DCA) and chenodeoxycholic acid (CDCA) used for surface

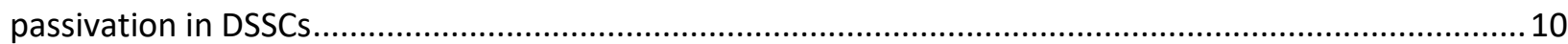

Figure 7 Electrolyte added surface passivator 4-tertbutyl pyridine ...................................................11

Figure 8 Lithium salt effects on titania conduction band and open circuit voltage .................................12

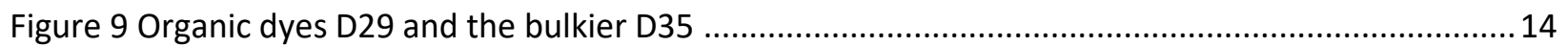

Figure 10 Cobalt complexes used by Chen et. al. to attain high open circuit voltages in DSSCs...............15

Figure 11 Dyes molecules derived from natural sources................................................................... 17

Figure 12 Ruthenium based dyes Black dye and N719 synthesized by the Gratzel group ......................18

Figure 13 Zinc porphyrin dye SM315 used to fabricate 13.0\% efficient DSSC........................................19

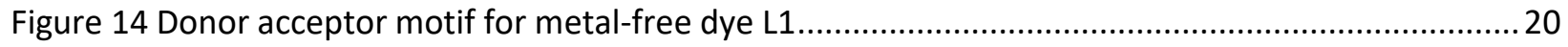

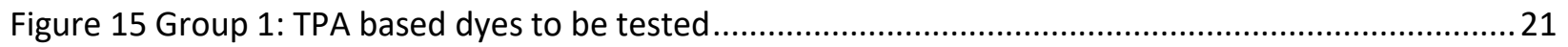

Figure 16 Group 2: bis-TPA based dyes to be tested .........................................................................22

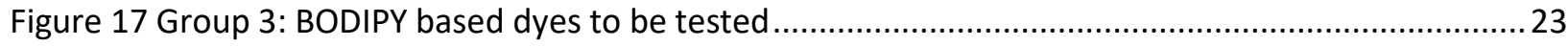

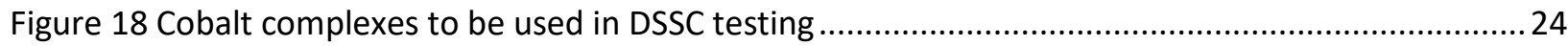

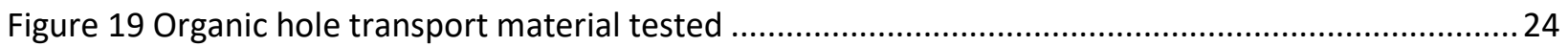

Figure 20 Flow chart outlining the anode preparation process which was adapted from previous work ${ }^{64}$

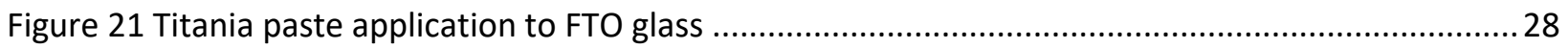

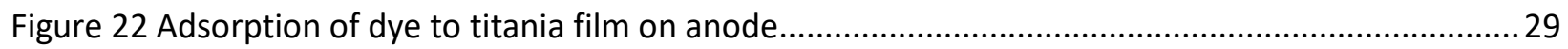

Figure 23 Surlyn border cut to fit around the titania film ................................................................. 30

Figure 24 Alignment of anode and cathode for adhesion together ....................................................31

Figure 25 Front and side view of DSSC filling apparatus with vacuum hose and septum appropriately placed (designed and fabricated by Dirk Verdoold at York University) ..................................................33

Figure 26 Solar simulator with reference cell positioned for testing. .....................................................35

Figure 27 SciRunIV program interface with example calibration data ................................................... 36

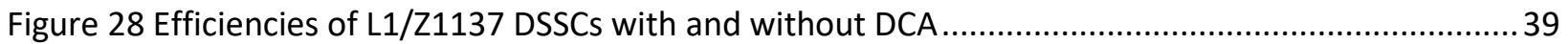

Figure 29 Efficiencies of L1, L1OMe, and L1SMe DSSCs with Z1137 electrolyte ....................................40

Figure 30 UV-Vis spectra of L1, L1OMe, and L1SMe dyes in DCM ...................................................... 41

Figure 31 Average efficiency of L1/Z1137 DSSCs tested periodically over one year ............................... 42

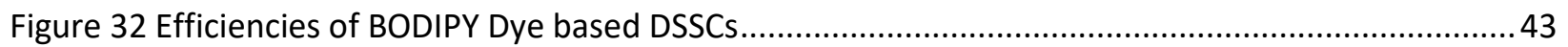

Figure 33 Efficiencies of long alkyl chain BODIPY DSSCs................................................................. 43

Figure 34 Efficiencies of BODIPY dye DSSCs with and without $\mathrm{Li}^{+}$added to the $\mathrm{Z1137}$ electrolyte ...........44

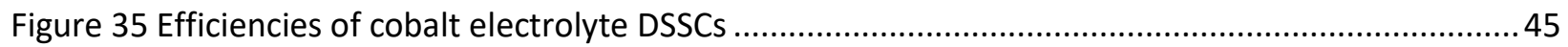

Figure $36 \mathrm{~d}$ electron configuration in Co-dmpb complex vs Co-bpy and Co-terpy complexes ..................46

Figure 37 Efficiencies of Co-dmpb electrolyte DSSCs ...................................................................... 47 
Figure 38 Efficiencies of L1 DSSCs with varied MeCN and DCM electrolyte mixtures with and without DCA

Figure 39 Efficiencies of L1 DSSCs with oxidant containing HTM electrolyte and regular HTM electrolyte

Figure 40 Colour change upon addition of oxidant to HTM electrolyte mixture .................................... 49

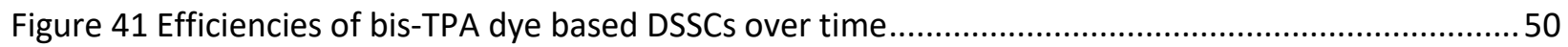

Figure 42 Efficiencies of OA1 DSSCs with varying DCA concentrations ................................................51

Figure 43 Change in sun power measured over a 15-minute window between 3:55 pm and 4:10 pm on

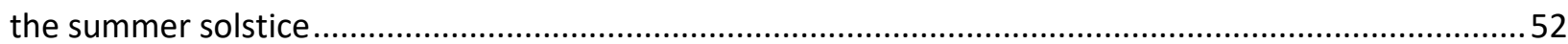

Figure 44 Measured incident power of sun from different light sources at different conditions..............53 Figure $45 \mathrm{~J}-\mathrm{V}$ curves of DSSC 130 (OA1+DCA/Z1137) after 112 days under full outdoor sun, outside

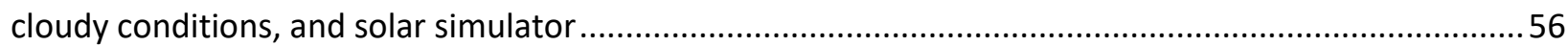

Figure 46 Thiophene functionalized TPA based dyes ..........................................................................59

Figure 47 DSSC containing a thiophene functionalized TPA dye paired polymerized with the PEDOT HTM 59

Figure 48 Anodes dipped in various coloured dye solutions used in DSSC fabrication .............................60

Figure 49 Efficiency data for all bis-TPA dyes with and without DCA ..................................................61 


\section{List of Tables}

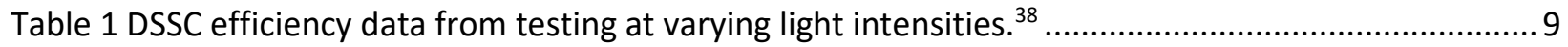

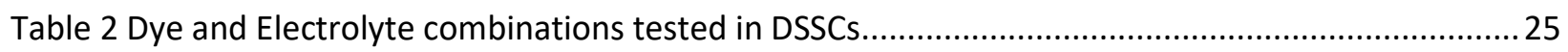

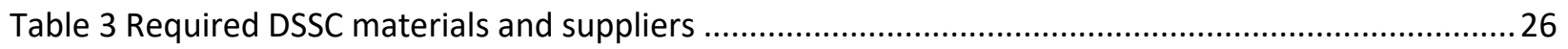

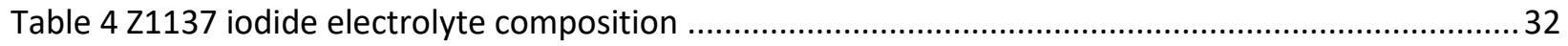

Table 5 Best performance data of L1 DSSCs with and without DCA ( 7 days after fabrication) ...................39

Table 6 Best performance data of dyes L1, L1OMe, and L1SMe (48 hours after fabrication) ...................40

Table 7 Average DSSC performance data of dye 10B paired with Z1137+Li ${ }^{+}$and Z1137 ........................44

Table 8 Average efficiency data of cobalt electrolyte DSSCs with L1 and DCA ......................................46

Table 9 Average efficiency data of HTM based DSSCs with and without DCA .....................................48

Table 10 Average DSSC data for bis-TPA dyes tested without DCA 24 hours after fabrication .................50

Table 11 Average DSSC performance parameters of 10:1 and 0:1 DCA:OA1 at 2 and 10 days ................52

Table 12 Efficiencies of DSSCs tested under full outdoor sun, cloudy or shady conditions, and solar simulator 54

Table 13 DSSC performance data for DSSC \# 130 (OA1+DCA, Z1137) under varying light intensities 112

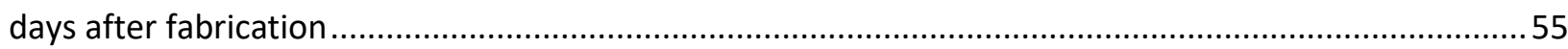

Table 14 Efficiencies (\%) of dye and electrolyte combinations tested in DSSCs ....................................58 


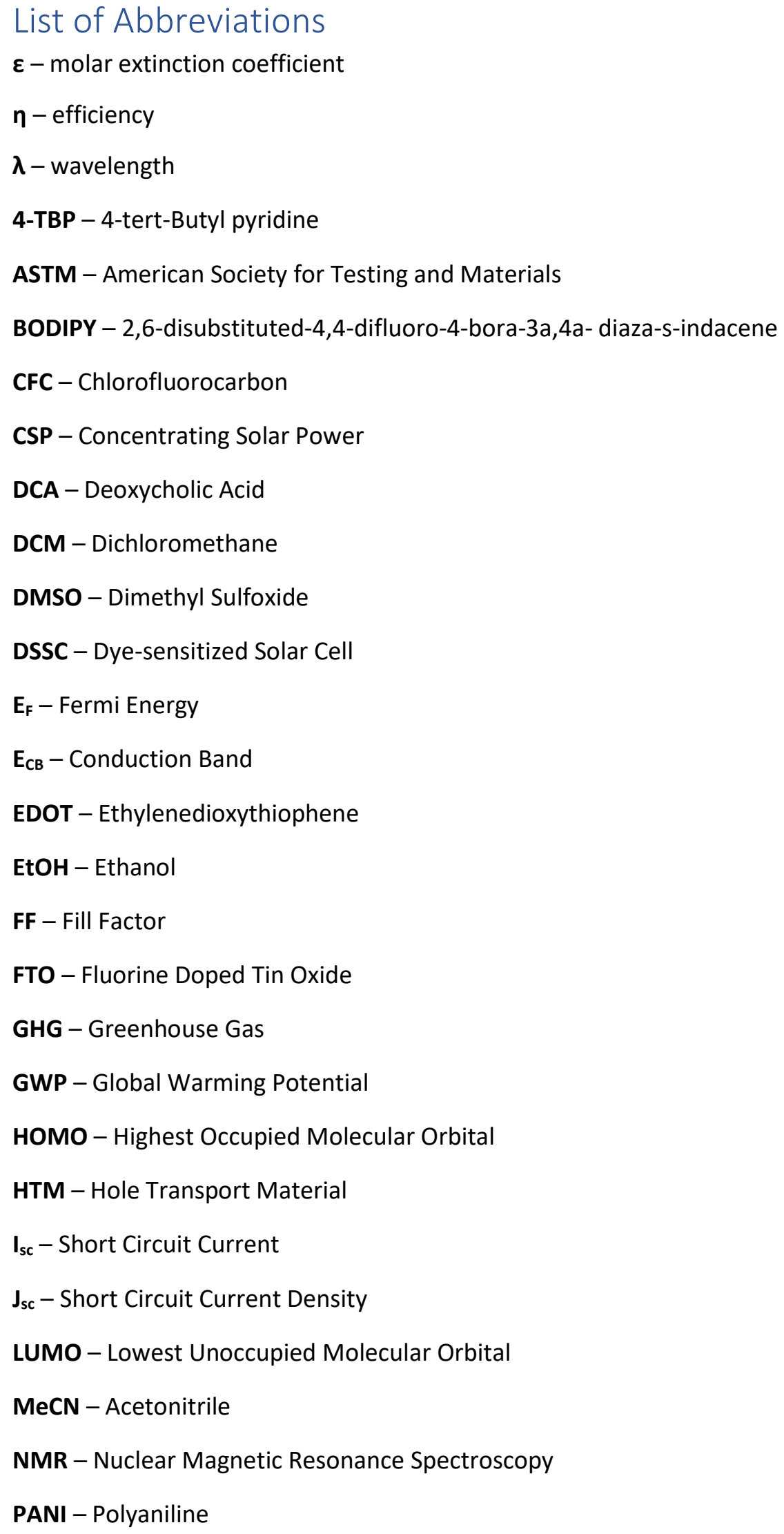


PEDOT - Polyethylenedioxythiophene

$P_{\text {in }}-$ Incident Power

$\mathbf{P}_{\max }$ - Maximum Power Output

PV - Photovoltaic

TPA - Triphenylamine

$\mathbf{V}_{\text {oc }}$ - Open Circuit Voltage

XRD - X-ray Diffraction 


\section{Chapter 1: Introduction}

\subsection{Current State of Energy Production and Consumption}

Global primary energy consumption in 2015 was 13.1 billion tonnes of oil equivalents of which $86 \%$ was generated by fossil fuels. ${ }^{1}$ Electricity generation accounts for $40 \%$ of global energy use ${ }^{2}$ and $66 \%$ of that is generated from fossil fuels. ${ }^{3}$ Fossil fuel energy generation results in over 10 gigatonnes of carbon dioxide $\left(\mathrm{CO}_{2}\right)$ emissions annually which severely contribute to the global climate change problem. ${ }^{2,4}$ Due to this catastrophic issue and the finite nature of fossil fuels, there needs to be a paradigm shift to reduce and eventually eliminate reliance on fossil fuels to avoid the effects of climate change. Although technological methods such as increasing the efficiency of residential and industrial consumption can alleviate concerns, they can not fully mitigate them. To solve this problem, renewable energy sources must be improved to meet global energy demands. To that end, this thesis aims to improve the efficiency and long-term stability of next generation solar cells such that they are a viable alternative energy option.

\subsection{Fossil Fuels and Climate Change}

The effect of greenhouse gasses (GHGs) is well established, with $\mathrm{CO}_{2}$ studied as far back as the $1930 \mathrm{~s}^{5}$ and other GHGs studied widely by national bodies dating back to the early 1980 s. ${ }^{6}$ The greenhouse effect occurs by the following mechanism; shortwave radiation emitted by the sun passes through the earths atmosphere, the earth absorbs this radiation and then re-emits longer wavelength radiation, gases present in the atmosphere then absorb and re-emit the longer wavelength radiation. This absorption and re-emission warms the earth making it habitable. However, if the concentration of GHGs increases beyond appropriate levels, temperatures can warm beyond ideal ranges. ${ }^{7}$

Carbon dioxide $\left(\mathrm{CO}_{2}\right)$, methane $\left(\mathrm{CH}_{4}\right)$, nitrous oxide $\left(\mathrm{N}_{2} \mathrm{O}\right)$, ozone $\left(\mathrm{O}_{3}\right)$, and water $\left(\mathrm{H}_{2} \mathrm{O}\right)$ are all naturally occurring greenhouse gases that can also be anthropogenic, while other GHGs such as 
chlorofluorocarbons (CFCs) do not naturally occur and are solely anthropogenic. ${ }^{7}$ The extent to which GHGs contribute to the greenhouse effect depends on how strongly a GHG absorbs and the lifetime over which it is present in the atmosphere. ${ }^{8}$ Based on these factors, the overall impact of a GHG can be summed up by its Global Warming Potential (GWP). $\mathrm{CO}_{2}$ acts as the base unit with a GWP of 1.0 while other GHGs are assigned relative to $\mathrm{CO}_{2}$. $\mathrm{CH}_{4}$ for example has a GWP of $10 .^{8}$

Economic and population growth are the largest drivers of increased $\mathrm{CO}_{2}$ emissions. As populations and economies grow, the need for energy increases which has made fossil fuel combustion and industry the largest contributors to increasing GHG emissions. Approximately half of anthropogenic $\mathrm{CO}_{2}$ emissions from 1750 to 2010 were emitted in the last 40 years $^{9}$ indicating the correlation between emissions and economic and population growth. The effects of increased global temperatures include rising sea levels, changes to ocean currents, and changes to regional precipitation among others. ${ }^{7}$ These changes can have profound impacts on populations which illustrates the need to phase out fossil fuels and replace them with renewable energy sources.

\subsection{Renewable Energy}

A number of low carbon intensity energy sources exist. ${ }^{10}$ Hydroelectric, tidal, wind, geothermal, and solar are all possible alternative energy sources but each have their own unique challenges. ${ }^{2}$ The desire for renewable energy is motivated by many factors, including independence from commodity fuel prices but more importantly reduced impact on the environment. In the 1970's when fossil fuel consumption was growing much faster than production, the need to reduce dependence on imports brought conservation to the forefront of the energy sector. ${ }^{11}$ This change in thinking paved the way for renewable energy development. 


\subsection{Solar Energy}

Solar energy is a promising option given that the earth receives $\sim 174 \mathrm{PW}$ of power from the sun. ${ }^{4}$ Compared with human power consumption, this is approximately 10,000 times the global annual demand as seen in Figure 1.,12 Solar energy can be harnessed in three main ways. The simplest method is through water and space heating. ${ }^{13}$ Although this method does not generate electricity, it can offset the need for electric water or space heating, lowering overall demand. Solar energy can also be used to generate electricity indirectly through concentrating solar power (CSP). ${ }^{13}$ In CSP, light is focused on a central point, generally by a mirror but potentially using lenses, which heats a molten salt to high temperatures. This salt is then used to boil water generating steam which can turn a turbine to generate electricity by the standard Rankine cycle. ${ }^{14}$ Lastly, solar energy can be converted directly into electricity through the use of photovoltaics (PV). ${ }^{4}$

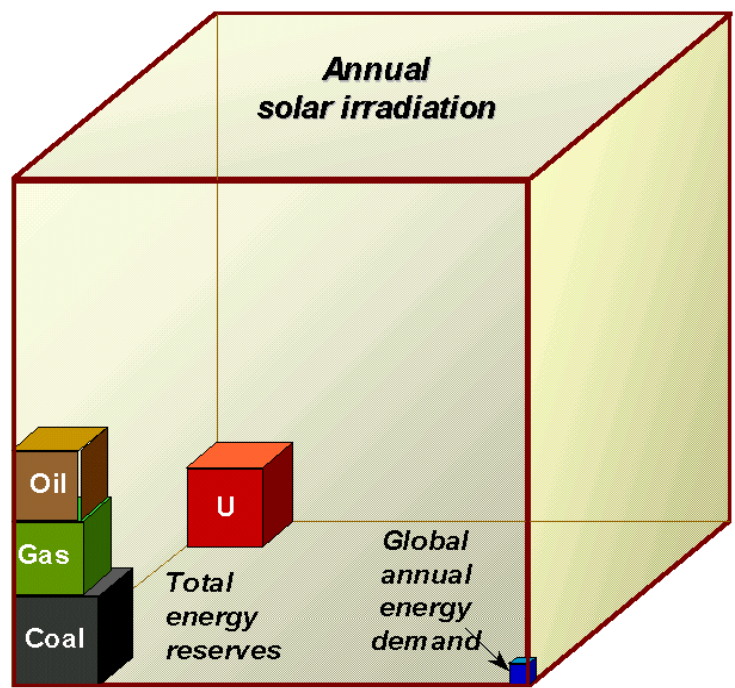

Figure 1 Annual solar irradiation compared to demand and fossil fuel reserves

\subsection{Solar Photovoltaics}

The development of PV dates to 1839 when Alexandre Becquerel first observed the photovoltaic effect. Becquerel observed that illumination of certain materials would generate electric current. ${ }^{15}$ In 1877 researchers Adams and Day corroborated this when they observed the photovoltaic effect in selenium. ${ }^{12}$ Before the first modern PV device was created, the closest work was on thermoelectric generators in 
which heat was used to generate electricity. ${ }^{16}$ These devices had efficiencies of approximately $1 \%$ emphasizing the importance of the landmark $6 \%$ efficiency achieved by silicon solar cell when created in $1954 .{ }^{17}$

First generation solar began with the first silicon solar cell in 1954 and encompasses all mono and polycrystalline silicon solar cells which are shown in Figure $2 .{ }^{12}$ These cells contain a single junction between the $\mathrm{p}$ and $\mathrm{n}$ doped silicon. Through continued innovation ${ }^{18}$ efficiencies of commercially available first generation solar cells have reached well into the $20 \%$ range. As such, research on first generation solar technology has slowed as cells are limited by the properties of silicon to a theoretical $30 \%$ efficiency. ${ }^{19}$

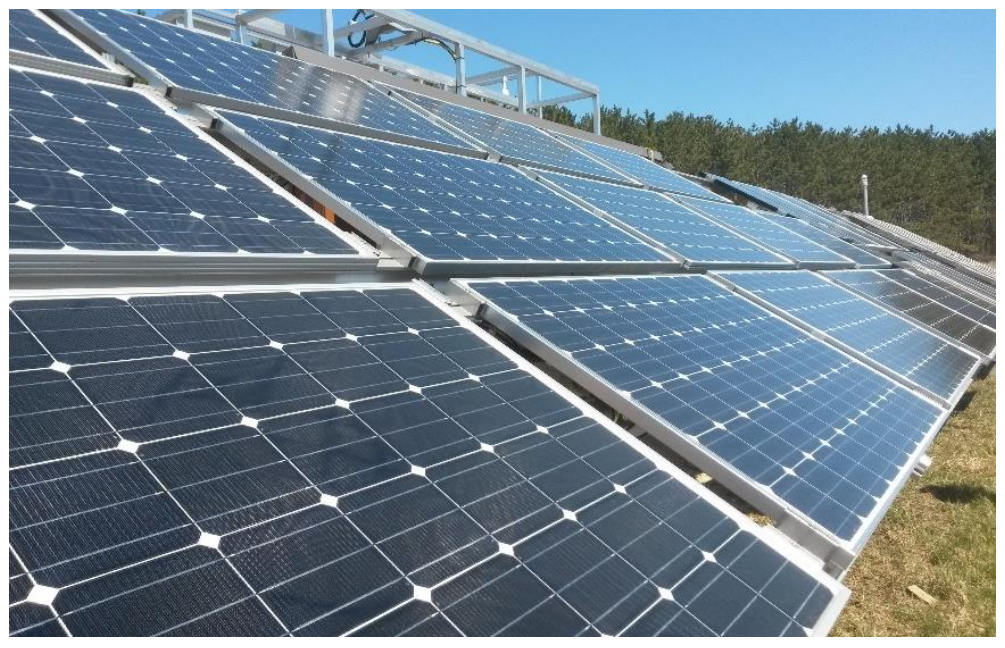

Figure 2 First generation (monocrystalline silicon) solar cells (Woodbridge, ON)

Second generation solar includes work on alternative materials in pursuit of lower production costs and thus lower energy costs. ${ }^{12}$ Some of the technologies developed as part of this generation are thin film solar cells including cadmium telluride (CdTe), gallium arsenide (GaAs), and copper indium diselenide $\left(\mathrm{CulnSe}_{2}\right) \cdot{ }^{20}$

Third or next generation solar is also focused on reducing costs and increasing efficiency, however the focus is on using multijunction cells, tandem cells, nano-substrates to increase surface area, and dyesensitized solar cells (DSSCs)..$^{12,21}$ 


\subsection{Evaluating Photovoltaic Performance}

When testing solar cells, the spectrum of light used is crucial. As solar cells are generally designed for use under the sun, they should be tested under similar conditions. As such, it is relevant that the sun produces a spectrum of light with varying intensities at each wavelength.

The American Society for Testing and Materials (ASTM) has defined the standard spectrum of light that reaches the earth's outer atmosphere as AM 0. Various gases present in the atmosphere absorb a portion of the light as it passes through the atmosphere necessitating another standard spectrum of light that reaches the earths surface. This is designated AM $1.5 \mathrm{G}$ and has a power of $1000 \mathrm{~W} / \mathrm{m}^{2}$. Both of these spectra are shown in Figure $3 .^{22}$ When testing solar cell performance, a simulator which can replicate the AM $1.5 \mathrm{G}$ spectrum of light must be used. Generally, the AM $1.5 \mathrm{G}$ power of $1000 \mathrm{~W} / \mathrm{m}^{2}$ is used, however sometimes higher or lower intensities of light are used to investigate performance under varied conditions (solar simulation will be elaborated later in section 2.4.1).

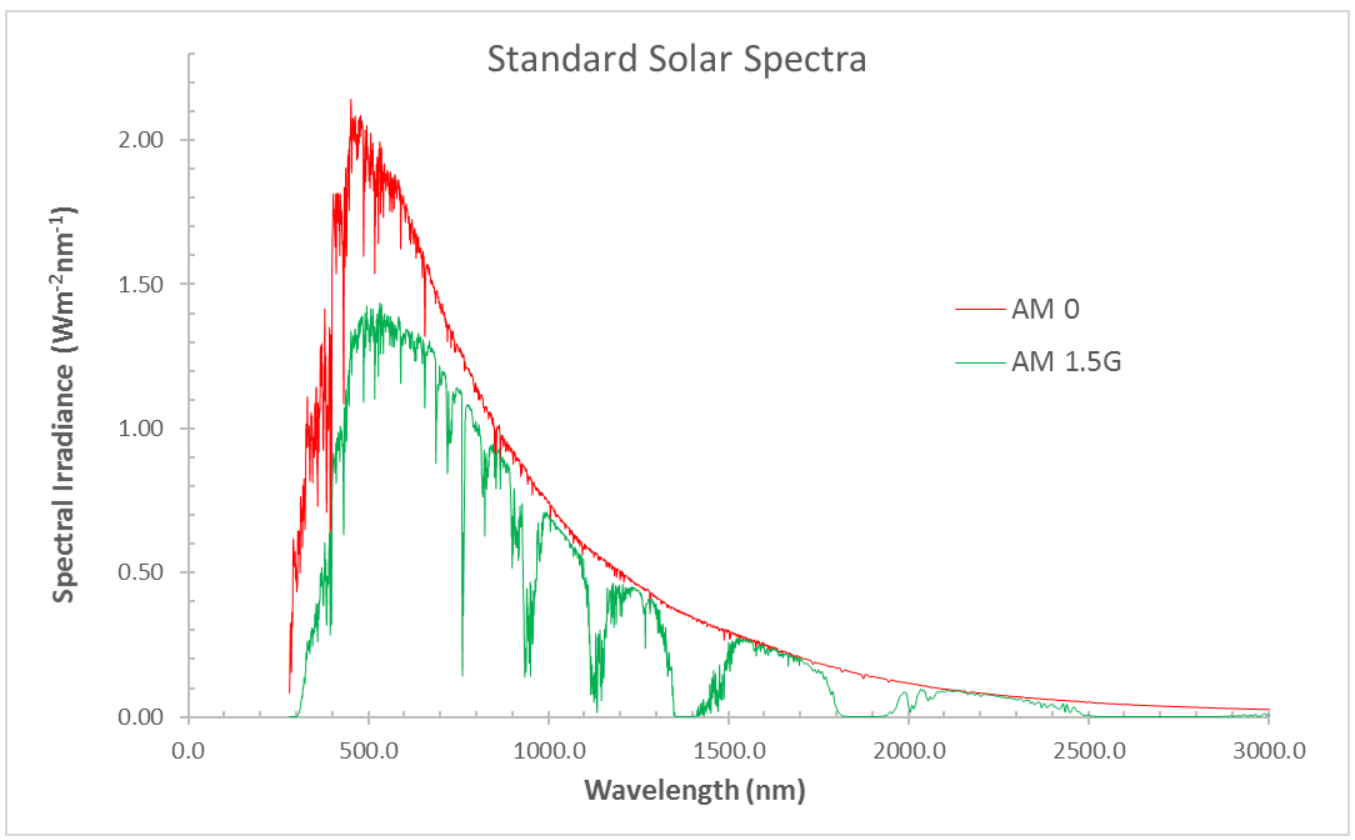

Figure 3 The standard solar spectra used for evaluating photovoltaics ${ }^{22}$ 
When testing solar cells, they are illuminated by the solar simulator and connected to a source meter. This source meter applies an equal and opposite voltage to the voltage produced by the solar cell until current can no longer flow. At this point, current drops to zero and the voltage at this point is known as the open circuit voltage $\left(\mathrm{V}_{\mathrm{oc}}\right)$. The maximum current generated is called the short circuit current $\left(\mathrm{J}_{\mathrm{sc}}\right)$. Additionally, fill factor (FF) which is a measure of the squareness of the curve, and the incident power ( $\left.P_{\text {in }}\right)$ are used to determine efficiency $(\eta)$ from the following relationship, $\eta=\frac{V_{o c} \times J_{s c} \times F F}{P_{\text {in }}}$ in which $V_{o c}$ is measured in volts $(V), J_{s c}$ is measured in amperes $(A)$ or $m A / \mathrm{cm}^{2}, F F$ is unit less, and $P_{\text {in }}$ is measured in watts $(\mathrm{W})$ or $\mathrm{Wm}^{-2} .{ }^{23}$ When this current and voltage data is plotted it yields a J-V curve like the on shown in Figure 4.

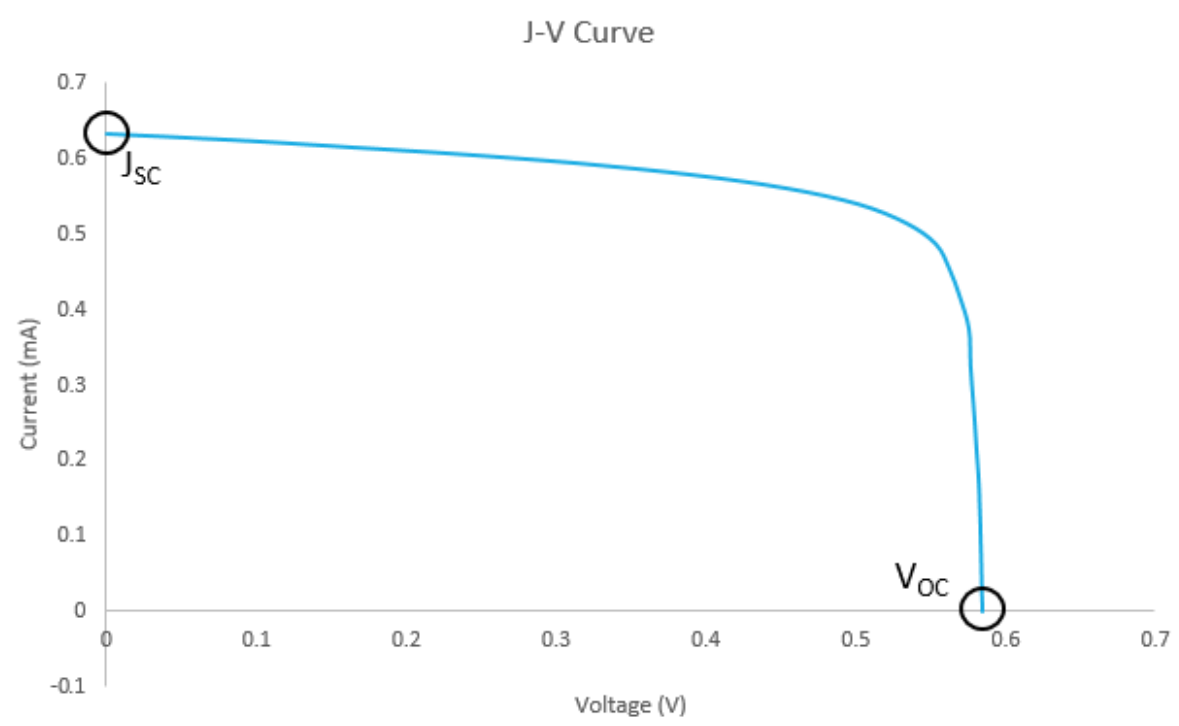

Figure 4 Sample J-V Curve

\subsection{Dye-sensitized Solar Cells}

In contrast to traditional crystalline silicon solar cells which rely on a semiconductor (silicon) to generate electricity, DSSCs use a dye molecule to harvest light. ${ }^{24}$ DSSCs were first created by the Michael Grätzel group in 1991 and used a ruthenium-containing dye.$^{25}$ The structure of a DSSC starts with two 
conducting glass electrodes, a cathode which has a thin layer of platinum deposited on it to catalyze reduction of the electrolyte, and an anode which has a thin layer of titania $\left(\mathrm{TiO}_{2}\right)$ nanoparticles coated onto it. The dye is then adsorbed onto the surface of the nanoparticles. The cathode and anode are then pressed together and sealed with a thin $(\sim 30 \mu \mathrm{m})$ thermoplastic sealent. ${ }^{26}$ An electrolyte is added between the two electrodes which shuttles electrons between the cathode and anode as illustrated in Figure 5.

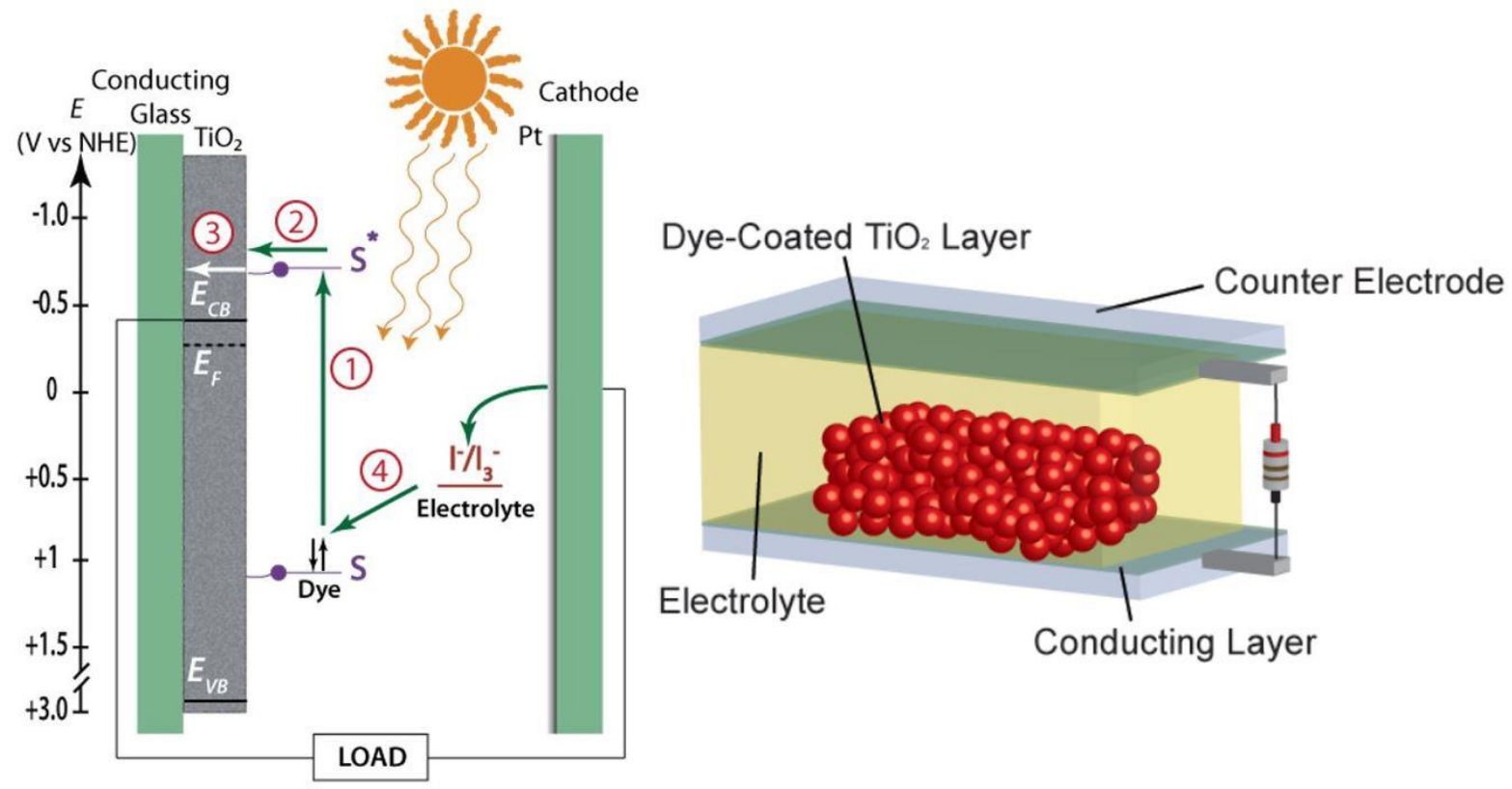

Figure 5 Left - The structure and working principle of the DSSC, Right - A three-dimensional representation of the DSSC

When light shines on a DSSC, the dye will absorb a photon (discrete packet of light) causing electronic redistribution in the molecule - in fact the dye acts like an electron pump. Electrons will move from the ground state or highest occupied molecular orbital (HOMO) to an excited state or lowest unoccupied molecular orbital (LUMO). When the dye is unbound, the excited electrons would relax back to the ground state. When the dye is bound, or adsorbed to titania, this opens a new path through which the excited electrons can travel. Electron injection into the titania is faster relative to relaxation back to the ground state of the dye making it more favourable for the electrons to enter the titania. Once electrons have 
moved into the titania, they can travel into the conducting glass electrode (anode) and from there pass though an external circuit powering a load. When the electrons reach the counter electrode (cathode), reduction of the electrolyte occurs. The electrolyte then shuttles an electron back to the dye reducing it to its original state. ${ }^{25}$

DSSCs present some distinct advantages when compared to crystalline silicon solar cells. ${ }^{21}$ DSSCs use a discrete molecule to absorb light. The advantage of this is that the molecule can be structurally tuned to absorb different regions of the electromagnetic spectrum. ${ }^{27} \mathrm{~A}$ large body of work exists on molecular tuning of dyes to broaden the spectrum of light that is absorbed and improve interaction with the electrolyte. ${ }^{28-30} \mathrm{~A}$ broader range of absorption will result in greater photon absorption leading to more current generation. This molecular nature of the DSSC also means that it allows some light to pass through. DSSCs are fabricated using a transparent substrate giving them the possibility of being incorporated into building windows in place of traditional glass. DSSCs also perform better than crystalline silicon solar cells in diffuse light conditions ${ }^{31}$ and at higher temperatures. ${ }^{21}$ This means DSSCs can still harvest energy on cloudy days while crystalline silicon solar cells can not. Research on DSSCs originates from the components of the DSSC itself. These include the conductive substrates ${ }^{32}$, the $\mathrm{TiO}_{2}$ nanoparticles ${ }^{33}$, the electrolyte ${ }^{34,35}$, and the dye. ${ }^{36}$ The focus of much of the research on DSSCs is to improve efficiencies and increase longterm stability.

\subsubsection{Low-light Intensity Testing of DSSCs}

Despite AM 1.5G being the standard spectrum cells are tested at, these conditions do not accurately reflect the conditions that solar cells operate at for most the year. Depending on time of day, time of year, and weather conditions, solar cells are rarely exposed to a full $1000 \mathrm{~W} / \mathrm{m}^{2}$. Although testing at AM 1.5G allows consistency when comparing measurements, there is merit in determining how the cells tested will perform under more realistic conditions. For example, Toyoda et al. previously tested a 
64 cell DSSC module for 6 months and observed 10-20\% higher electricity generation than from comparable crystalline silicon solar cells. ${ }^{37}$

More recent work by Bandara et. al. fabricated DSSCs utilizing a polyacrylonitrile-based gel electrolyte paired with the ruthenium dye N719 (discussed further in section 1.7.4) and tested them at 7 different light intensities ranging from $3 \%$ to $100 \%$ of AM $1.5 \mathrm{G}$ which is shown in Table $1 .{ }^{38}$ Their results showed an increase in efficiency of $236.4 \%$ when moving from $100 \%$ to $3 \%$ of AM 1.5 G. A similar trend was observed for fill factor with increasing values as light intensity decreased. $J_{s c}$ and $V_{o c}$ showed the opposite trend however. $\mathrm{J}_{\mathrm{sc}}$ decreased to $5.2 \%$ of the value observed at AM $1.5 \mathrm{G}$ while $\mathrm{V}_{\text {oc }}$ decreased to $86.7 \%$ of the value observed at AM $1.5 \mathrm{G}$.

Table 1 DSSC efficiency data from testing at varying light intensities. ${ }^{38}$

$\begin{array}{cccc}\text { (Intensity/one sun }) / \% & \left(\mathrm{~J}_{\mathrm{sc}} / \mathrm{J}_{\mathrm{sc}} \text {, one sun }\right) / \% & \left(\mathrm{~V}_{\mathrm{oc}} / \mathrm{V}_{\mathrm{oc}} \text {, one sun }\right) / \% & \eta / \eta \text { one sun/\% } \\ \mathbf{3 . 0} & 5.2 & 86.7 & 236.4 \\ \mathbf{1 1 . 0} & 22.1 & 89.8 & 218.3 \\ \mathbf{3 3 . 0} & 60.2 & 94.3 & 163.1 \\ \mathbf{5 5 . 0} & 78.8 & 96.0 & 128.7 \\ \mathbf{7 9 . 0} & 95.6 & 98.6 & 114.5 \\ \mathbf{9 3 . 0} & 97.8 & 99.2 & 102.6 \\ \mathbf{1 0 0 . 0} & 100 & 100 & 100.1\end{array}$

The authors explain that as light intensity increases, the charge generation rate increases causing an increase in the chemical potential of the cell, resulting in higher $\mathrm{V}_{\mathrm{oc}}{ }^{\prime} \mathrm{s}$. $\mathrm{J}_{\mathrm{sc}}$ improves with increasing light intensity due to a higher flux rate exciting more electrons. In contrast fill factor, benefits from low 
photocurrent. When the current is low, the series resistance decreases due to decreased diffusion limitations in the electrolyte allowing fill factor to increase.

\subsubsection{Recombination and Surface Passivation}

One of the drawbacks of molecular absorption of light (particularly with organic dyes) is that dye molecules can aggregate together. This can lead to recombination of the excited electron and the corresponding positive charge. One method to combat this is through co-adsorbents which bind to the titania and passivate the surface. Co-adsorbents occupy space between dye molecules so the dyes do not come in contact with one another preventing recombination. If dye molecules come in contact, an exciplex can be formed from which vibrational relaxation can prevent charge injection. Additionally, surface passivators block the surface of the titania, preventing recombination with the electrolyte. Some of the most common co-adsorbents are deoxycholic acid (DCA $)^{39}$ and chenodeoxycholic acid (CDCA $)^{21}$ which are both shown in Figure 6 . Both structures function similarly in that the carboxylic acid component binds to the titania and the bulky nature of the fused ring system allows it to effectively fill the space between dye molecules. The only difference between these two structures is the position of one alcohol group making them both reasonable options of surface passivation.

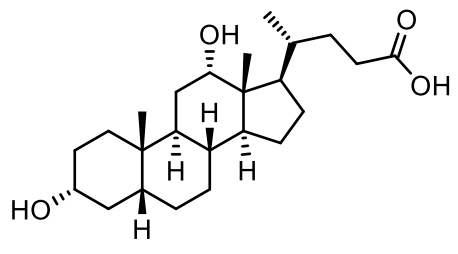

1.1 Deoxycholic acid

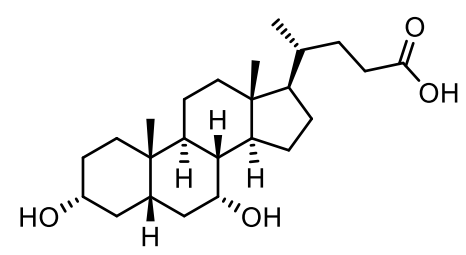

1.2 Chenodeocycholic acid

Figure 6 Co-adsorbents deoxycholic acid (DCA) and chenodeoxycholic acid (CDCA) used for surface passivation in DSSCS

\subsubsection{Types of Electrolytes and Challenges}

Although electrolytes are generally a mixture of compounds, the most important component is the redox couple which is responsible for shuttling electrons from the cathode to the dye. The redox 
potential of the electrolyte species also directly affects the $V_{o c}$ of the device further illustrating its importance. ${ }^{40}$ One of the most common redox couples used in DSSCs is iodide/triiodide $\left(I^{-} / I_{3}{ }^{-}\right) .{ }^{41}$ The redox couple plays a crucial role in the efficiency of the DSSC because it regenerates the dye allowing it to continuously repeat the cycle. If regeneration is delayed or inefficient, the dye cannot inject electrons into the titania halting current generation. ${ }^{41}$ There are many challenges that can occur with the electrolyte. When an electron is injected into the titania it migrates towards the anode near the surface of the titania close to the titania-electrolyte interface. This gives rise to the possibility that the electron can recombine with the redox couple preventing it from traveling through the external circuit and generating current. ${ }^{42}$ One of the ways to alleviate this problem is through surface passivation as discussed previously. Similar to surface passivation, 4-tertbutyl pyridine (4-TBP) shown in Figure 7 can be added to the electrolyte mixture. ${ }^{29} 4-$ TBP can improve electron percolation through the titania because when binding to the titania it fills trap states in the conduction band. ${ }^{21}$

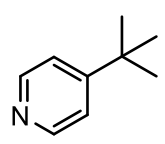

1.3 4-TBP

Figure 7 Electrolyte added surface passivator 4-tertbutyl pyridine

Lithium salts are also commonly found in electrolyte mixtures as they increase the driving force for charge transfer from the dye to the titania. Bai et. al. used electrical impedance and transient emission spectroscopy to demonstrate the decrease in charge transfer resistance upon the addition of $\mathrm{Li}^{+}$to an electrolyte mixture. ${ }^{43} \mathrm{As} \mathrm{Li}^{+}$concentration increased, charge transfer resistance decreased. This implied that the thermodynamic driving force for the injection of an electron from the dye excited state to the conduction band of the titania had increased. The Li facilitates this by binding with the titania and lowering its conduction band. Figure 8 illustrates that although the addition of $\mathrm{Li}^{+}$decreases charge transfer resistance, the lower conduction band negatively impacts the $V_{o c}$ of the device. These phenomena are 
apparent in the increasing $\mathrm{J}_{\mathrm{sc}}$ and decreasing $\mathrm{V}_{\mathrm{oc}}$ in device characterization data. Despite the $\mathrm{V}_{\mathrm{oc}}$ decrease, Bai et. al. observed an overall increase in efficiency with increasing concentrations of $\mathrm{Li}^{+}{ }^{43}$
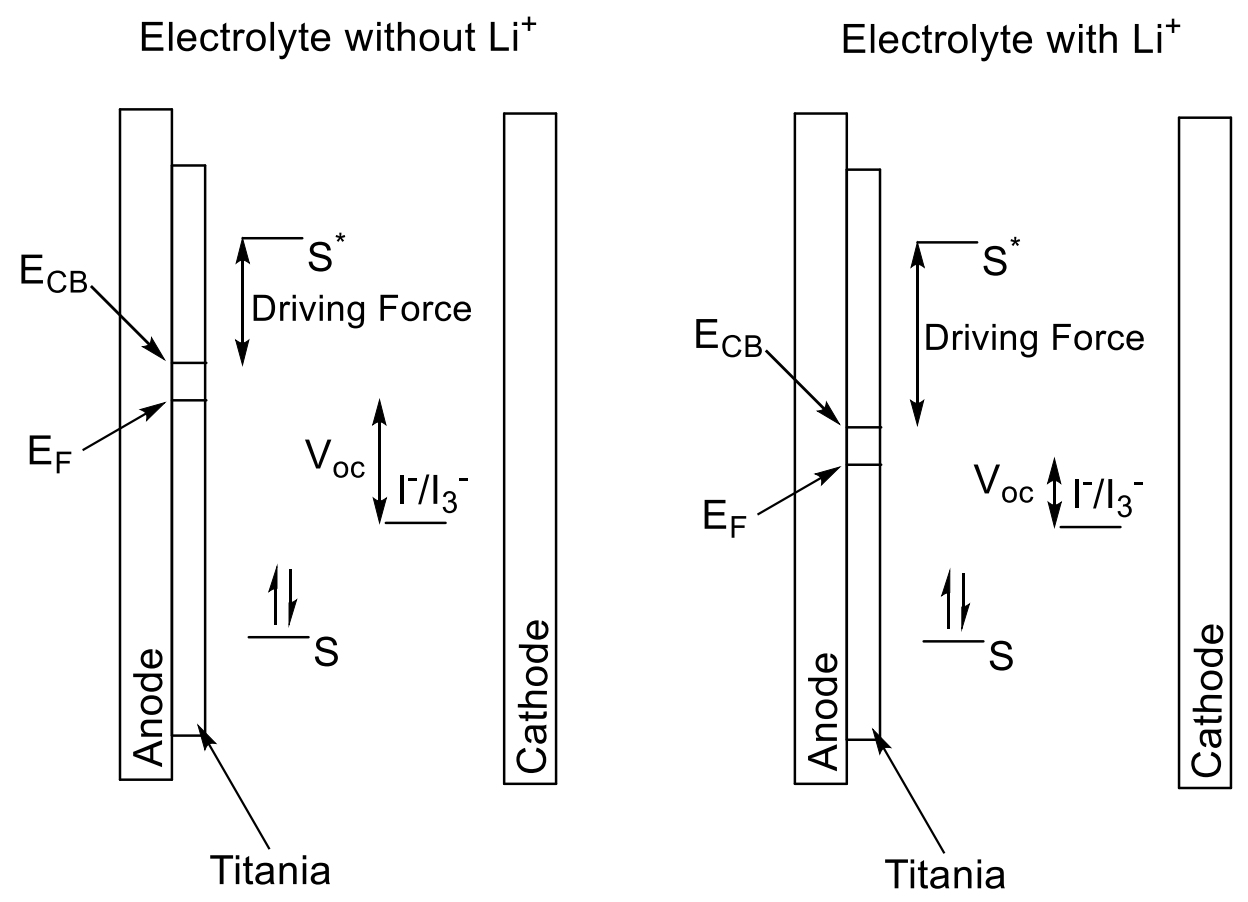

Figure 8 Lithium salt effects on titania conduction band and open circuit voltage

The reasoning for the decreasing energy of titania's conduction band in the presence of the lithium cation is that $\mathrm{Li}^{+}$ions present in the electolyte insert into the $\mathrm{TiO}_{2}$ by the following equation

$$
x \mathrm{Li}^{+}+\mathrm{TiO}_{2}+x \mathrm{e}^{-} \leftrightarrow \mathrm{Li}_{x} \mathrm{TiO}_{2}
$$

where $x$ represents the fraction of $\mathrm{Li}^{+}$in $\mathrm{TiO}_{2} \cdot{ }^{44}$ The presence of a cation in the crystal lattice of the $\mathrm{TiO}_{2}$ causes electrons to move from the valence band to the conduction band to compensate for the positive charge. This insertion of $\mathrm{Li}^{+}$has a similar effect to semiconductor doping in which a new conduction band is formed at a lower energy. ${ }^{45}$

The diffusion rate of the redox couple from cathode to dye is also significant. Depending on the viscosity of the electrolyte mixture, the diffusion rate and performance can vary greatly. ${ }^{46}$ This requires 
concentration changes to be made to alleviate the impact but this can also result in higher recombination rates. ${ }^{41}$ Another drawback of the iodide/triiodide electrolyte is that it competitively absorbs light in the visible region. Light needs to pass through the electrolyte before it can reach the dye where it generates current; thus any absorption of light by the electrolyte will reduce the amount of light available to the dye, reducing efficiency. ${ }^{41}$ With a redox potential of $\sim 0.4 \mathrm{~V}$ (which can vary based on the solvent used to determine the redox potential) iodide/triiodide also has a relatively high overpotential for dye regeneration which can hinder operation. ${ }^{47}$ Lastly, the iodide/triiodide electrolyte is corrosive to metals. This is relevant to the DSSC because the cathode is often deposited with a thin platinum film to catalyze the iodide reduction reaction at the interface. The electrolyte can corrode the platinum hindering DSSC performance when in contact for long periods of time. ${ }^{41}$ The corrosive nature of the iodide/triiodide electrolyte can also cause degradation of the dye further reducing the DSSCs lifetime. Research has been done investigating the efficacy of other redox couples in liquid electrolytes including disulfide/thiolate, ${ }^{48}$ cobalt (discussed further below), ${ }^{30}$ ferrocene ${ }^{49}$ and copper complexes ${ }^{50}$ with some success. ${ }^{41}$ However, despite the challenges the iodide/triiodide redox couple faces, it still remains one of the most efficient electrolytes owing to its slow rate of recombination. ${ }^{41}$

Alternative to the iodide/triiodide electrolyte, cobalt electrolytes offer the benefits of weak absorption in the visible region, have higher redox potentials, and are more benign to DSSC components. ${ }^{30}$ Co electrolytes do however, experience the problems of high recombination rates and mass transport limitations within the mesoporous titania film. These mass transport limitations can have a pronounced effect on longevity of the DSSC as they manifest in increased dye regeneration time. A dye regeneration time of $10^{-6} \mathrm{~s}$ is required to limit the time the dye spends in the oxidized state to $100 \mathrm{~s} .{ }^{21}$ The increased time the dyes spends in the oxidized state as a result of the mass transport limitations can prevent the DSSC from having the desired 20 year operational lifetime. ${ }^{21}$ In a report from Feldt et al., the authors attempted to alleviate these problems by tuning the steric properties of the sensitizer and mediator to 
reduce recombination. Figure 9 illustrates the dyes D29 and the more sterically hindered D35 chosen for investigation. Both dyes are triphenylamine (TPA) based dyes with high molar extinction coefficients.

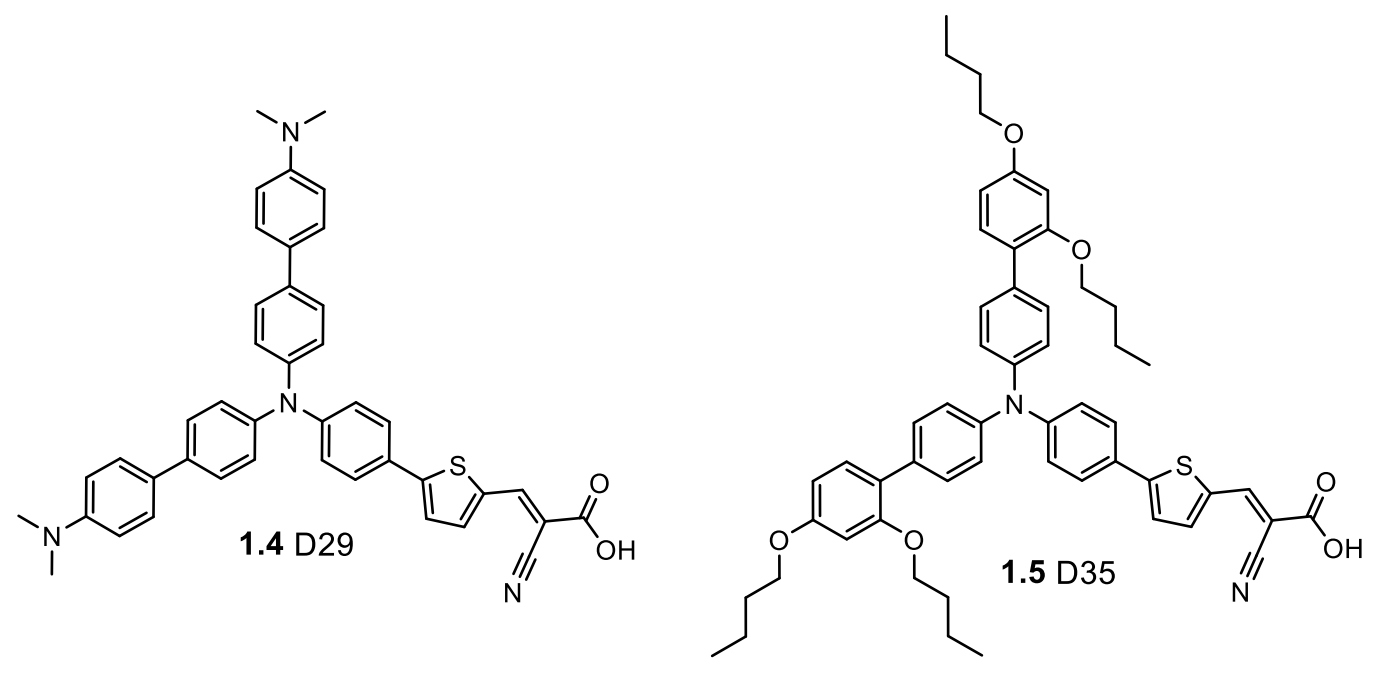

Figure 9 Organic dyes D29 and the bulkier D35

The high molar extinction coefficient (approximately double that of the ruthenium dye N719) allowed for a thinner titania layer, reducing complications in the titania. The various Co complexes paired with these dyes included complexes with bipyridine and phenanthroline ligands functionalized with assorted alkyl chains. The redox potentials of the complexes tested ranged from 0.43 to $0.62 \mathrm{~V}$ illustrating their versatility. Compared with the ground state potential of D29 $(0.84 \mathrm{~V})$ and D35 $(1.04 \mathrm{~V})$, the overpotential for dye regeneration is lower than with iodide/triiodide increasing $V_{\text {oc }}$ but still large enough to ensure regeneration. Compared to an iodide/triiodide DSSC, the cobalt bipyridine electrolyte displayed higher current surmised to be due to less absorption by the electrolyte, and a higher $\mathrm{V}_{\text {oc }}$ owing to the higher redox potential resulting in an overall efficiency of $6.7 \%$ illuminated at AM1.5G. ${ }^{30}$

Much of the attention cobalt redox couples have enjoyed in literature is due to the ease with which ligand modification can be used to tune redox potential. Chen et al. have tested a Co $2,2^{\prime}$-bypyrimidine (Co-bpm) complex against a benchmark Co bypyridine (Co-bpy) complex (Figure 10), in DSSCs and found the Co-bpm cells to exibit high $\mathrm{V}_{\text {oc }}$ above $1.0 \mathrm{~V} .^{51}$ 


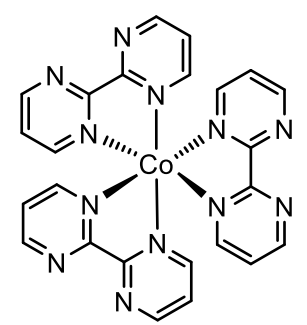

1.6 Co-bpm

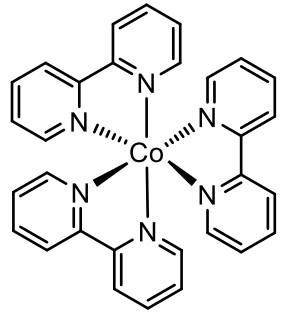

1.7 Co-bpy

Figure 10 Cobalt complexes used by Chen et. al. to attain high open circuit voltages in DSSCS

UV-Vis revealed that the Co-bpm electroylte exhibited low absorption in the visible region reducing competition with the dye for photon absorption while cyclic voltammetery revealed a redox potential of $1.07 \mathrm{~V}$, approximatley double that of the Co-bpy electroylte. This drastic shift in oxidation potential is due to the electron withdrawing character of the $\mathrm{N}$ atoms in the pyrimidine rings. The addition of a $\mathrm{N}$ atom reduces the donating ability of the ligand making the oxidation (removal of an electron) harder.

Contrary to the improved $V_{o c}$ of the Co-bpm devices, the $J_{s c}$ and fill factor decreased. Generally, a concentration of $0.2 \mathrm{M}$ of the $\mathrm{Co}^{\prime \prime}$ complex is required for effective use as a mediator. However, the solubility of the Co-bpm complex is much lower, approximately $0.02 \mathrm{M}$, in any of the solvents used including acetonitrile (MeCN) and an $\mathrm{MeCN}$ and dimethyl sulfoxide (DMSO) mix. In addition to the solubility challenges, the driving force for dye regeneration is only $200 \mathrm{meV}$, which is below the threshold of $400 \mathrm{meV}$ that ensures efficient dye regeneration from cobalt mediators. Combined, these problems kept $\mathrm{J}_{\mathrm{sc}}$ around $2.0 \mathrm{~mA} / \mathrm{cm}^{2}$. Lastly, the Co-bpm mediated cells which exhibited the best performance, those employing the MeCN/DMSO solvent, displayed poor robustness as the solvent contributed to desorption of the dye.

Although liquid electrolytes have commonly been used for DSSCs, solid electrolytes can also be employed. ${ }^{21,52}$ Solid electrolytes have the benefit of not requiring a volatile organic solvent to dissolve electrolyte components as the components make up the entirety of the electrolyte. As opposed to the redox couples previously discussed which shuttle electrons, solid electrolytes use hole-transport materials 
(HTM). HTMs transport positive charge from the dye to the cathode to regenerate the dye. Given that HTMs fill the entire cavity of the DSSC, there is no diffusion taking place as there is with liquid electrolytes which are dissolved in solvent. In this case, a positive charge jumps from molecule to molecule towards the cathode, eliminating the challenges that diffusion rate imposes on the DSSCs performance. ${ }^{50}$ Examples of solid HTMs include polyethylenedioxythiophene (PEDOT), polyaniline (PANI), and polypyrole. ${ }^{50}$

The main challenges associated with polymeric HTMs are HTM penetration into the titania pores and recombination at the titania/dye/HTM interface. Liu et al. reported an in situ polymerization method of PEDOT whereby the photo oxidized dye initiates the polymerization process after the HTM monomer had penetrated the titania pores..$^{53}$ To this end, dye selection plays an important role in the performance of polymeric HTM DSSCs. When PEDOT was paired with the organic dye D149 the authors reported an average conversion efficiency of $6.1 \%$ marking a large improvement over previous work. However, when paired with the ruthenium dye Z907 a lower efficiency of $1.7 \%$ was observed further illustrating the importance of the dye in initiating polymerization.

Since the late 1990s, triarylamine-based compounds have been investigated as HTMs for DSSCs. A specific triarylamine-based HTM known as spiro-OMeTAD has been investigated against iodide/triiodide electrolytes. The spiro-OMeTAD containing DSSC was found to give a higher efficiency than the standard iodide/triiodide electrolyte mainly due to the increased $V_{o c}$ observed. ${ }^{52}$ Despite the better efficiency

relative to the iodide/triiodide electrolyte DSSC, efficiency was still only in the $2 \%$ range. ${ }^{52}$ This is still low compared to the maximum efficiency of about $13 \%$ that DSSCs have reached. ${ }^{24}$ Thus, significant work on HTM based DSSCs is still needed to reach parity with the efficiency of other DSSCs.

\subsubsection{Dye Design and Considerations}

Although much work has been done synthesizing dyes for DSSCs, it is possible to fabricate DSSCs with naturally occuring pigments. ${ }^{54}$ The requirements for a dye to be effective in a DSSC are that it must 
strongly absorb visible and near IR light, and it must posess a functional group capable of binding to titania (caboxylic acid or cyanoacetic acid). Beyond this, it is important that the dye is redox active and paired with a suitable electrolyte such that the cell has a strong enough driving force to ensure dye regeneration occurs. $^{54}$

The use of natural pigments in DSSCs is desirable due to their low cost, abundancy, and sustainability. The main classes of pigments used in DSSCs to date include, caretinoids, betalains, flavonoids, and chlorophylls. Although numerous pigments have been tested in DSSCs, they have been tested by different research groups under a variety of conditions making it challenging to compare the performance of these pigments. Some of the highest performing pigment based DSSCs include those sensitized with modified chlorophyll/lutein from spinach $(\eta=4.0 \%)$, Betaxanthin from prickly pear $(\eta=2.06 \%)$, and cyanin from red sicillian orange $(\eta=0.66 \%)$ seen in Figure 11 . Although these dyes could offer reduced environmental effects and low fabrication cost, efficiencies are much lower than commercial dyes making cost per unit of energy generated too high.

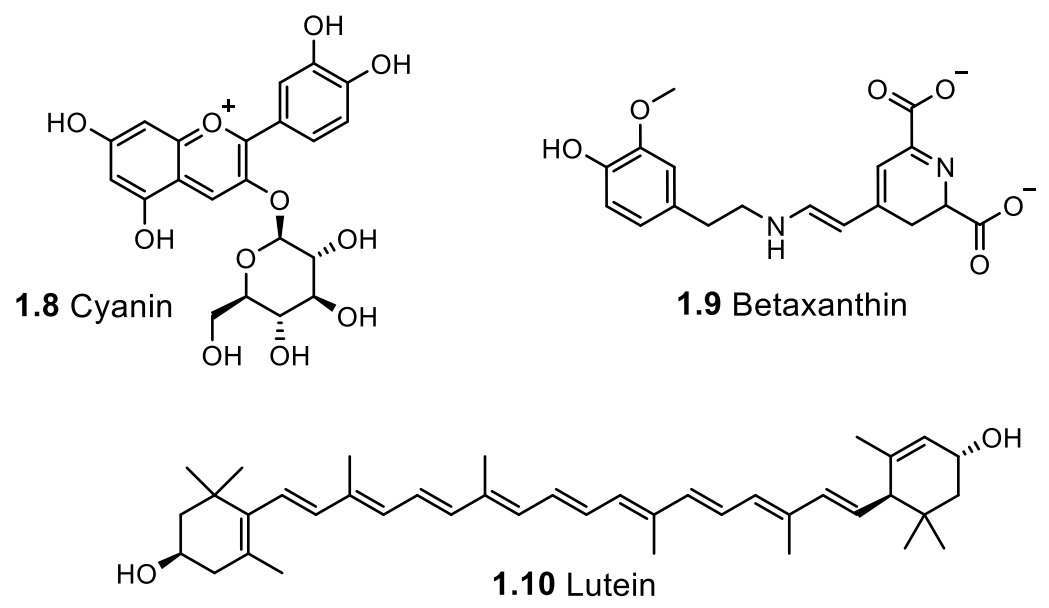

Figure 11 Dyes molecules derived from natural sources.

Some of the most widely used dyes in DSSC research are ruthenium based dyes such as Black dye and N719 seen in Figure 12. These dyes were both synthesized by the Grätzel group, Black dye being the 
highest efficiency DSSC when published in 2001 at $10.4 \%{ }^{55}$ and N719 the highest at the time of publication in 2005 at $11.04 \% .{ }^{56}$ Despite the longstanding use of these ruthenium based dyes, the highest performing dye used in a DSSC to date is SM315 (Figure 13) with an efficiency of $13.0 \% .{ }^{57}$ Building off previous work ${ }^{58}$ Matthew et al. synthesized SM315 as part of the Grätzel group in 2014. Despite the record holding performance of these metal based dyes, the incorporation of metals with limited abundance on earth makes them expensive and likely to increase further as supply decreases. For these reasons, there is merit in designing metal-free dyes in hopes that the increased abundance will lower overall dye cost and in turn, lower the cost of energy generated by DSSCs.

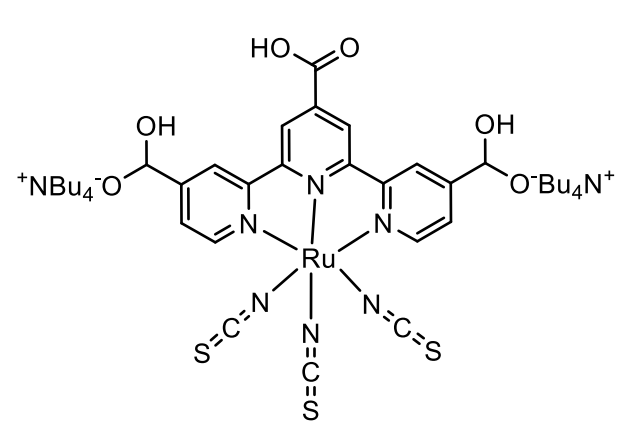

1.11 Black Dye

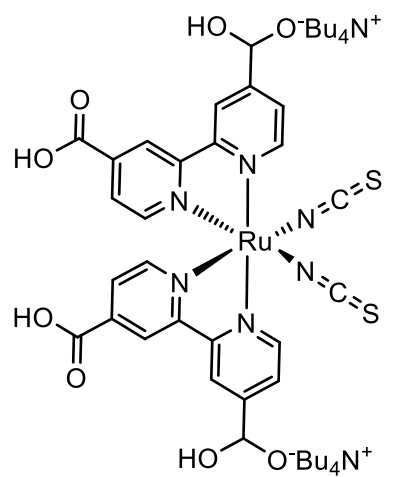

1.12 N719

Figure 12 Ruthenium based dyes Black dye and N719 synthesized by the Gratzel group 


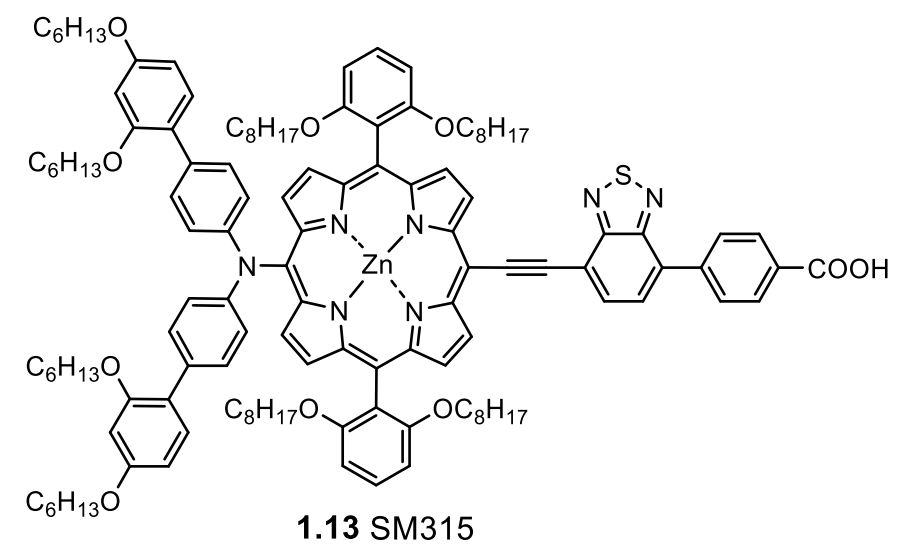

Figure 13 Zinc porphyrin dye SM315 used to fabricate $13.0 \%$ efficient DSSC

There are many considerations to be mindful of when designing dyes for incorporation into DSSCs.

The dye needs to have a large enough photo cross-section so that the likelihood of absorbing a photon is high. Additionally, the dye should exhibit panchromatic absorption meaning that it absorbs light from the entire spectrum that earth receives. The dye needs to be redox stable meaning that it can be oxidized and reduced repeatedly without breaking down. Additionally, the dye's frontier molecular orbitals, its HOMO and LUMO, need to align favourably with the energy levels of the titania and electrolyte to ensure rapid injection of charge into the titania and regeneration of the dye.

A common motif used when designing metal-free dyes for use in DSSCs is the donor acceptor motif shown in Figure 14. In this motif, there is an electron rich donor portion, a non-innocent $\pi$-spacer, and an acceptor. The donor acts as a chromophore absorbing a photon and donates an electron. The noninnocent $\pi$-spacer separates charge within the molecule and is deemed non-innocent as it also plays a role in light absorption. Lastly, the acceptor accepts the electron from the donor and binds to the titania of the DSSC allowing for injection of the electron. The dye L1 in Figure 14 was one of the first successful metal-free dyes synthesized by Hagberg et al. in 2007. ${ }^{29}$ L1 incorporates TPA as a donor, thiophene as a non-innocent $\pi$-spacer, and cyanoacetic acid as an acceptor. 


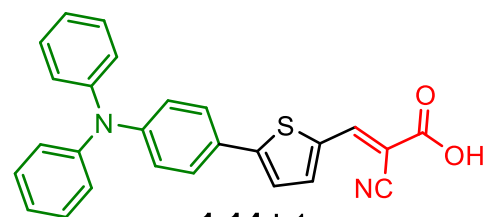

$1.14 \mathrm{~L} 1$

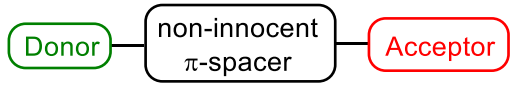

Figure 14 Donor acceptor motif for metal-free dye L1

Beyond the energetic considerations mentioned above, dyes can also be designed to alleviate practical challenges that arise within the DSSC including recombination and dye loading. Wang et al. designed a series of dyes to investigate the effect of hexyl chains on DSSC performance. ${ }^{59}$ It was found that inclusion of these hexyl chains increased electron lifetime which led to improved $V_{\text {oc. }}$ Incorporation of the hexyl chains also impacted dye loading on the titania which reduced regeneration of the dye as electrolyte penetration into the pores of the titania decreased which reduced $\mathrm{J}_{\mathrm{sc}}$ and $\mathrm{FF}$. The authors hypothesized however, that this effect could be alleviated by increasing the concentration of the redox species in the electrolyte.

\subsection{Objectives}

This thesis aims to test various options for two different components of DSSCs, the dye and the electrolyte. The goals for the dye testing are to test three different groups of dyes including,

- Group 1: TPA based dyes (synthesized by Selvyn Simoes and Hardeep Devgan)

- Group 2: bis-TPA based dyes (synthesized by Omar Abdi) ${ }^{60}$

- Group 3: BODIPY based dyes (synthesized by Catherine Bonnier et al. $)^{27}$

Of the group 1 dyes shown in Figure 15, L1 $1^{29,61}$ and $\mathrm{L} 1 \mathrm{OM} \mathrm{C}^{62}$ have been previously tested and offer a benchmark to compare to. While L1SMe has not previously been tested, L1SMe analogues appended with longer carbon chains have been tested, ${ }^{63}$ thus testing will determine if similar results are obtained. 

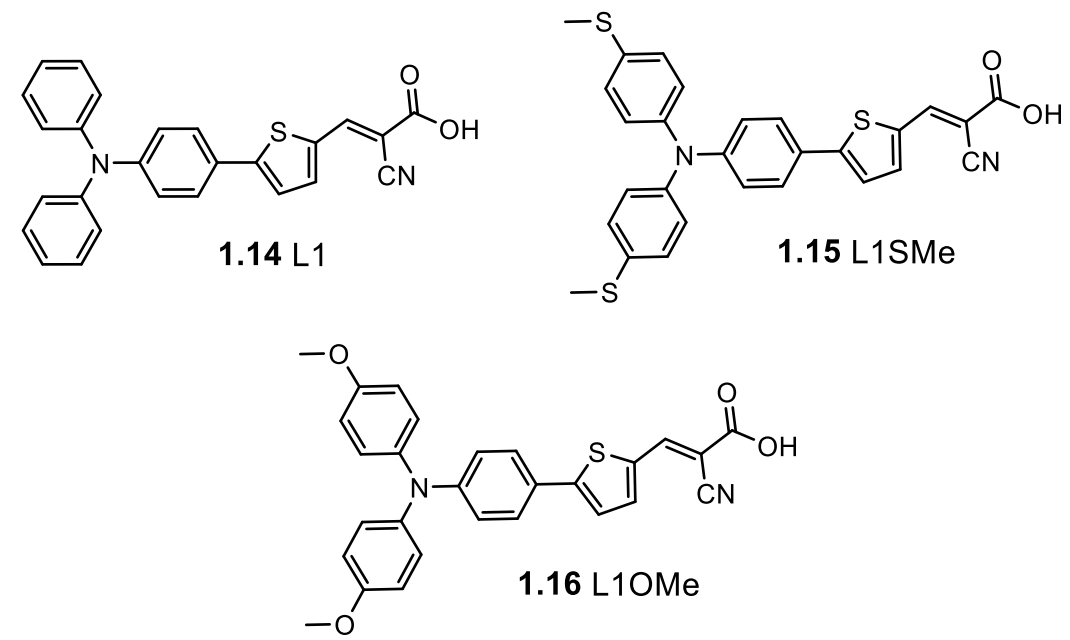

Figure 15 Group 1: TPA based dyes to be tested

The group 2 dyes shown in Figure 16 were previously synthesized by Abdi et. al. ${ }^{60}$ and differ from the group 1 dyes in that they have two TPA units serving to increase photo cross section and extend conjugation to red shift absorption. Additionally, they are all bipedal meaning that they bear two anchoring groups in hopes that they will bind more intensely with the titania. Of the group 2 dyes OA1 is simply two TPA units with two cyanoacetic acids. OA2 has a thiophene inserted between the TPA units to further extend conjugation. OA3 places a thiophene between the TPA and the cyanoacetic acid groups. This allows investigation of how the thiophene placement affects dye performance. Lastly OA4 is a single TPA unit with two cyanoacetic acids to act as a baseline. 

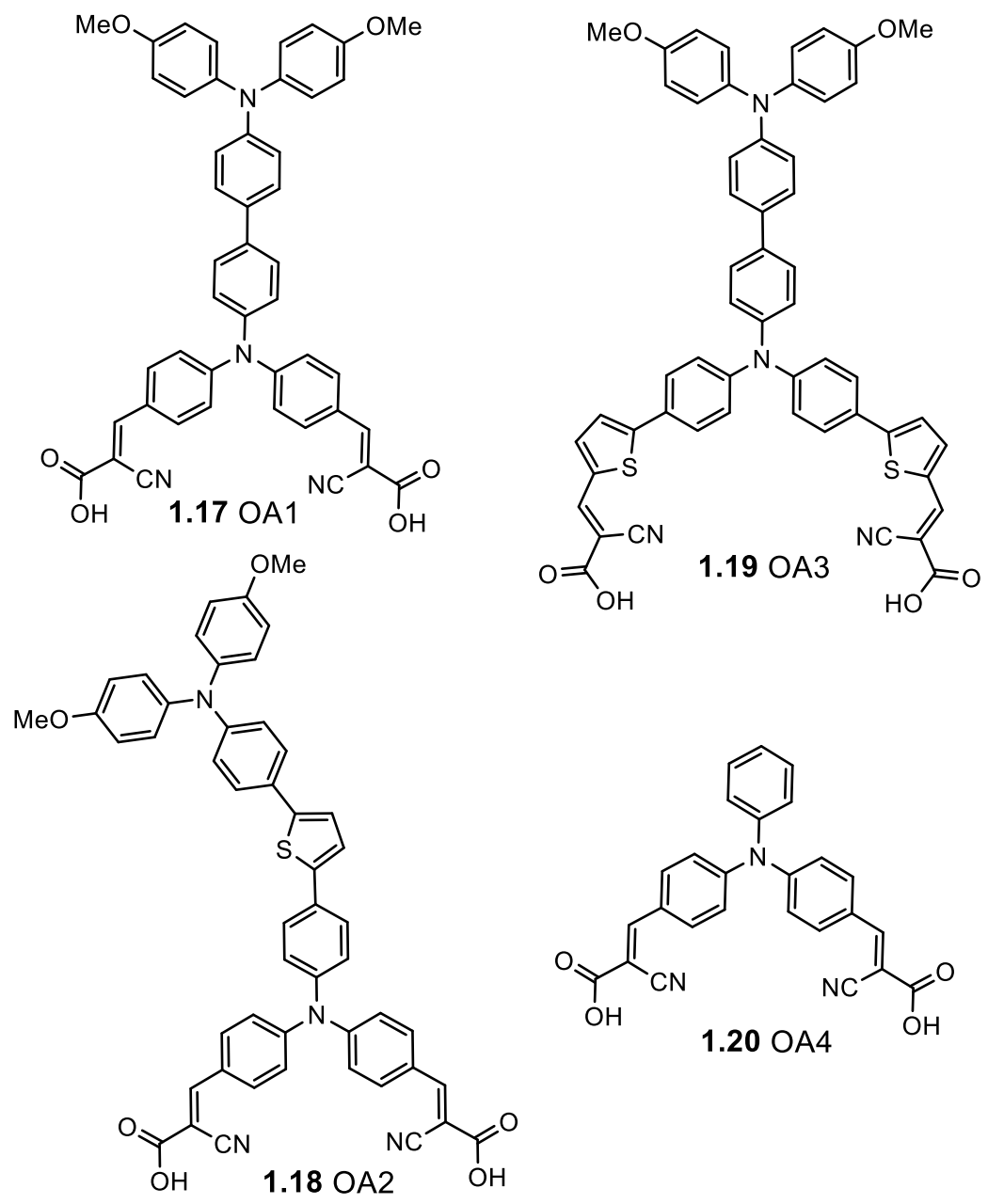

Figure 16 Group 2: bis-TPA based dyes to be tested

The group 3 dyes shown in Figure 17 poses a similar architecture to L1 from group 1, but the thiophene spacer is replaced with or complimented by a BODIPY unit. BODIPY is included as it is a strongly absorbing molecule and is relatively redox stable. Starting from molecules $5 \mathrm{a}$ and $5 \mathrm{~b}$ there is a thiophene added to the right of the BODIPY (10a and 10b), to the left of the BODIPY (CB4), and on both sides of the BODIPY (16a and 16b). Additionally, each dye is made with a single carbon R group (R1) and a six-carbon long R group (R2) except for CB4 for which only the six-carbon long version was available. The longer chain is included in hopes of reducing dye aggregation and recombination. 


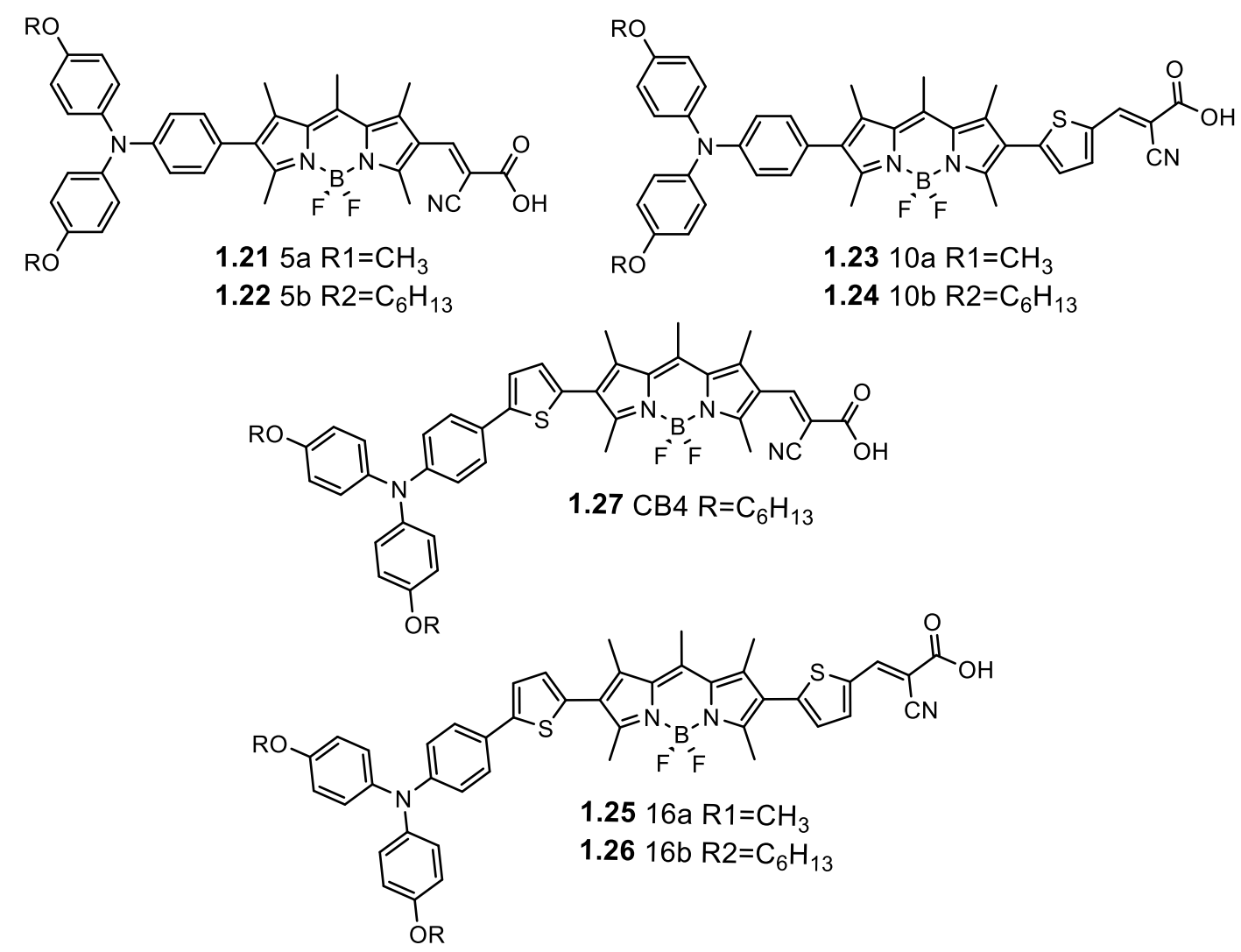

Figure 17 Group 3: BODIPY based dyes to be tested

The electrolytes to be tested fall into three different groups including,

- $\quad$ lodide based electrolytes

- Cobalt based electrolytes (synthesized by Muntaser Farooque)

- Organic hole transport materials (synthesized by Anjuli Szawiola, University of Toronto)

Of the iodide electrolytes, the Z1137 iodide electrolyte will be used as well as a Z1137 iodide electrolyte with $\mathrm{LiPF}_{6}$ added. There are three cobalt complexes to be tested in various electrolyte mixtures which are shown in Figure 18. Of these complexes, the Co-bpy and Co-terpy have been previously employed in electrolyte mixtures ${ }^{30}$ and are to be tested with a mixture of the $2+$ and $3+$ oxidation states, however the Co-dmpb is a novel complex and owing to its difficulty to oxidize, it was tested without any of the $3+$ oxidation state species, and again with an oxidant added to the mixture in the same ratio. 


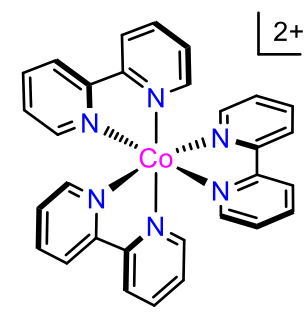

1.28 Co-bpy

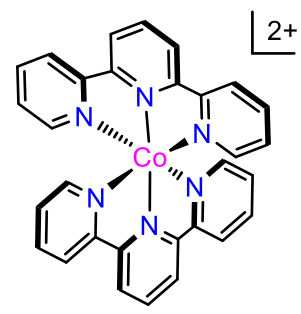

1.29 Co-terpy

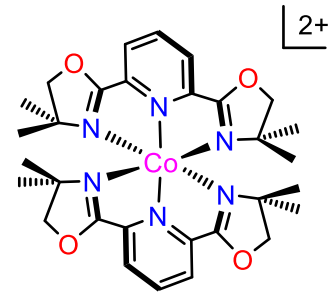

1.30 Co-dmpb

Figure 18 Cobalt complexes to be used in DSSC testing

An organic hole transport material which is shown in Figure 19 was also tested. Similarly, to the Co-dmpb electrolyte mixture, the HTM was also tested with an oxidant added in the same ratio as with the other electrolyte mixtures.

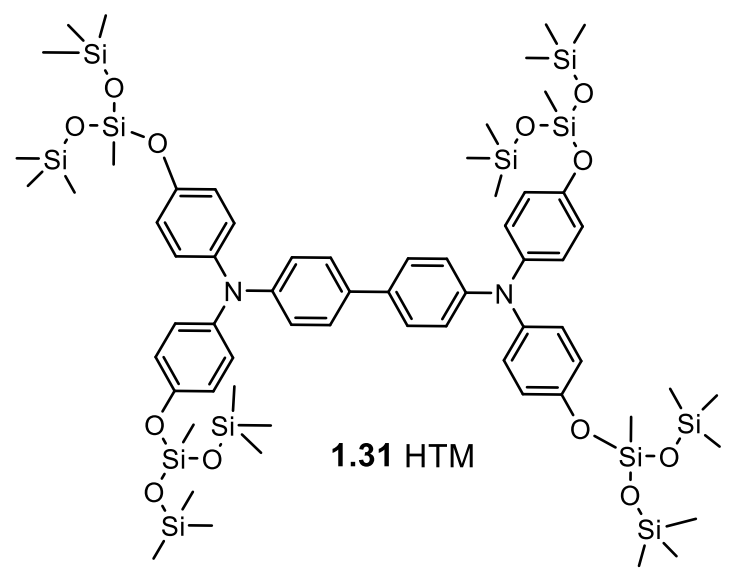

Figure 19 Organic hole transport material tested

Lastly, Table 2 displays all 40 of the combinations of dyes, co-adsorbents, and electrolytes to be fabricated and tested over the course of this project. 
Table 2 Dye and Electrolyte combinations tested in DSSCS

\begin{tabular}{|c|c|c|c|c|c|c|c|c|c|c|c|c|c|c|c|}
\hline Electrolyte & DCA/Dye & L1 & L1OMe & L1SMe & OA1 & OA2 & OA3 & OA4 & $5 a$ & $5 b$ & $10 a$ & $10 \mathrm{~b}$ & $16 a$ & $16 b$ & CB4 \\
\hline \multirow{4}{*}{ Z1137 } & No DCA & $x$ & & & $x$ & $x$ & $x$ & $x$ & & & & & & & \\
\hline & $1 \times D C A$ & & & & $x$ & & & & & & & & & & \\
\hline & $5 \times D C A$ & $x$ & $x$ & $x$ & $x$ & $x$ & $x$ & $x$ & $x$ & $x$ & $x$ & $x$ & $x$ & $x$ & $x$ \\
\hline & $10 \times D C A$ & & & & $x$ & $x$ & & & & & & & & & \\
\hline \multirow{2}{*}{ Z1137+Li } & No DCA & $x$ & & & & & & & & & & $x$ & & $x$ & $x$ \\
\hline & $5 \times \mathrm{DCA}$ & & & & & & & & & & & $x$ & & & $x$ \\
\hline \multirow{2}{*}{ Co-bpy } & No DCA & $x$ & & & & & & & & & & & & & \\
\hline & $5 \times D C A$ & $x$ & & & & & & & & & & & & & \\
\hline \multirow{2}{*}{ Co-terpy } & No DCA & $x$ & & & & & & & & & & & & & \\
\hline & $5 \times D C A$ & $x$ & & & & & & & & & & & & & \\
\hline \multirow{2}{*}{ Co-dmpb } & No DCA & $x$ & & & & & & & & & & & & & \\
\hline & $5 \times D C A$ & $x$ & & & & & & & & & & & & & \\
\hline \multirow{2}{*}{$\begin{array}{l}\text { Co-dmpb } \\
+ \text { NOPF6 }\end{array}$} & No DCA & $x$ & & & & & & & & & & & & & \\
\hline & $5 \times D C A$ & $x$ & & & & & & & & & & & & & \\
\hline \multirow{2}{*}{ HTM } & No DCA & $x$ & & & & & & & & & & & & & \\
\hline & $5 \times$ DCA & $x$ & & & & & & & & & & & & & \\
\hline \multirow{2}{*}{ HTM+NOPF6 } & No DCA & $x$ & & & & & & & & & & & & & \\
\hline & $5 \times D C A$ & $x$ & & & & & & & & & & & & & \\
\hline
\end{tabular}




\section{Chapter 2: DSSC Fabrication}

Reagents and supplies used for DSSC fabrication were ordered from the suppliers listed in Table 3 shown below.

Table 3 Required DSSC materials and suppliers

Item

FTO Coated Glass

Titanium (IV) Chloride

Titania Paste

Silver Conductive Paste

Surlyn Thermoplastic Sealant

Predrilled Platinized Cathodes
Item Number

735159

208566

798495

735825

MS004610

MS001651
Supplier

Sigma Aldrich

Sigma Aldrich

Sigma Aldrich

Sigma Aldrich

Greatcell Solar (Formerly Dyesol)

Greatcell Solar (Formerly Dyesol)

All anodes were fabricated using $2.3 \mathrm{~mm}$ thick, $7 \mathrm{ohm} / \mathrm{sq}$ (TEC 7) fluorine doped tin oxide (FTO), supplied by Sigma Aldrich. Titania films were prepared with Titanium Dioxide $22 \mathrm{~nm}$, nanocrystalline colloidal paste for transparent film, >95\% (Anatase (XRD)) supplied by Sigma Aldrich. Cathodes used were $3.2 \mathrm{~mm}$ thick, $15 \mathrm{ohm} / \mathrm{sq}$ (TEC 15) pre-platinized and pre-drilled, supplied by Dyesol. Spacers used were $30 \mu \mathrm{m}$ thick Suryn thermoplastic sealant, supplied by Dyesol.

\subsection{Preparation of Fluorine Doped Tin Oxide Substrate}

The process by which the FTO is treated, the titania is applied, and the dye is adsorbed, is laid out in Figure 20 for reference, but detailed descriptions are presented in the sections included below. 


\section{Anode Preparation}

Treat electrode in $\mathrm{TiCl}_{4}$ bath for $30 \mathrm{~min}$ and rinse

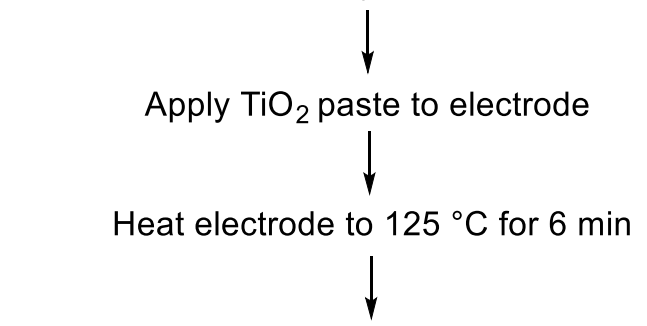

Heat electrode to $325^{\circ} \mathrm{C}$ for $5 \mathrm{~min}, 375^{\circ} \mathrm{C}$ for $5 \mathrm{~min}$, $450{ }^{\circ} \mathrm{C}$ for $15 \mathrm{~min}$, and $500{ }^{\circ} \mathrm{C}$ for $15 \mathrm{~min}$

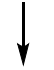

Treat electrode in $\mathrm{TiCl}_{4}$ bath for $30 \mathrm{~min}$ and rinse

$\downarrow$

Heat electrode to $500{ }^{\circ} \mathrm{C}$ for $30 \mathrm{~min}$

$\downarrow$

Dip electrode in $0.25-0.5 \mathrm{mM}$ dye solution for 16 hours

Figure 20 Flow chart outlining the anode preparation process which was adapted from previous work ${ }^{64}$

\subsubsection{Cutting Substrate}

The FTO was lightly scored with a glass cutter using a ruler (similar pressure to writing). When broken with pliers only a light amount of pressure was required. If the FTO did not break, rather than applying more pressure, the pliers were repositioned directly over the score line. If FTO still did not break, the FTO was rescored with a small increase in pressure. Pliers were clamped onto glass about $1 \mathrm{~cm}$ from the edge as the pliers could damage the FTO surface. When scoring glass, the shorter length of the overall piece was scored first as it was easier to be consistent and generate a clean break over a shorter distance. Lastly, when breaking the glass, the pliers were positioned so that the scored side of the glass would split (scored side facing up), increasing the chances of a clean break.

\subsection{2 $\mathrm{TiCl}_{4}$ (pre)Treatment}

Deionised water was heated to $70^{\circ} \mathrm{C}$ in a beaker before $\mathrm{TiCl}_{4}$ was added by needle and allowed to equilibrate in a fume hood for about 2 hours making a $0.05 \mathrm{M}$ solution (appears pearly white and translucent). The bath was covered with a watch glass while not in use. Electrodes were gently lowered 
into the bath using tweezers and leaned on the wall so titania films were exposed to the solution. Electrodes were left in the $70{ }^{\circ} \mathrm{C}$ solution for 30 min before removing and rinsing clean, first with water, then after repositioning tweezers repeated once more. The overall rinse process was then repeated with $\mathrm{EtOH}$.

\subsubsection{Titania Paste Application}

In the same progression as is shown in Figure 21, Scotch tape was applied to the FTO coated side of the glass (note that only one face of the glass is coated with FTO and the opposite face will not conduct but will fluoresce blue under short wave UV light) to leave an approximately $7 \mathrm{~mm} \times 9 \mathrm{~mm}$ square of FTO exposed. 2-3 drops of the titania paste were then placed on the tape directly adjacent to the area to be coated. A glass rod was then used to doctor blade (swipe the titania across the electrode leaving a thin film) the titania onto the electrode. The film was left to cure for $\sim 30$ seconds before the tape was then gently removed by pulling on the bottom piece. This ensured that the all pieces of tape were removed together and lowered the chances of damaging the film. The electrode was then allowed to sit in ambient conditions for about $10 \mathrm{~min}$. During this $10 \mathrm{~min}$, the titania film turned from an opaque white consistency to transparent. The anode was then heated to $125^{\circ} \mathrm{C}$ for $6 \mathrm{~min}$ in a muffle furnace to remove any solvent, depositing a homogenous titania film on the anode (at this point the anodes may be stored until they are to be used).
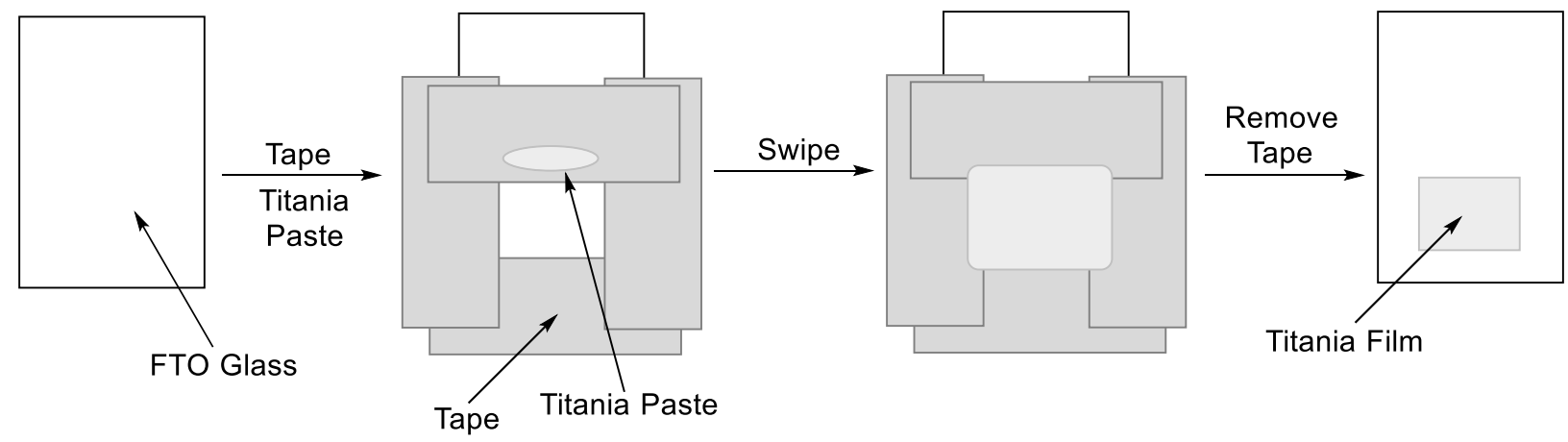

Figure 21 Titania paste application to FTO glass 


\subsubsection{Cutting Counter Electrode}

The counter electrode material came pre-scored, however additional scoring along the line in a similar manner to what was described earlier was needed to ensure a clean break. Once scored, the counter electrode was broken as described earlier.

\subsection{Dye Adsorption}

Before the dye was adsorbed, anodes were heated to $350^{\circ} \mathrm{C}$ for $10 \mathrm{~min}, 450^{\circ} \mathrm{C}$ for $15 \mathrm{~min}$, and lastly $500{ }^{\circ} \mathrm{C}$ for $15 \mathrm{~min}$ in a muffle furnace before cooling to room temperature. Another $\mathrm{TiCl}_{4}$ bath was prepared and the anodes were treated and rinsed as described earlier. The anodes were sintered at 500 ${ }^{\circ} \mathrm{C}$ for $30 \mathrm{~min}$ and allowed to cool to room temperature slowly in the muffle furnace. A dilute solution of the dye ( 0.25-0.5 mmol/L in EtOH) was prepared in a small beaker and transferred to Teflon dipping chambers or glass beakers as required. Once the anodes cooled (after the previously mentioned $\mathrm{TiCl}_{4}$ bath and sintering), they were dipped into the dye solution ensuring the $\mathrm{TiO}_{2}$ area was fully submerged and was not covered by the wall or another anode. The beaker was covered with parafilm and left overnight ( 16 h).

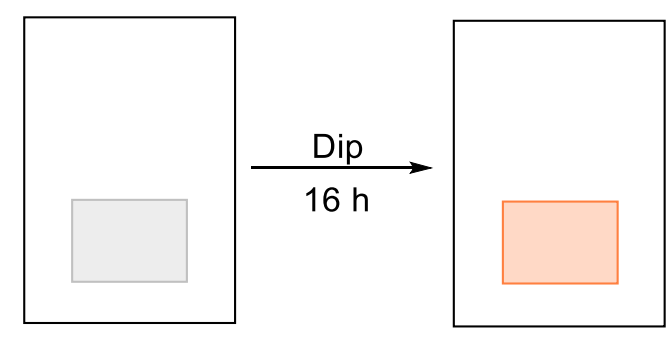

Figure 22 Adsorption of dye to titania film on anode

When the anodes were removed from the dye solution, the titania film had turned the colour of the dye as seen in Figure 22. The anodes were then rinsed with EtOH and allowed to dry on the benchtop for about $5 \mathrm{~min}$. It should be noted that saturation of the titania with dye molecules is assumed to take place over the $16 \mathrm{~h}$ dipping period. However, to investigate different dye loadings, UV-vis absorption 
spectroscopy could be carried out and the molar extinction coefficient used to determine relative differences in loading relative to a standard solution.

\subsection{Assembly}

\subsubsection{Cutting Spacer}

A border of $30 \mu \mathrm{m}$ Surlyn thermoplastic sealant about $2 \mathrm{~mm}$ wide was cut to fit around the active area leaving about $1 \mathrm{~mm}$ between the active area and the border (Figure 23).

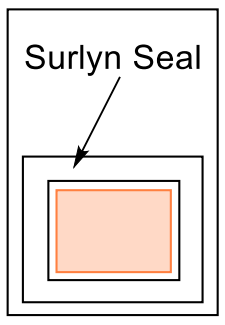

Figure 23 Surlyn border cut to fit around the titania film

\subsubsection{Adhesion of Cathode and Anode}

The Surlyn border was carefully placed on the anode and the cathode placed on top with the platinized surface facing the anode. When aligning the two electrodes there were a few important considerations to be mindful of to ensure optimal performance. First, it was important to ensure that the platinized portion of the cathode covered the entire active area as the platinum catalyzes reduction of the electrolyte. Second, the fill hole needed to be as centered as possible on the active area as this reduced the distance the electrolyte needed to diffuse during injection increasing the chances of a complete filling. Lastly, there needed to be sufficient overhang on the cathode and anode so that silver paste (bus bars) could be applied and alligator clips could be attached. Often these priorities will conflict with each other in which case a balance needs to be struck. Once the electrodes are optimally aligned, as demonstrated in Figure 24, the two electrodes with the cathode side down were pressed firmly onto a hot plate with a cork ring ( $185^{\circ} \mathrm{C}$ measured by IR thermometer) for about 25 seconds to melt the Surlyn, sealing the 
electrodes together. The cork ring was rolled back and forth over the DSSC and periodically visually inspected to ensure sealing was occurring uniformly. The presence of bubbles in the Surlyn indicates unsealed portions and that further heat and pressure is required.

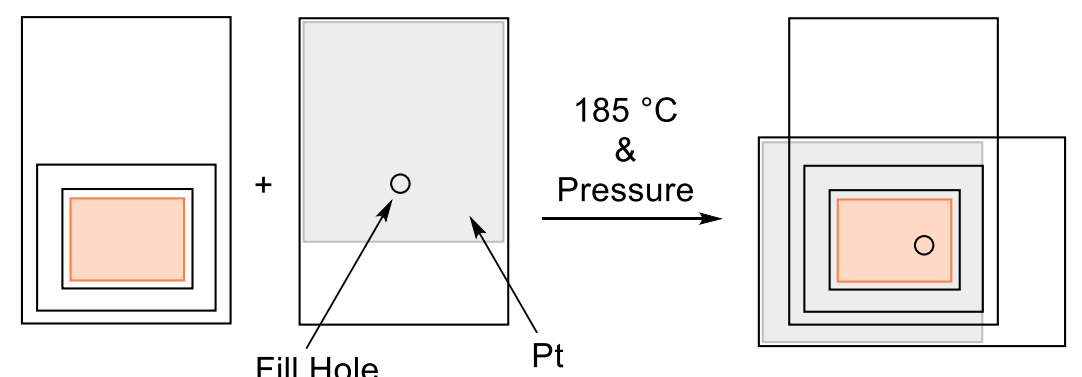

Figure 24 Alignment of anode and cathode for adhesion together

\subsubsection{Electrolyte Preparation}

Multiple electrolyte mixtures were tested and are described fully in the appendix, however, the baseline mixture chosen was a version of the Z1137 electrolyte which is described fully in Table 4 . This mixture was chosen because it was used for previous studies ${ }^{61}$ with the dye L1 which allowed for comparisons and validation of the fabrication method. The mixture differed in that it used $\mathrm{MeCN}$ as a solvent rather than an $\mathrm{MeCN}$ :valeronitrile $(85: 15, \mathrm{v} / \mathrm{v})$ mixture. This change was made to simplify the mixture and decrease viscosity allowing for easier electrolyte injection. The DMII, I2, and Nal were added to supply the iodide for the $\mathrm{I}^{-} / \mathrm{I}_{3}^{-}$redox couple. The GuNCS has historically been added because many ruthenium based dyes have incorporated thiocyanate ligands and having additional thiocyanate present in the electrolyte mixture could allow for re-coordination to the metal if they came detached. Presently they are included for consistency sake however. The 4-TBP, as discussed earlier in section 1.7.3, was added to fill trap states in the titania. 
Name

1,3-dimethylimidazolium iodide

lodine

t-butylpyridine

Sodium iodide

\section{Guanidinium thiocyanate}

Acetonitrile
Short

DMII

$\mathrm{I}_{2}$

4-TBP

$\mathrm{Nal}$

GuNCS

$\mathrm{MeCN}$
Concentration

$0.55 \mathrm{M}$

$60 \mathrm{mM}$

$0.5 \mathrm{M}$

$0.05 \mathrm{M}$

$0.1 \mathrm{M}$

Solvent

\subsubsection{Electrolyte Injection}

An O-ring was placed around the fill hole in the cathode and the filling apparatus, which is depicted in Figure 25, was placed onto the O-ring. The stopcock was turned to the vacuum and allowed to evacuate for $\sim 2$ minutes and 30 seconds (A strong vacuum such as a high vac needed to be used). Next, the stopcock was closed to place the system under a static vacuum. A small quantity of the electrolyte $(\sim 0.3 \mathrm{~mL})$ was drawn into a syringe and any air present was pressed out. The needle was then carefully inserted through the septum. 3-4 drops of electrolyte were then injected directly into the fill hole and the needle carefully removed. Looking perpendicular to the fill hole, the DSSC was inspected to make sure the electrolyte had entered the fill hole and then gently shaken to allow the electrolyte to permeate into the edges of the cavity. Next, the DSSC was lowered just above the bench and the vacuum was released allowing the DSSC to fall to the lab bench. As air moved into the apparatus, electrolyte was pushed into the cavity filling it. Any residual electrolyte was wiped off the surface of the DSSC. 


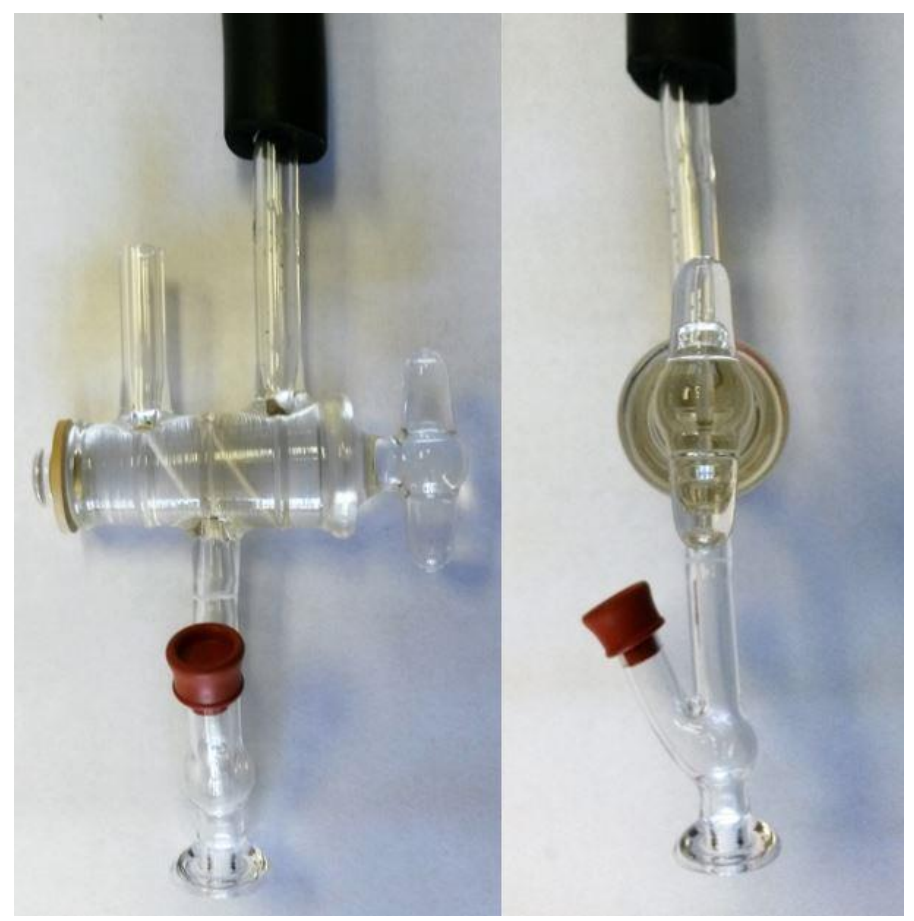

Figure 25 Front and side view of DSSC filling apparatus with vacuum hose and septum appropriately placed (designed and fabricated by Dirk Verdoold at York University)

\subsubsection{Sealing DSSC}

The DSSC was left to sit for a few min before sealing, as electrolyte can wick out of the fill hole. Once ready, a small piece of Surlyn was placed over the fill hole and a microscope cover slip was placed over top of the Surlyn. The cover slip was heated with a soldering iron until the Surlyn melted, sealing the DSSC. As described earlier, if any bubbles are present in the Surlyn, the sealing process is incomplete.

\subsubsection{Silver Paste Application}

The silver paste was painted onto the edge of the FTO side of the anode and cathode to increase conductivity to the wires. This was completed with consideration not to connect the cathode and anode with the paste creating a short circuit. Once dried, the DSSC was ready for testing. 


\subsection{Performance Testing}

\subsubsection{Solar Simulator Use}

The solar simulator was turned on with the physical switch located on the back of the unit. After turning the instrument on, a fan starts and a message appeared on the screen prompting the user to select "OK" if the fan started. This is important in that the instrument uses a $300 \mathrm{~W}$ short xenon arc lamp (obtained from Sciencetech, Sku: 650-0050, \$960), that gets extremely hot and can be damaged if not cooled properly. The "cooling" sub menu was entered and under "blower control" "start" was selected. The knob on the front of the power supply was turned 4 rotations above zero, then under lamp control "start lamp" was selected. After the lamp turned on, "Main" was selected to return to the previous menu and the knob on the front of the power supply was turned to adjust the power to $\sim 250$.

Once the power is adjusted, the lamp was left to warm up for $15 \mathrm{~min}$, during which the power slowly increased to $\sim 300$ giving an incident power of roughly $70 \mathrm{~mW} / \mathrm{cm}^{2}$, or the equivalent of 0.7 sun intensity. At this point the Keithly unit was turned on and the reference cell connected to it via the four ports on the front right side of the unit (counter clockwise from top right, red, white, green, black wires into the 4 ports) and the IV port on the back of the reference cell. The reference cell was placed under the solar simulator as Figure 26 depicts. On the computer, the SciRunIV program (Figure 27) was opened, and when ready "measure" was clicked. A prompt appeared to enter an identifier (the format used was "Date Trial \# calibration") and then "OK" was clicked. The test ran and the data appeared in the left side of the program window and a J-V curve in the right side of the window. 


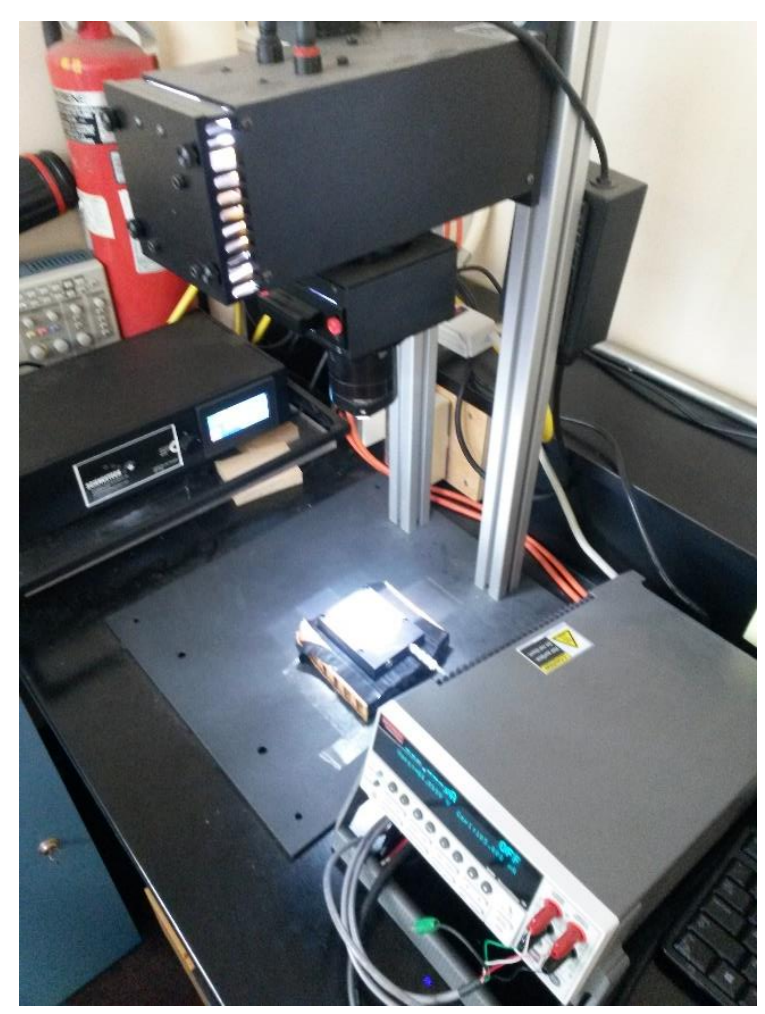

Figure 26 Solar simulator with reference cell positioned for testing.

The maximum power output (Pmax) from this test was compared to the certified Pmax value for the reference cell to determine incident power of the light as follows, $\frac{\text { Pmax(experimental) }}{\text { Pmax(certified })}=$ Fraction of 1 Sun Intensity. The reference cell was disconnected and the other cord containing alligator clip connections was connected to the Keithly unit with the four wires in the same orientation described above. The alligator clips were connected to the DSSC (black to anode and red to cathode) and the DSSC was placed under the light of the solar simulator with the anode facing up. A $0.25 \mathrm{~cm}^{2}$ plastic mask was placed over the DSSCs active area so that a consistent illuminated area was used every time and "measure" was clicked. The program prompted for an identifier once again which was entered as follows (Date Trial \# DSSC \# Variables) and then "OK" was clicked. The test ran and the data appeared immediately after. 


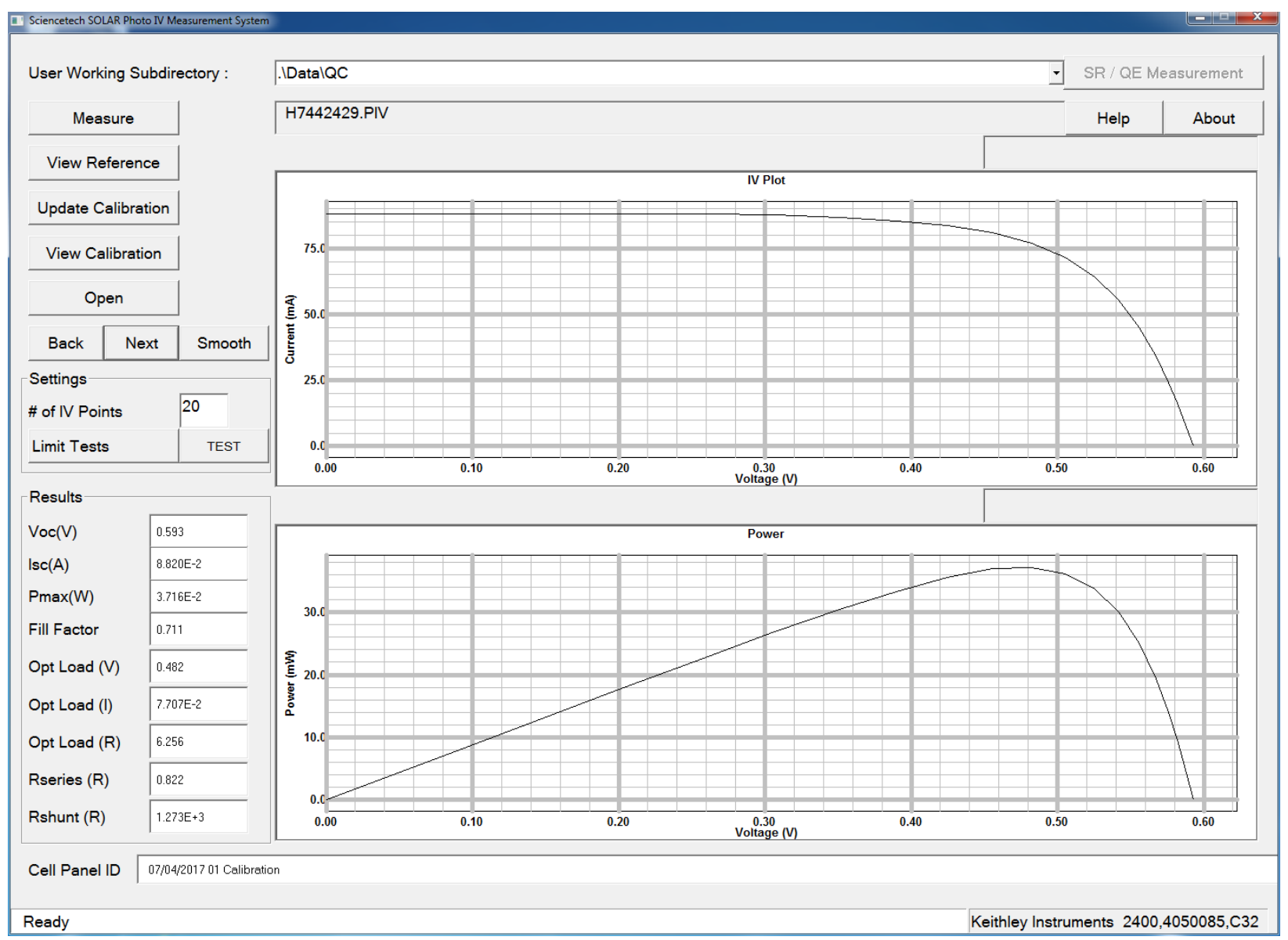

Figure 27 SciRunIV program interface with example calibration data

Once all desired trials were completed, the reference cell was tested once again to ensure consistency of the light source. Once the final calibration was complete, the "cooling" submenu was entered and "stop lamp" was selected. A countdown began from $600 \mathrm{~s}$ at the end of which the fan was turned off by selecting "stop" under blower control. Lastly, the power supply was turned off with the physical switch on the rear.

\subsubsection{Accessing Data}

The data was viewed in the left side of the program window as mentioned before. To navigate through the measurements in the SciRunIV program, the "next" or "back" buttons were used. Alternatively, to jump to a specific measurement the "open" button could be used. This opened a window 
with all the data files, by selecting the desired one it was displayed in the window. However, this does not allow for export of the data. To access this data as well as the current and voltage data that make up the J-V curve, the SciRunIV data folder was opened. In this folder, the " $Q C^{\prime}$ " folder was opened and each test appeared as a separate .out file. These files were opened with excel where the raw current and voltage data was then plotted for further use or analysis. 


\section{Chapter 3: Results \& Discussion}

All DSSC efficiency and individual performance parameters including $\mathrm{J}_{\mathrm{sc}}, \mathrm{V}_{\mathrm{oc}}$, and FF data are reported as an average of at least three DSSCs unless otherwise noted and have standard deviation either reported or displayed by uncertainty bars on graphs.

\subsection{L1 Benchmark Testing}

Throughout this thesis, new cells using L1 were fabricated multiple times, to remove any time dependence, or fabrication errors with this important benchmark. In one particular study using L1, with and without the co-adsorbent DCA, and Z1137 electrolyte was examined. Figure 28 shows that the DCA containing DSSCs showed a slightly higher performance. This was expected as the DCA adsorbs to the titania preventing recombination between the excited electron in the titania and the electrolyte mixture. Additionally, an increase in efficiency was seen after the initial testing. This was due to the extensive porosity of the titania film. When the DSSC was filled, the electrolyte could not immediately diffuse completely into the pores of the titania. This reduced regeneration of the dye because there was no contact between the dye and electrolyte to transfer charge. As such, the dye molecules that had the ability to absorb a photon were reduced limiting the current generated. However, $24-48$ hours after filling, the electrolyte had diffused more completely into the pores of the titania and dye regeneration increased. Once the pores were filled, the efficiency leveled off through to day 7 with a maximum average efficiency of $0.52 \%$ for the DSSC not containing DCA and $0.60 \%$ for the DSSC containing DCA. Looking at the performance data in Table 5, a nominal change in $\mathrm{V}_{\mathrm{oc}}$ is observed while more of a change is see in the $\mathrm{J}_{\mathrm{sc}}$ and FF. 


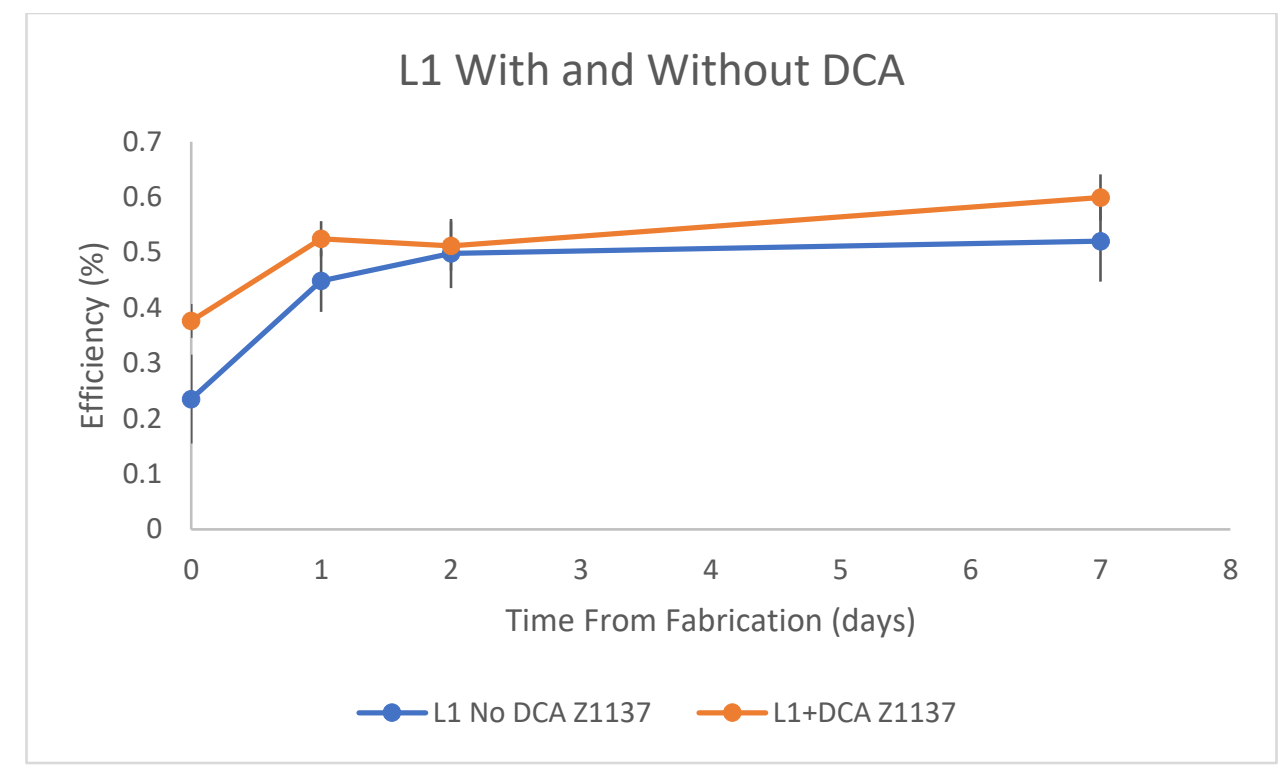

Figure 28 Efficiencies of L1/Z1137 DSSCS with and without DCA

Table 5 Best performance data of L1 DSSCS with and without DCA (7 days after fabrication)

$\begin{array}{ccccc}\text { Variable } & \mathrm{V}_{\mathrm{oc}}(\mathrm{V}) & \mathrm{J}_{\mathrm{sc}}\left(\mathrm{mA} / \mathrm{cm}^{2}\right) & \mathrm{FF} & \eta(\%) \\ \text { L1+DCA } & 0.55 \pm 0.02 & 1.3 \pm 0.24 & 0.57 \pm 0.05 & 0.59 \pm 0.08 \\ \text { L1 No DCA } & 0.54 \pm 0.04 & 1.2 \pm 0.25 & 0.54 \pm 0.04 & 0.5 \pm 0.15\end{array}$

\subsection{Substituted TPA Dyes}

The OMe and SMe substituted dyes paired with DCA and the Z1137 electrolyte were tested along with an L1 DSSC that was made at the same time to ensure consistency in the fabrication procedure. Figure 29 shows a comparison between L1 ((a freshly prepared set of cells) and L1OMe and L1SMe. L1 performed similarly to the benchmark testing, while L1OMe and L1SMe showed a higher efficiency with L1OMe showing a max average efficiency of $1.27 \%$ and L1SMe showing a max average efficiency of $1.79 \%$. Looking closer at the performance data displayed in Table 6, although there is an increase in $\mathrm{V}_{\text {oc }}$ and $\mathrm{FF}$ moving from L1 to L1OMe to L1SMe it is minor compared to the change in $\mathrm{J}_{\mathrm{sc}}$ when following the same progression. 


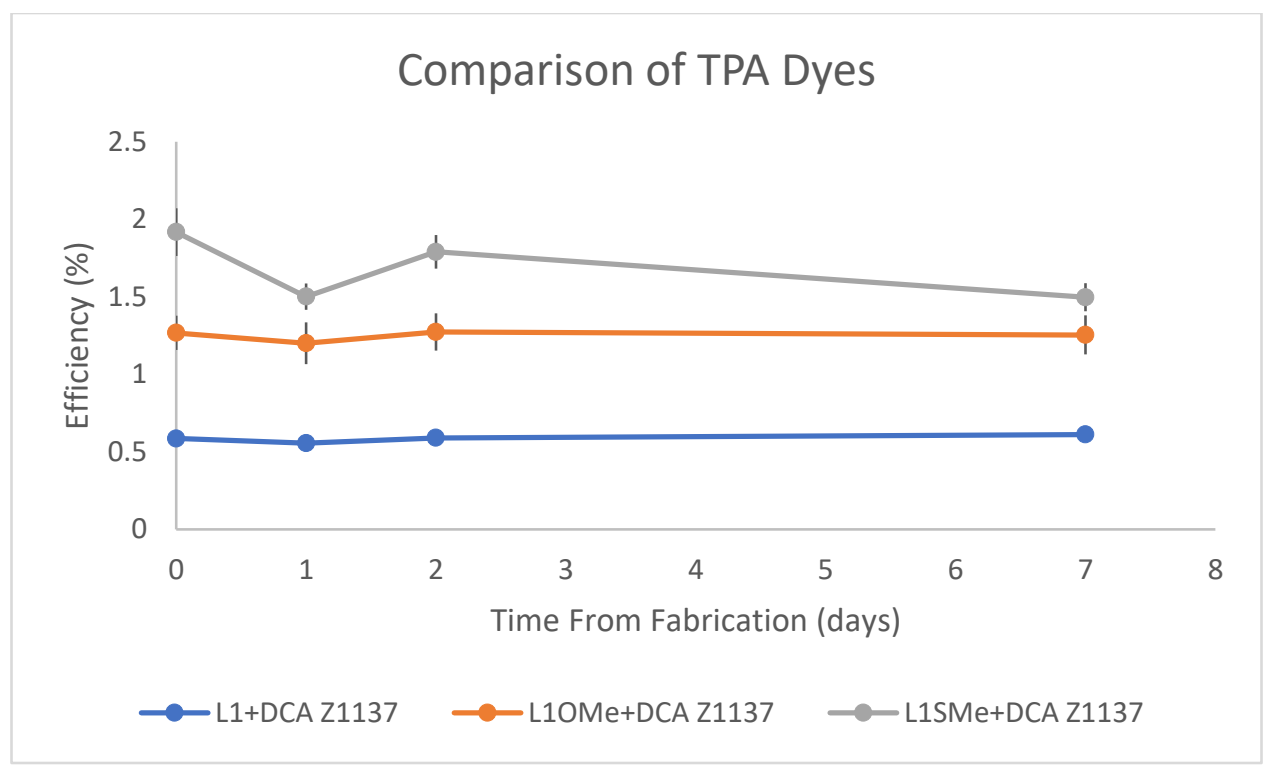

Figure 29 Efficiencies of L1, L1OMe, and L1SMe DSSCs with $Z 1137$ electrolyte

Table 6 Best performance data of dyes L1, L1OMe, and L1SMe (48 hours after fabrication)

$\begin{array}{ccccc}\text { Variable } & \mathrm{V}_{\mathrm{oc}}(\mathrm{V}) & \mathrm{J}_{\mathrm{sc}}\left(\mathrm{mA} / \mathrm{cm}^{2}\right) & \mathrm{FF} & \eta(\%) \\ \text { L1 } & 0.54 \pm 0.02 & 1.5 \pm 0.19 & 0.51 \pm 0.07 & 0.59 \pm 0.08 \\ \text { L1OMe } & 0.59 \pm 0.02 & 2.6 \pm 0.17 & 0.57 \pm 0.06 & 1.3 \pm 0.24 \\ \text { L1SMe } & 0.62 \pm 0.02 & 3.8 \pm 0.16 & 0.52 \pm 0.06 & 1.8 \pm 0.22\end{array}$

The UV-Vis spectra shown in Figure 30 offer a possible explanation for the improved efficiency of the L1SMe containing DSSCs. L1SMe and L1OMe, likely have improved performance because, when compared to L1, both dyes have absorptions that are redshifted with L1OMe having a $\lambda_{\max }$ of $499 \mathrm{~nm}$ and L1SMe having a $\lambda_{\max }$ of $491 \mathrm{~nm}$ and shows some absorption in the $300-350 \mathrm{~nm}$. A redshifted absorption better overlaps with the solar spectrum leading to a higher number of incident photons. In addition, the spectrum for $\mathrm{L} 1$ has a lower molar extinction coefficient (although that can be partially explained a solvent impurity in the sample) compared to the other two dyes and showed a similarly low efficiency in DSSCs. However, the worse performance of L1 in a DSSC may be due more to red shifting of the absorption than 
the molar extinction coefficient as it has been previously measured $\left(25000 \mathrm{M}^{-1} \mathrm{~cm}^{-1}\right)^{29}$ which is close to that of L1SMe $\left(25430 \mathrm{M}^{-1} \mathrm{~cm}^{-1}\right)$ and L1OMe $\left(24502 \mathrm{M}^{-1} \mathrm{~cm}^{-1}\right)$. Regardless, the $\lambda_{\max }$ is consistent with the data presented in Table 6 as increased absorption would manifest itself in an increased $\mathrm{J}_{\mathrm{sc}}$.

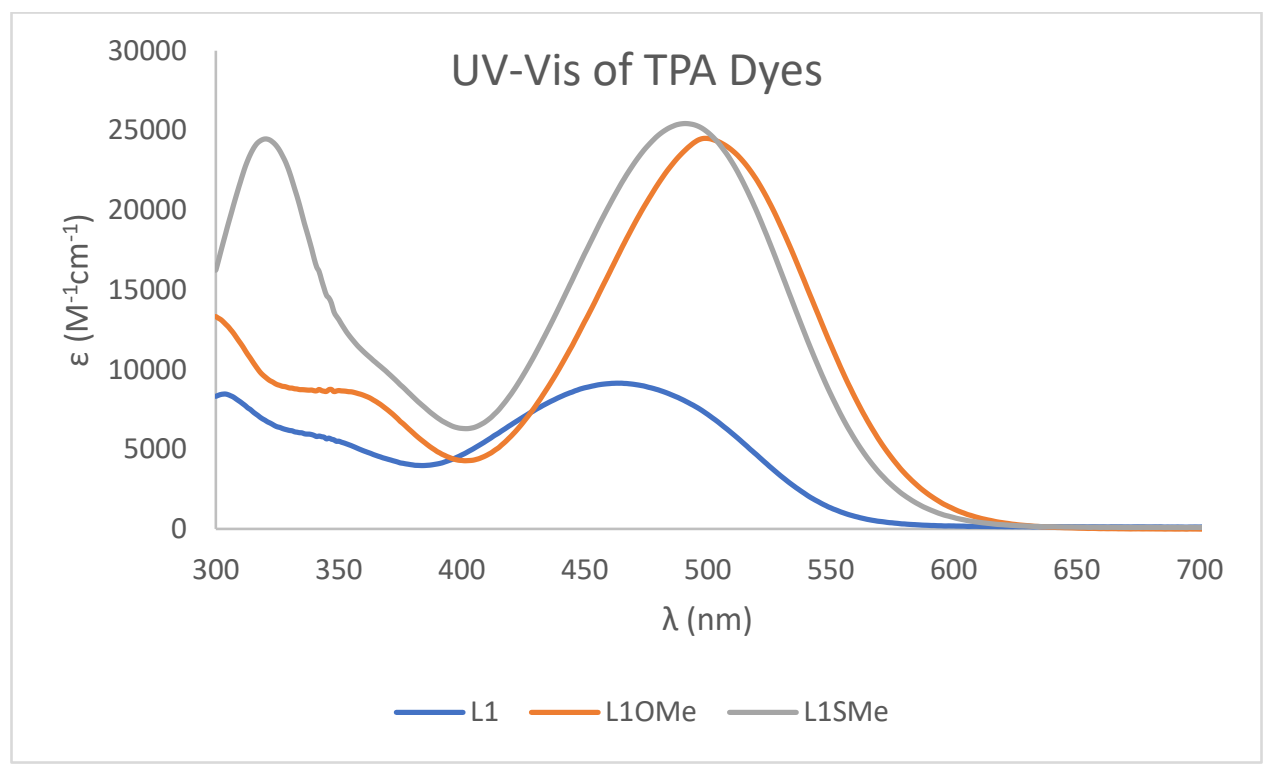

Figure 30 UV-Vis spectra of L1, L1OMe, and L1SMe dyes in DCM

\subsection{Long-term testing of L1 DSSCS}

DSSCs are often tested under continuous irradiation for periods of up to 60 days, ${ }^{35,65}$ however due to the challenges of continuous illumination (expensive equipment unavailable for other use), little data exists on stability over a longer time period. For these reasons, a set of DSSCs containing the dye L1 and the Z1137 electrolyte were tested periodically for a period of one year. The dyes were not left under continued irradiation, rather they were measured every 7-14 days and left in ambient indoor conditions when not being tested. As Figure 31 shows, there is some variation observed over the testing period, however the overall trend in the data is a slightly positive slope indicating that no degradation of the DSSCs took place over the testing period. 


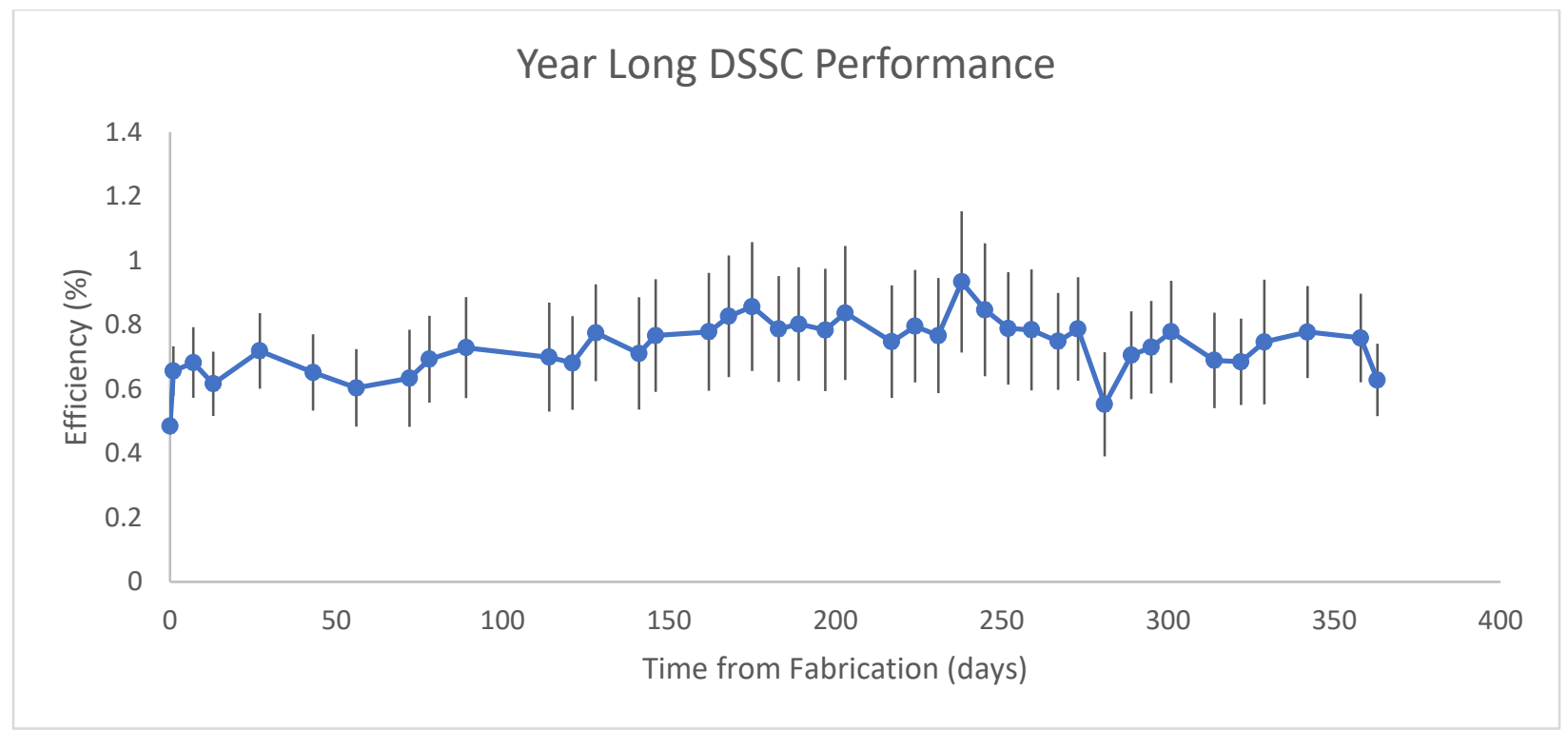

Figure 31 Average efficiency of L1/Z1137 DSSCs tested periodically over one year

\subsection{BODIPY Dyes}

All BODIPY dyes were first tested while paired with DCA and the Z1137 electrolyte. As seen in Figure 32, all DSSCs tested were lower than the other groups of dyes. In contrast to the other dye groups, the performance of these DSSCs dropped sharply after the initial test at the time of fabrication. A possible explanation for this is that the dye may be decomposing or desorbing from the titania over time however, there were no visual signs (such as colour changes) to support this. To determine which possibility may be occurring, UV-vis absorption spectroscopy could be carried out. UV-vis will determine the absorbance. The molar extinction coefficient can then be determined from Beers Law, $A=\varepsilon l c$ where $A$ is absorbance (unitless), $\varepsilon$ is molar extinction coefficient $\left(\mathrm{M}^{-1} \mathrm{~cm}^{-1}\right), \mathrm{I}$ is the path length $(\mathrm{cm})$, and $\mathrm{c}$ is the concentration (mol/L). If the dye is desorbing from the titania, a shift in the $\lambda_{\max }$ of the absorption spectrum will be observed, however, if a decrease in $\varepsilon$ is observed, it suggests that the dye is decomposing. 


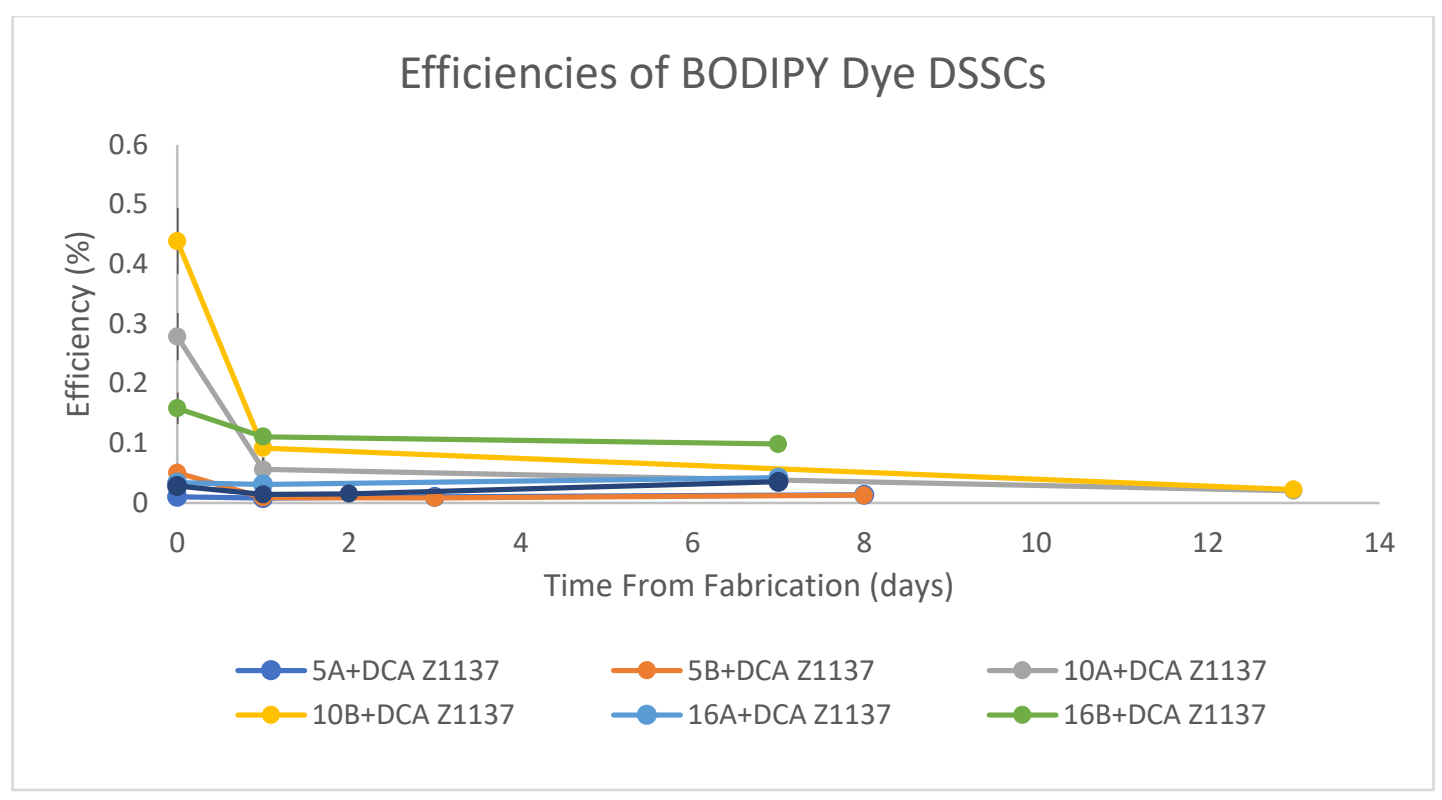

Figure 32 Efficiencies of BODIPY Dye based DSSCS

When looking at the data some trends emerge between the dyes with the long alkyl chains $(A)$ and those without (B). In all instances, the B derivative outperformed the A derivative which is likely due to the long chains preventing dye aggregation. Additionally, dyes $10 \mathrm{~A}$ and $10 \mathrm{~B}$ were markedly higher than the rest with $10 \mathrm{~B}$ having a maximum average efficiency of $0.44 \%$ which is highlighted in Figure 33.

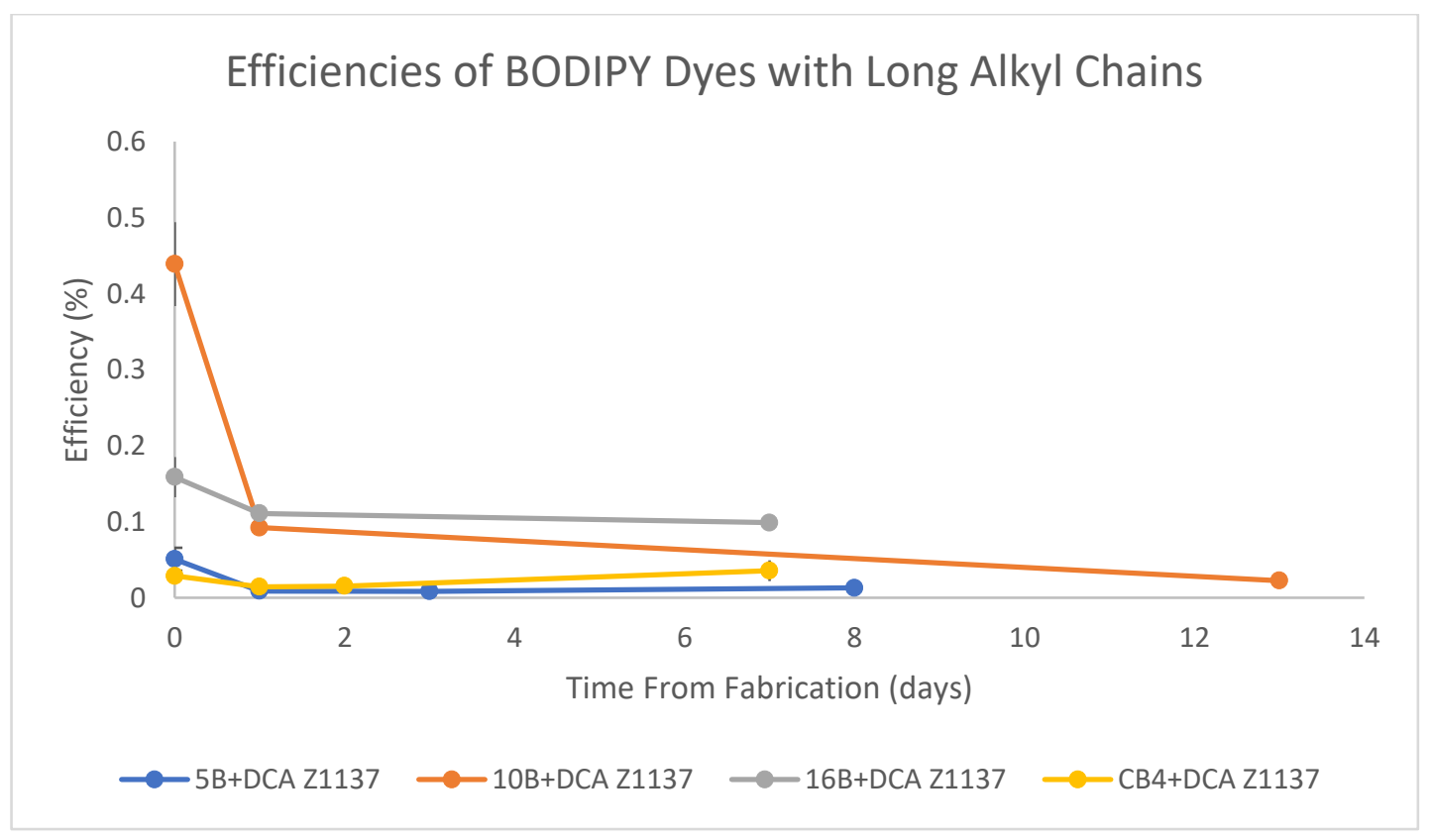

Figure 33 Efficiencies of long alkyl chain BODIPY DSSCS 
In the hopes of improving performance, the dyes were tested again with Li added to the Z1137 electrolyte to lower the titania conduction band. However, due to limited materials, only 10B and CB4 were re-tested, this time with and without DCA. From Figure 34, the efficiency of 10B and CB4 roughly double upon the addition of $\mathrm{Li}^{+}$. However, despite the improvement in initial performance, there is still a prompt decline just as observed without the addition of $\mathrm{Li}^{+}$. A possible explanation for the prompt decline in performance is that BODIPY is not as stable as previously thought. Recent work has demonstrated this ${ }^{66}$ and it is possible that BODIPY can't withstand repeated oxidation and reduction causing the decline.

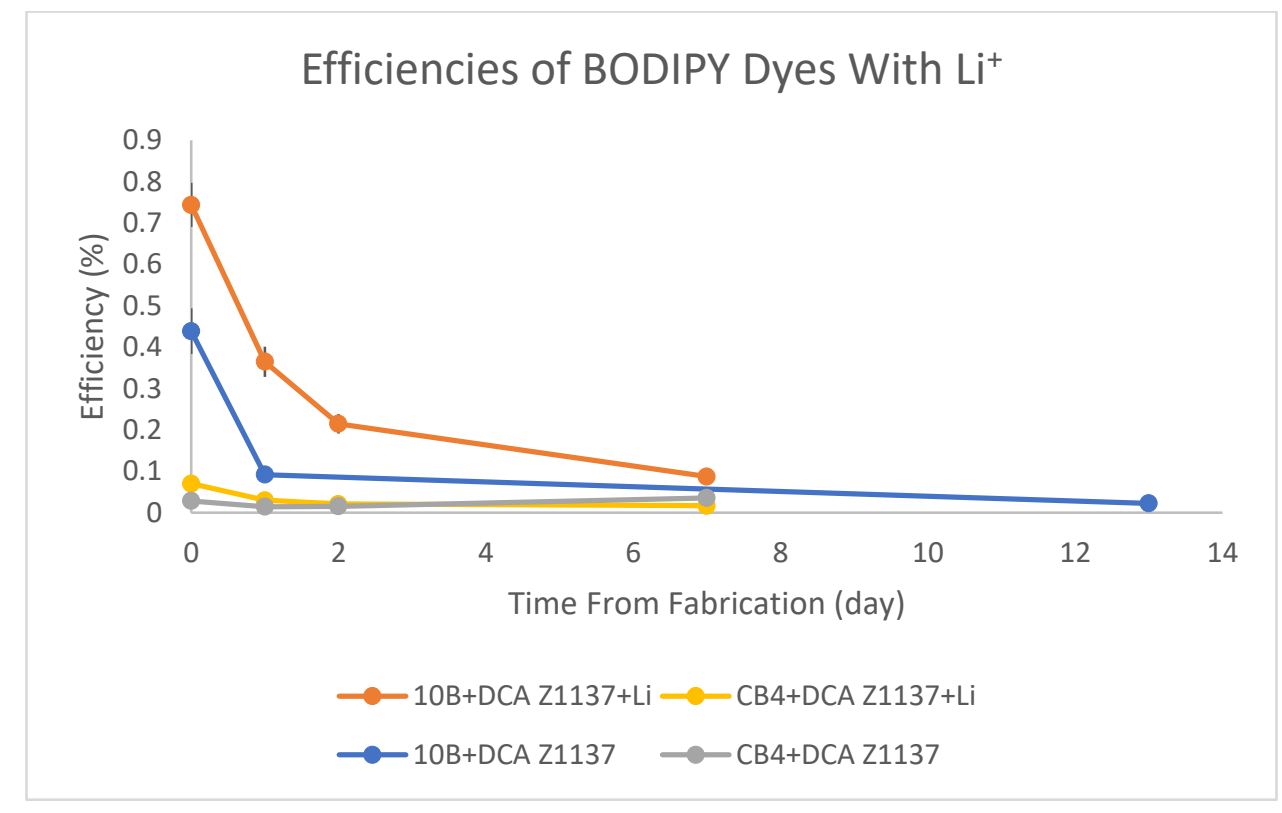

Figure 34 Efficiencies of BODIPY dye DSSCs with and without $\mathrm{Li}^{+}$added to the Z1137 electrolyte

When looking at the $V_{o c}$ and $J_{s c}$ of the two tests of $10 \mathrm{~B}$ shown in Table 7, it is seen that when moving from no $\mathrm{Li}^{+}$to added $\mathrm{Li}^{+}$, the average $\mathrm{V}_{\mathrm{oc}}$ increased slightly and the average $\mathrm{J}_{\mathrm{sc}}$ increased more dramatically. However, only minor differences in FF were seen between the two.

Table 7 Average DSSC performance data of dye $10 B$ paired with $Z 1137+L^{+}$and $Z 1137$

$\begin{array}{ccccc}\text { Variable } & \mathrm{V}_{\text {oc }}(\mathrm{V}) & \mathrm{J}_{\mathrm{sc}}\left(\mathrm{mA} / \mathrm{cm}^{2}\right) & \mathrm{FF} & \eta(\%) \\ \mathrm{Z1137+ \textrm {Li } ^ { + }} & 0.54 \pm 0.01 & 1.6 \pm 0.11 & 0.57 \pm 0.04 & 0.7 \pm 0.11 \\ \mathrm{Z1137} & 0.53 \pm 0.01 & 1.0 \pm 0.20 & 0.60 \pm 0.02 & 0.4 \pm 0.11\end{array}$




\subsection{Cobalt Electrolytes}

The first two cobalt electrolytes tested were the Co-bpy and the Co-terpy containing electrolytes which were tested using L1 with and without DCA. As Figure 35 shows, in both cases the DSSC containing DCA performed better as expected and the Co-bpy electrolyte performed the best with a maximum average efficiency of $1.05 \%$ while the Co-terpy electrolyte had a maximum average efficiency of $0.44 \%$.

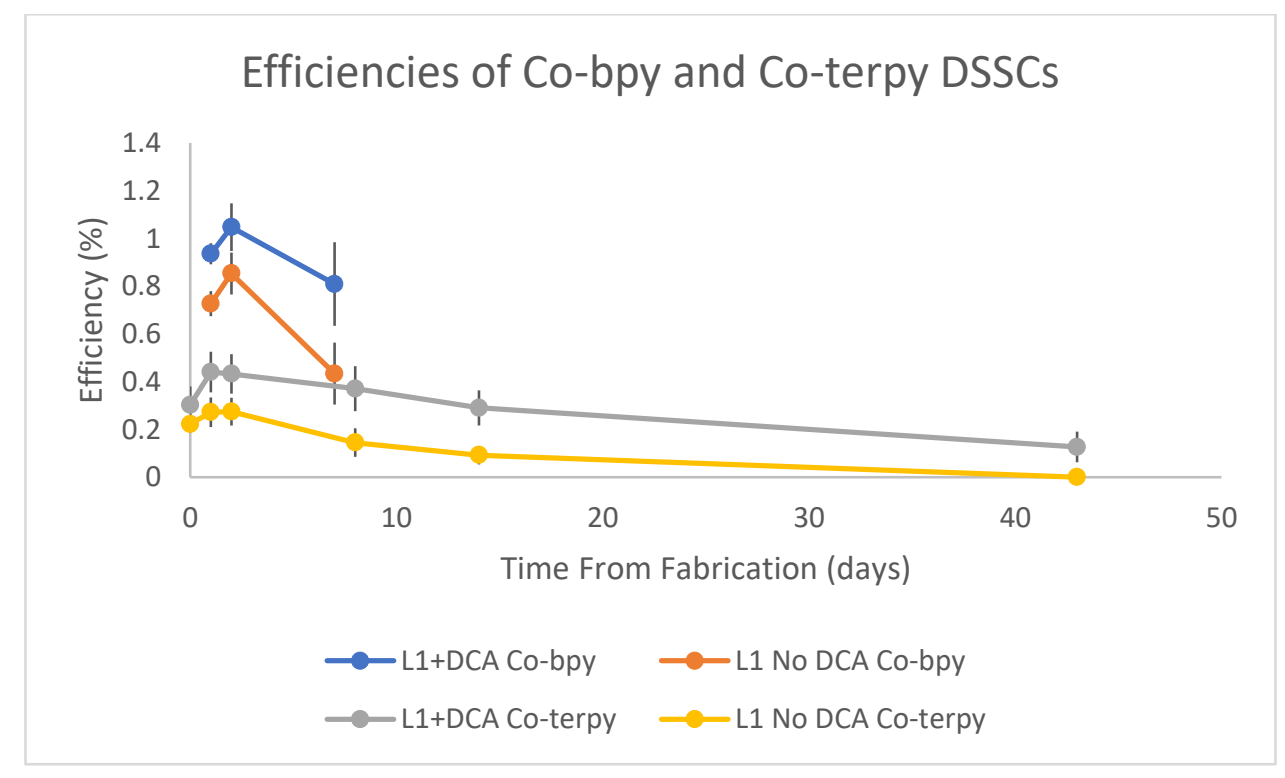

Figure 35 Efficiencies of cobalt electrolyte DSSCS

The next electrolyte tested was the Co-dmpb containing electrolyte. Although all cobalt complexes tested are $\mathrm{d}^{7} \mathrm{Co}^{2+}$ complexes, the dmpb ligand is a weak-field ligand relative to the bpy and terpy ligands. As a result (as depicted in Figure 36), the oxidation to the $3+$ state was not achieved and the desired electrolyte mixture with $2+$ and $3+$ was not attained. Consequently, an electrolyte mixture was made containing the cobalt $2+$ species and a second electrolyte mixture was made containing an oxidant $\left(\mathrm{NOPF}_{6}\right)$ in the appropriate quantity in hopes that it would oxidize some of the cobalt species to the $3+$ state in situ. 


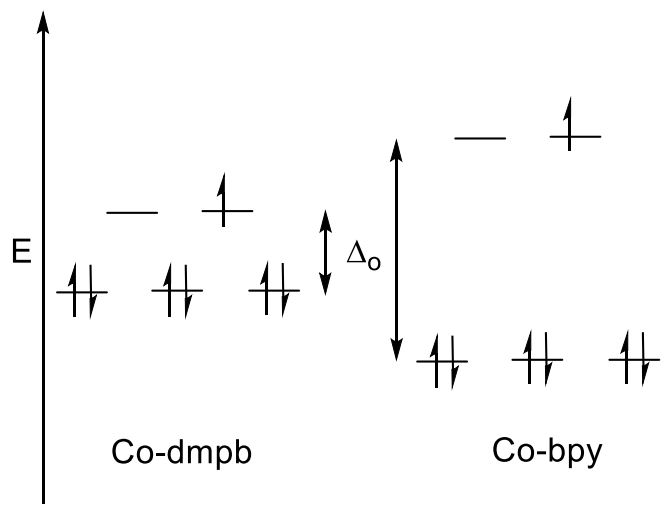

Figure 36 d electron configuration in Co-dmpb complex vs Co-bpy and Co-terpy complexes

As Figure 37 shows, the electrolyte mixture containing the oxidant performed better than the mixture without the oxidant indicating that the $\mathrm{NOPF}_{6}$ did serve to oxidize some of the cobalt complex. However, the performance of these DSSCs were lower than the Co-bpy and Co-terpy tested earlier as Table 8 shows. The drop in $\mathrm{J}_{\mathrm{sc}}$ observed from the Co-bpy and Co-terpy to the Co-dmpb could be explained by the absence of the Co $3+$ species. The Co $3+$ species is required to transfer charge back to the dye and regenerate it, if this process were hindered the dye could not give up an electron causing a drop in $\mathrm{J}_{\mathrm{sc}}$.

Table 8 Average efficiency data of cobalt electrolyte DSSCs with L1 and DCA

Variable

Co-bpy

Co-terpy

Co-dmpb+NOPF6

$$
V_{\text {oc }}(\mathrm{V})
$$

$0.66 \pm 0.01$

$0.49 \pm 0.06$

$0.66 \pm 0.03$
$\mathrm{J}_{\mathrm{sc}}\left(\mathrm{mA} / \mathrm{cm}^{2}\right)$

$2.0 \pm 0.29$

$1.3 \pm 0.38$

$0.44 \pm 0.06$
FF

$0.55 \pm 0.03$

$0.44 \pm 0.05$

$0.6 \pm 0.16$ $\eta(\%)$

$1.1 \pm 0.20$

$0.4 \pm 0.17$

$0.3 \pm 0.10$ 


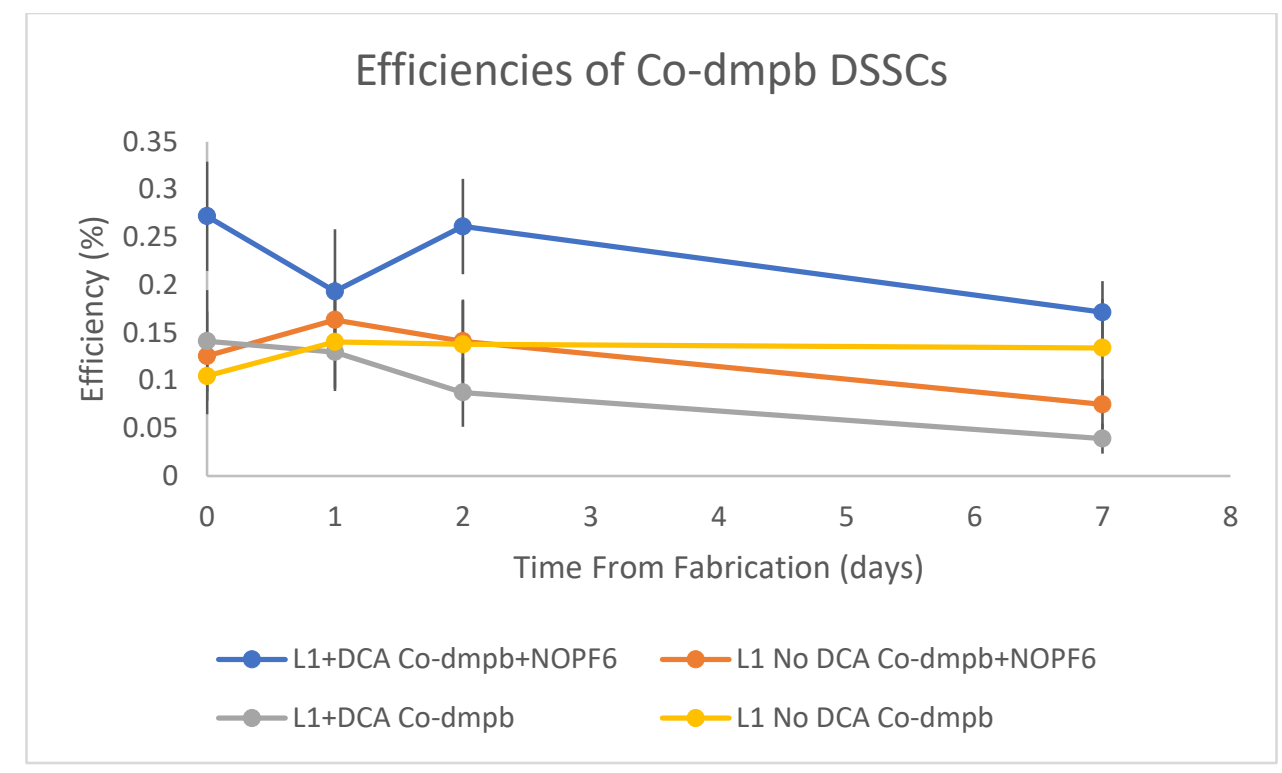

Figure 37 Efficiencies of Co-dmpb electrolyte DSSCS

\subsection{Hole Transport Material Testing}

Initially the HTM mixture prepared for use in DSSCs was made with DCM as the solvent to closely

match previous work with a similar compound, ${ }^{52}$ however, the efficiency of these DSSCs was low, as Figure

38 shows. The low solubility of electrolyte components in DCM prevented the desired concentrations

from being reached. Thus, MeCN, a solvent with better solubility towards the electrolyte components was chosen. When tested, the mixture was tested with and without DCA, with the DCA free mixture performing much better. However, even the best performance was still quite low compared to the worst performing of the other DSSCs tested. 


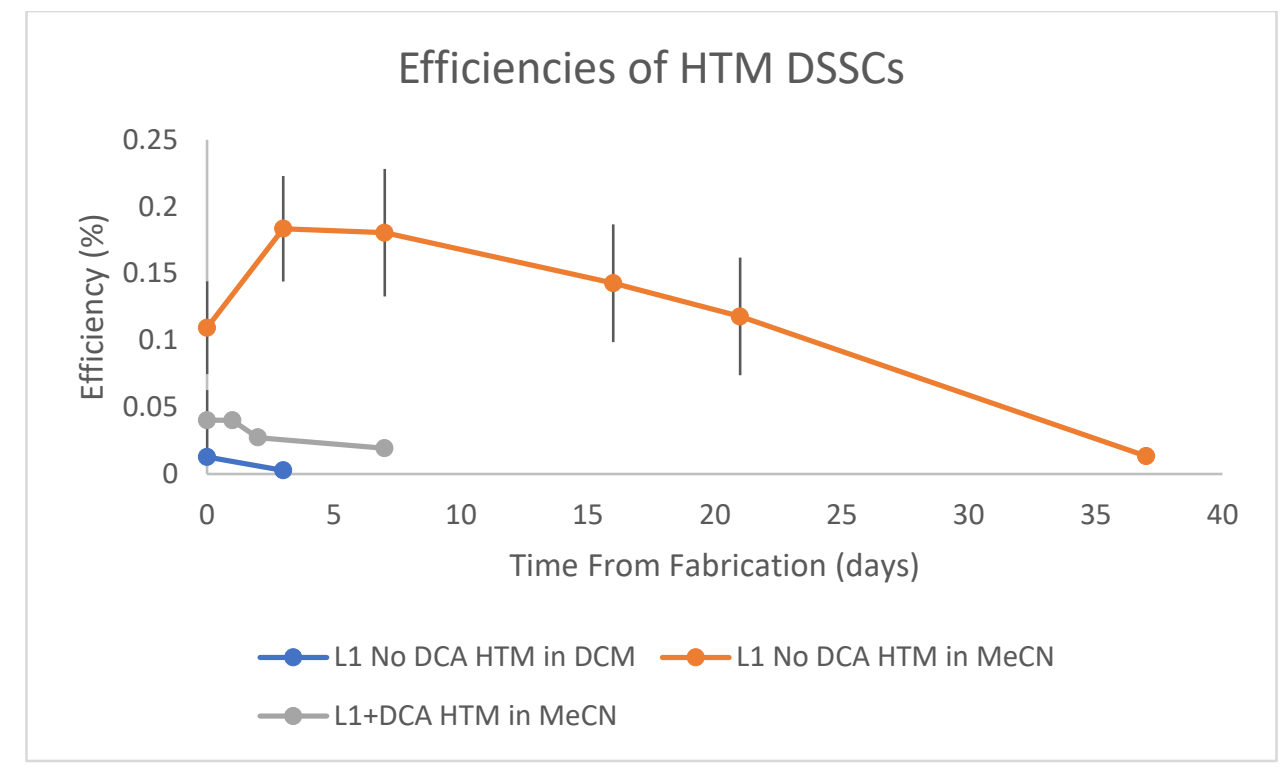

Figure 38 Efficiencies of L1 DSSCS with varied MeCN and DCM electrolyte mixtures with and without DCA

To improve performance, the electrolyte mixture was altered to include an oxidant (NOPF 6$)$. Like the inclusion of an oxidant in the Co-dmpb testing, the HTM was not present in an oxidized state. The oxidant was included at 10 molar percent to oxidize the HTM in situ in the hopes of increasing efficiency. Again, the mixture was tested with and without DCA showing the same result as earlier with the addition of DCA hindering performance as shown in Table 9 and Figure 39. Although passivating the titania surface has been effective with the $Z 1137$ electrolyte through reduced recombination, it also reduces dye loading. The reduced $\mathrm{J}_{\mathrm{sc}}$ observed implies that the performance bottleneck is not recombination and it is possible that the use of DCA reduces dye loading.

Table 9 Average efficiency data of HTM based DSSCs with and without DCA

$\begin{array}{ccccc}\text { Variable } & \mathrm{V}_{\mathrm{oc}}(\mathrm{V}) & \mathrm{J}_{\mathrm{sc}}\left(\mathrm{mA} / \mathrm{cm}^{2}\right) & \mathrm{FF} & \eta(\%) \\ \text { DCA } & 0.42 \pm 0.08 & 0.3 \pm 0.31 & 0.3 \pm 0.21 & 0.03 \pm 0.04 \\ \text { No DCA } & 0.45 \pm 0.06 & 0.46 \pm 0.07 & 0.24 \pm 0.09 & 0.08 \pm 0.05\end{array}$




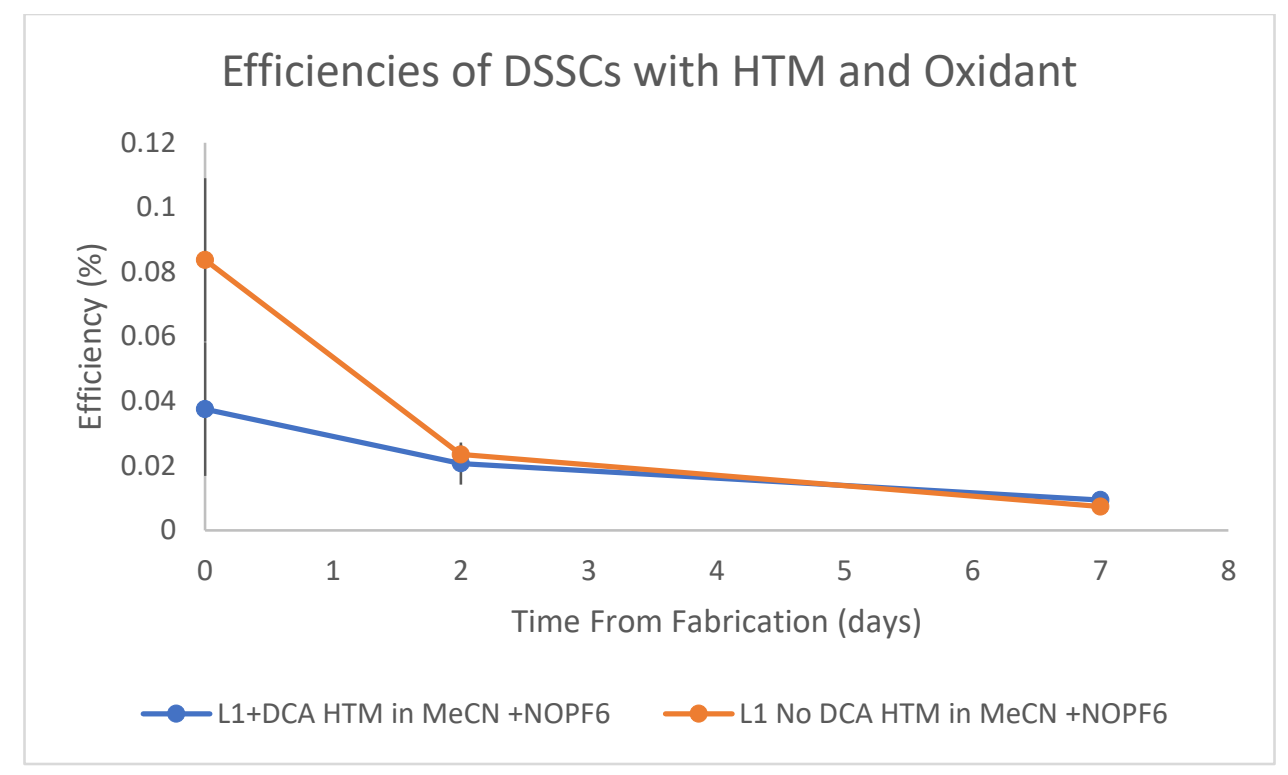

Figure 39 Efficiencies of L1 DSSCS with oxidant containing HTM electrolyte and regular HTM electrolyte

Additionally, Figure 39 shows that both sets of DSSCs performed significantly worse than the previous tests which did not include the oxidant. Upon oxidation, the HTM mixture went from a lightyellow colour to a dark brown colour, as Figure 40 shows. It is possible that the intense colour of the electrolyte was competitively absorbing light preventing it from reaching the dye.

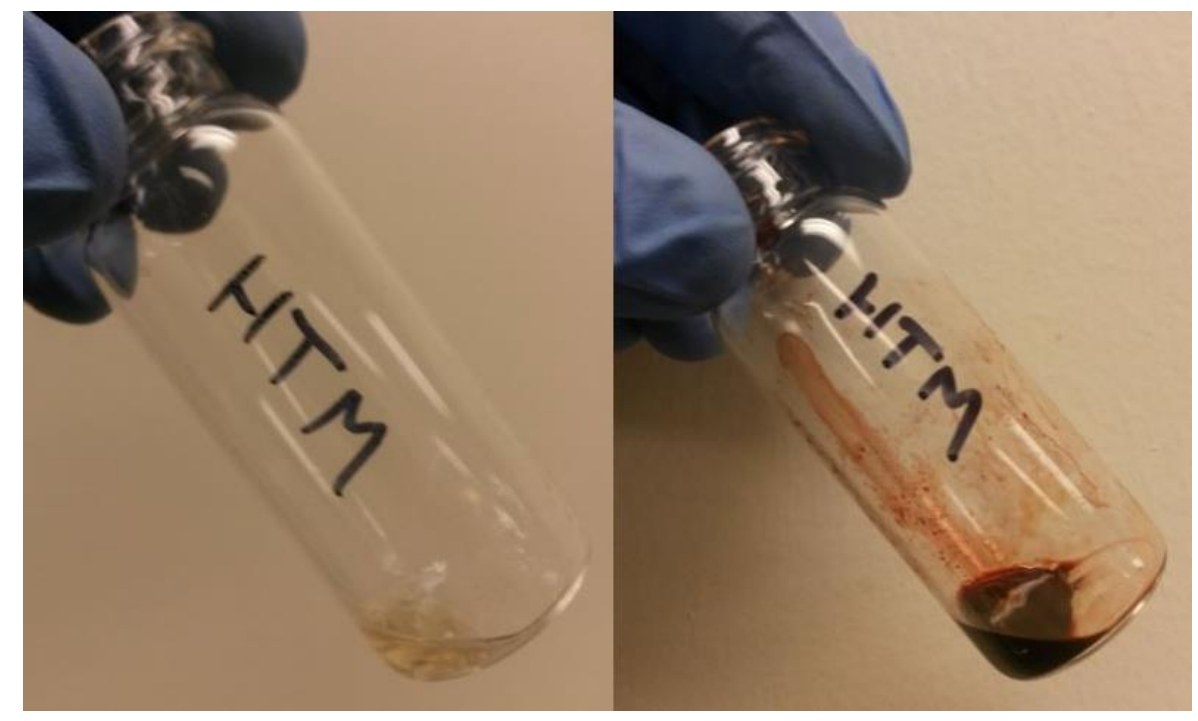

Figure 40 Colour change upon addition of oxidant to HTM electrolyte mixture 


\section{7 bis-TPA Dyes}

The bis-TPA dyes OA1-OA4 were all first tested with and without DCA using the Z1137 electrolyte.

As seen in Figure 41 and Table 10, OA1-OA3 fell mostly within the 1.5-2.5\% efficiency range. OA4, as expected, did not perform as well as the other dyes as it possesses only one TPA unit and thus has a lower cross-sectional area and has a lower absorption coefficient as discussed in chapter 1.

Table 10 Average DSSC data for bis-TPA dyes tested without DCA 24 hours after fabrication

$\begin{array}{ccccc}\text { Variable } & V_{\text {oc }}(V) & J_{s c}\left(\mathrm{~mA} / \mathrm{cm}^{2}\right) & \text { FF } & \eta(\%) \\ \text { OA1 } & 0.64 \pm 0.01 & 3.2 \pm 0.64 & 0.70 \pm 0.03 & 2.0 \pm 0.35 \\ \text { OA2 } & 0.68 \pm 0.01 & 3.3 \pm 0.43 & 0.67 \pm 0.05 & 2.2 \pm 0.23 \\ \text { OA3 } & 0.58 \pm 0.01 & 2.70 \pm 0.02 & 0.72 \pm 0.01 & 1.69 \pm 0.06 \\ \text { OA4 } & 0.4 \pm 0.17 & 0.8 \pm 0.16 & 0.5 \pm 0.16 & 0.3 \pm 0.20 \\ \text { L1 } & 0.52 \pm 0.02 & 1.18 \pm 0.03 & 0.58 \pm 0.04 & 0.53 \pm 0.05\end{array}$

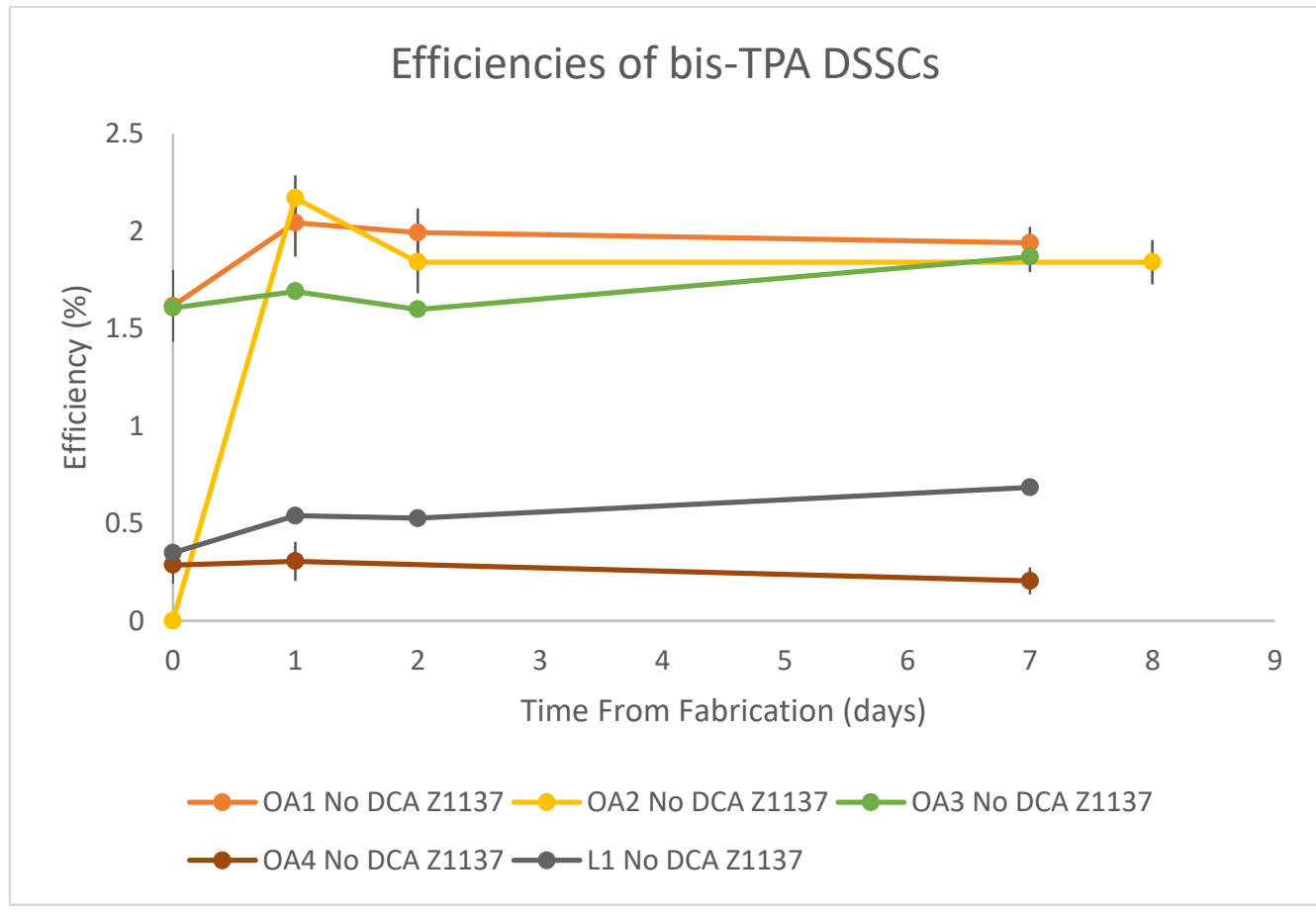

Figure 41 Efficiencies of bis-TPA dye based DSSCs over time 
As shown fully in chapter 6 according to previous trends, the OA3 DSSC with DCA performed better than the DSSC lacking DCA. However, OA3 started out following the same trend and over time flipped to the DCA free DSSC performing better while OA1 showed better performance when no DCA was included from the start. It is possible that given the bipedal nature of this family of dyes that when the DCA binds to the titania it inhibits binding by the dye. All other dyes tested with a single binding group could bind to a smaller area where the larger footprint of the bis-TPA dyes makes adsorption less favourable. To investigate further, OA1 and OA2 were tested again with varying concentrations of DCA.

Figure 42 shows that the 10:1 DCA DSSC initially showed the highest efficiency, while over time the performance of the 10:1 DCA DSSC dropped and the DSSC with no DCA had the highest efficiency. Although this switch seems odd, the switch is primarily driven by a decrease in the 10:1 DSSC while the no DCA stays relatively stable. As discussed earlier, perhaps the increased DCA destabilized the adsorption of the dye to the titania. This theory is supported by the sharp drop in $\mathrm{J}_{\text {sc }}$ (shown in Table 11) of the 10:1 DSSCs indicating lower absorption, of which the same drop is not observed for the DSSCs containing no DCA.

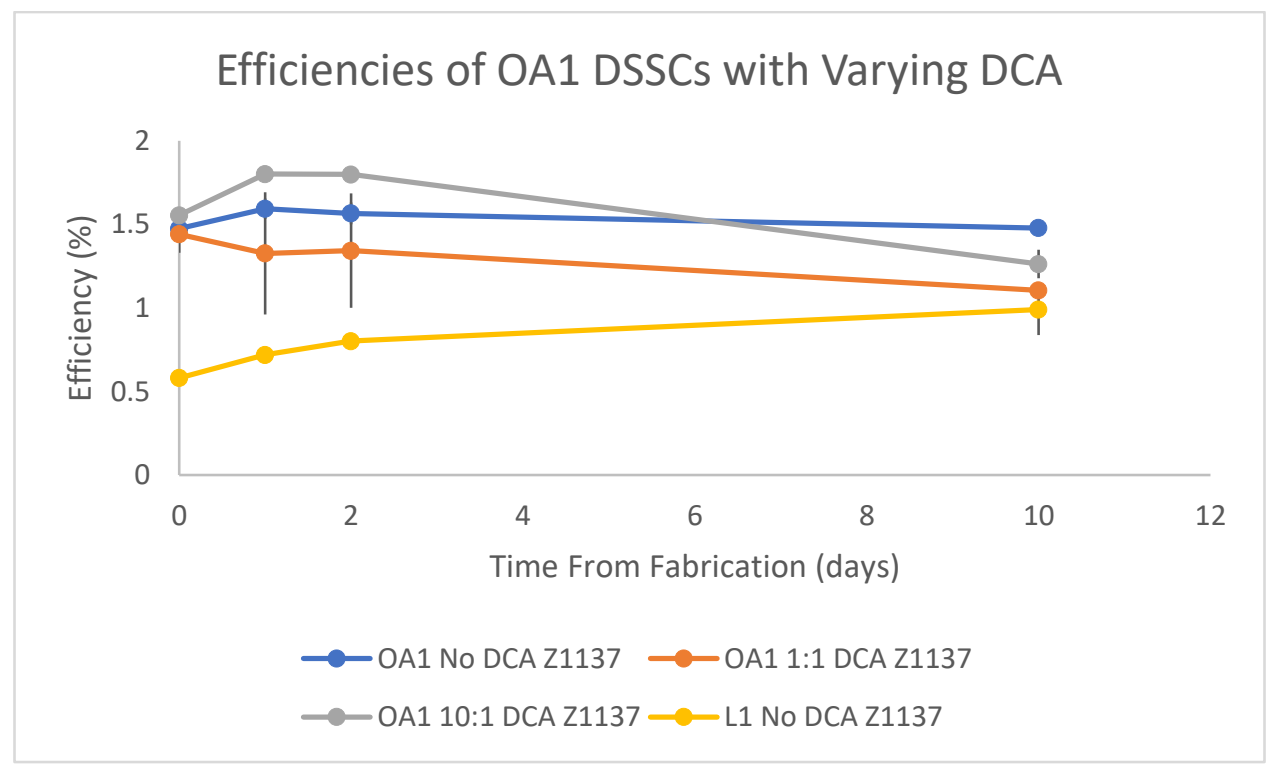

Figure 42 Efficiencies of OA1 DSSCS with varying DCA concentrations 
Table 11 Average DSSC performance parameters of 10:1 and 0:1 DCA:OA1 at 2 and 10 days

Variable

10:1 DCA (2 days)

10:1 DCA (10 days)

No DCA (2 days)

No DCA (10 days)
$V_{\text {oc }}(\mathrm{V})$

$0.65 \pm 0.03$

$0.59 \pm 0.05$

$0.66 \pm 0.01$

$0.62 \pm 0.02$
$\mathrm{J}_{\mathrm{sc}}\left(\mathrm{mA} / \mathrm{cm}^{2}\right)$

$2.9 \pm 0.10$

$2.1 \pm 0.14$

$2.4 \pm 0.18$

$2.4 \pm 0.14$

$0.71 \pm 0.01$ $\eta(\%)$

$1.8 \pm 0.10$

$1.3 \pm 0.17$

$1.6 \pm 0.13$

$1.48 \pm 0.09$

\subsection{Outdoor Testing}

DSSC testing was carried out outdoors on the summer solstice (June 21, 2017) at Ryerson University (approximate latitude of $43.658361^{\circ} \mathrm{N}$ ) with the sun replacing the simulator normally used. Multiple calibration measurements were taken in direct sunlight with power ranging from $67-88 \mathrm{~mW} / \mathrm{cm}^{2}$, close to the power generated by the solar simulator. These measurements were taken over a 15-minute window between 3:55 pm and 4:10 pm and a roughly linear drop in power was observed throughout this time which is shown in Figure 43.

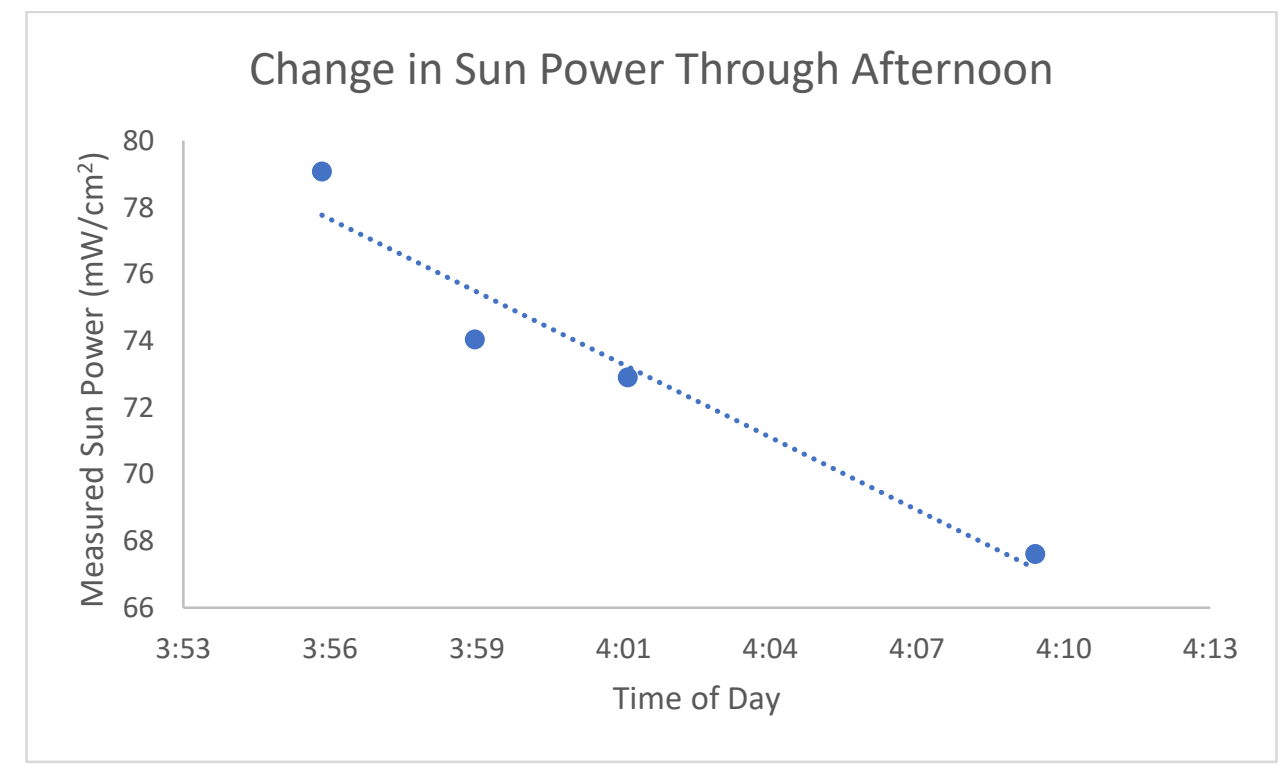

Figure 43 Change in sun power measured over a 15-minute window between 3:55 pm and 4:10 pm on the summer solstice 
Measurements were also taken under cloudy conditions $\left(5 \mathrm{~mW} / \mathrm{cm}^{2}\right)$ and in full shade while the sun was shining $\left(4 \mathrm{~mW} / \mathrm{cm}^{2}\right)$. While the power of the sun was similar to that of the solar simulator, there was a pronounced disparity between direct illumination and testing under cloudy or shady conditions which is shown in Figure 44. When testing DSSCs in full sun, a power of $73 \mathrm{~mW} / \mathrm{cm}^{2}$ was used as it was the calibration measurement taken closest to measurement of the DSSCs. Likewise, if testing was carried out in shade or cloud cover, the previously mentioned values were used.

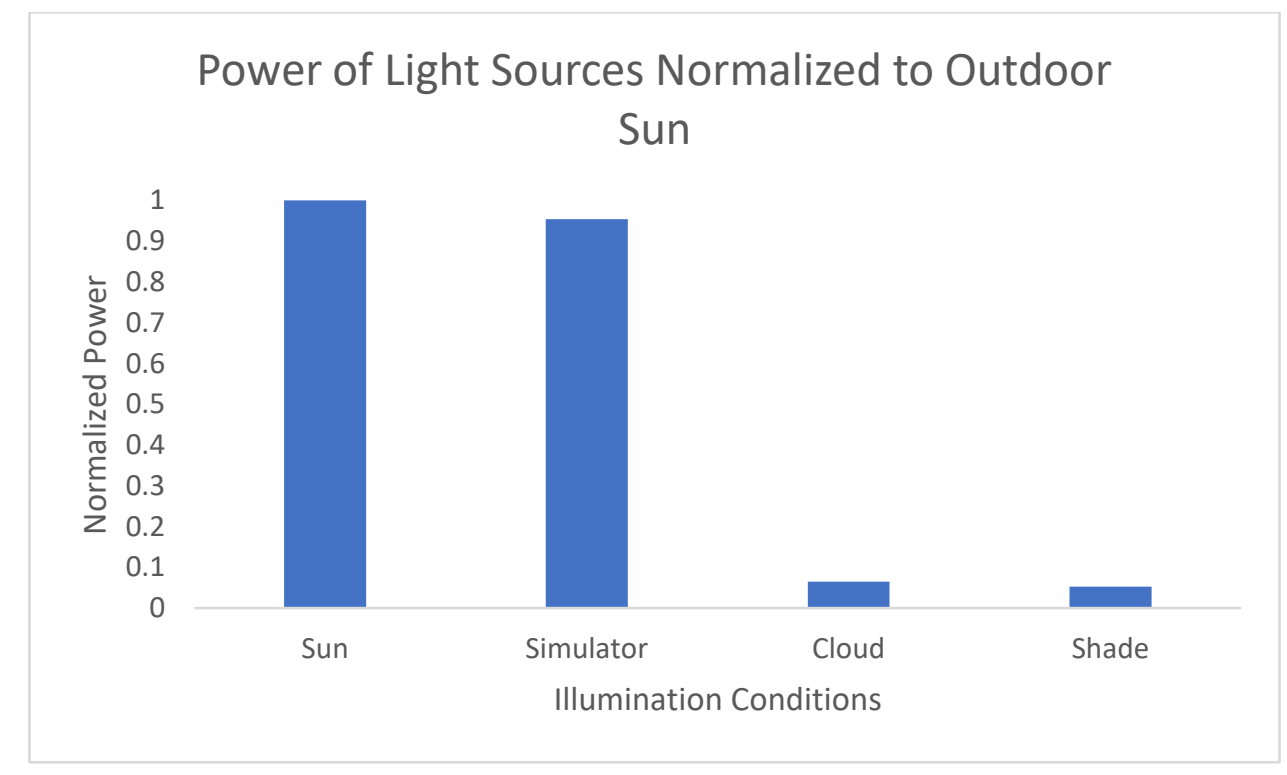

Figure 44 Measured incident power of sun from different light sources at different conditions

Table 12 shows the efficiency of the DSSCs tested under direct sunlight, in cloud/shade, and under the solar simulator all tested the same day. In almost all instances, the solar simulator gave the lowest efficiency with full outdoor sun giving a better efficiency, and outdoor shade/cloud giving the best efficiency. The only exception to this is for the DSSCs made with L1. In this case, one of the cells tested abnormally higher than the others, which can be seen in the increased standard deviation. This could be because the atmospheric conditions can cause variations in light intensity during testing and this may have been a particularly bright point. Given that the intensity of direct sun is slightly higher than that of the solar simulator, it would be expected that DSSCs tested under the solar simulator would be slightly 
higher but the opposite is observed. A possible explanation for this is that the DSSCs tested outside were continually exposed to full illumination. This is significant as this is a technique called light soaking which is used to fill trap states in the titania before testing to improve efficiency.

Table 12 Efficiencies of DSSCs tested under full outdoor sun, cloudy or shady conditions, and solar simulator

$\begin{array}{llccc} & \text { Efficiency from } & \text { Efficiency from } & \text { Efficiency in } & \text { Change from } \\ \text { DSSC Tested } & \text { Solar Simulator (\%) } & \text { Direct Sun (\%) } & \text { Shade/Cloud (\%) } & \text { High to Low } \\ & & & & \text { Light (\%) }\end{array}$

L1 No DCA Z1137

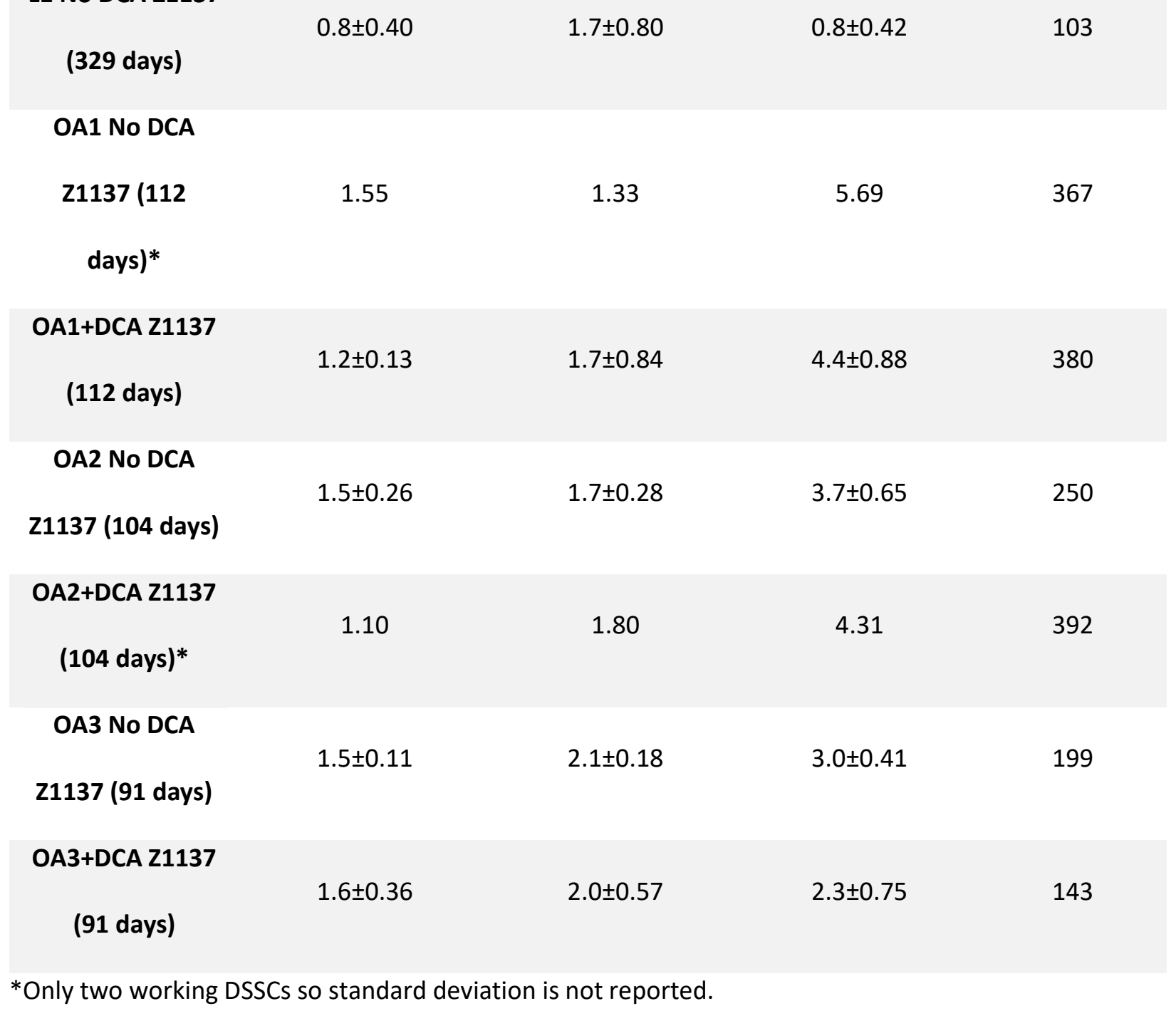


When looking at the last column in Table 12, the percent change in efficiency from testing under the solar simulator $\left(70 \mathrm{~mW} / \mathrm{cm}^{2}\right)$ to testing under shaded/clouded conditions $\left(5 \mathrm{~mW} / \mathrm{cm}^{2}\right)$ is shown. L1 showed a minor increase of $103 \%$, while the bis-TPA dyes showed more substantial increases. OA2 showed the largest increase, 392\%, with OA1 and OA3 close behind. These increases are substantial compared to L1 and previous work with $\mathrm{N}-719$ at low light irradiance ${ }^{38}$ and as such, warrant further investigation of the bis-TPA dyes as they may have applications in low light conditions that were previously not feasible.

Looking closer at the J-V data of the individual DSSC \# 130 from the OA1+DCA subset, Figure 45 and Table 13 show how $V_{\text {oc }}$ and $J_{s c}$ increased with increasing light intensity, but like efficiency, FF showed an opposite relationship increasing as light intensity decreased.

Table 13 DSSC performance data for DSSC \# 130 (OA1+DCA, Z1137) under varying light intensities 112 days after fabrication

Variable

$\mathrm{V}_{\mathrm{oc}}(\mathrm{V})$

$\mathrm{J}_{\mathrm{sc}}\left(\mathrm{mA} / \mathrm{cm}^{2}\right)$

FF

$\eta(\%)$

Full Sun

$\left(73 \mathrm{~mW} / \mathrm{cm}^{2}\right)$

0.592

3.55

0.715

2.06

\section{Solar Simulator}

$\left(70 \mathrm{~mW} / \mathrm{cm}^{2}\right)$

$$
0.583
$$

1.80

0.726

1.09

Cloudy

0.533

0.531

0.732

4.37

$\left(5 \mathrm{~mW} / \mathrm{cm}^{2}\right)$ 


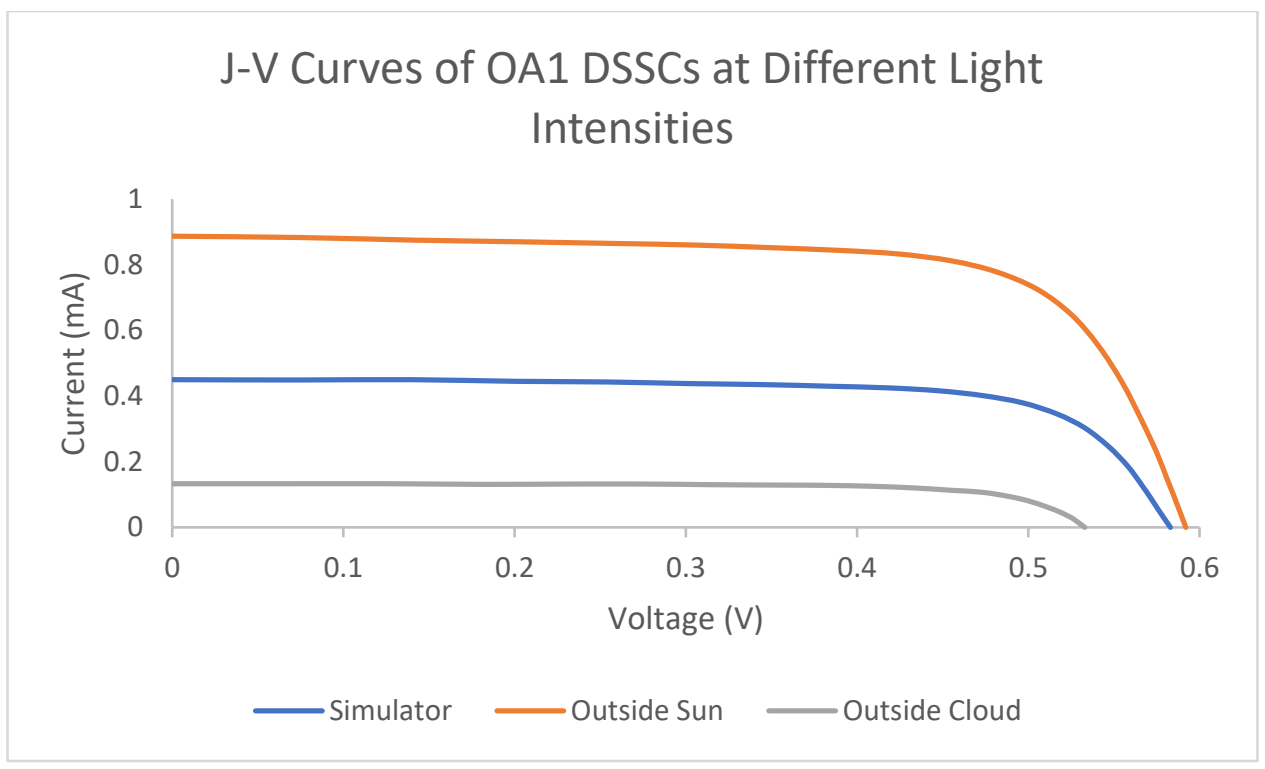

Figure $45 \mathrm{~J}-V$ curves of DSSC 130 (OA1+DCA/Z1137) after 112 days under full outdoor sun, outside cloudy conditions, and solar simulator 


\section{Chapter 4: Summary, Conclusions, and Future Work}

\subsection{Summary}

As Table 14 shows, the best performing group of dyes were the bis-TPA dyes of which OA2 was the highest with an average efficiency of $2.46 \%$. The next best performing set of dyes were the substituted TPA dyes with L1SMe reaching an average efficiency of $1.92 \%$. Finally, the BODIPY dye group was the lowest performing but an improvement was observed with the addition of $\mathrm{Li}^{+}$into the electrolyte with 10B reaching an average efficiency of $0.74 \%$, slightly higher than that of the benchmark dye, $L 1$, with an average efficiency of $0.60 \%$.

Of the electrolyte compositions tested, the Co-bpy electrolyte performed best with an efficiency of $1.05 \%$, followed by the Co-terpy, Co-dmpb+NOPF 6 , and lastly the HTM electrolyte. The long-term testing of the L1/Z1137 DSSCs revealed that in ambient conditions these DSSCs show consistent performance and stability over the course of one year with no obvious signs of degradation.

Lastly, the outdoor testing revealed that the power from the sun on the Summer Solstice was close to that of the solar simulator used. Additionally, the difference between the power from direct sunlight $\left(67-88 \mathrm{~mW} / \mathrm{cm}^{2}\right)$ and shady or cloudy weather $\left(4 \mathrm{~mW} / \mathrm{cm}^{2}\right.$ and $\left.5 \mathrm{~mW} / \mathrm{cm}^{2}\right)$ was determined as well as the performance differences of DSSCs under these conditions with shade/cloud being the best. 
Table 14 Efficiencies (\%) of dye and electrolyte combinations tested in DSSCS

\begin{tabular}{|c|c|c|c|c|c|c|c|c|c|c|c|c|c|c|c|}
\hline Electrolyte & DCA/Dye & L1 & L1OMe & L1SMe & OA1 & OA2 & OA3 & OA4 & $5 a$ & $5 b$ & $10 a$ & $10 \mathrm{~b}$ & $16 a$ & $16 b$ & CB4 \\
\hline \multirow{4}{*}{ Z1137 } & No DCA & 0.52 & & & 2.04 & 2.17 & 1.87 & 0.31 & & & & & & & \\
\hline & $1 \times D C A$ & & & & 1.33 & & & & & & & & & & \\
\hline & $5 \times D C A$ & 0.60 & 1.27 & 1.92 & 1.57 & 2.46 & 2.17 & 0.36 & 0.01 & 0.05 & 0.28 & 0.44 & 0.04 & 0.15 & 0.04 \\
\hline & $10 \times D C A$ & & & & 1.80 & 1.31 & & & & & & & & & \\
\hline \multirow{2}{*}{ Z1137+Li } & No DCA & 0.50 & & & & & & & & & & 0.35 & & 0.30 & 0.04 \\
\hline & $5 \times D C A$ & & & & & & & & & & & 0.74 & & & 0.07 \\
\hline \multirow{2}{*}{ Co-bpy } & No DCA & 0.85 & & & & & & & & & & & & & \\
\hline & $5 \times D C A$ & 1.04 & & & & & & & & & & & & & \\
\hline \multirow{2}{*}{ Co-terpy } & No DCA & 0.27 & & & & & & & & & & & & & \\
\hline & $5 \times D C A$ & 0.44 & & & & & & & & & & & & & \\
\hline \multirow{2}{*}{ Co-dmpb } & No DCA & 0.14 & & & & & & & & & & & & & \\
\hline & $5 \times D C A$ & 0.14 & & & & & & & & & & & & & \\
\hline \multirow{2}{*}{$\begin{array}{c}\text { Co-dmpb } \\
\text { +NOPF6 }\end{array}$} & No DCA & 0.16 & & & & & & & & & & & & & \\
\hline & $5 \times D C A$ & 0.27 & & & & & & & & & & & & & \\
\hline \multirow{2}{*}{ HTM } & No DCA & 0.18 & & & & & & & & & & & & & \\
\hline & $5 \times D C A$ & 0.04 & & & & & & & & & & & & & \\
\hline \multirow{2}{*}{ HTM+NOPF6 } & No DCA & 0.08 & & & & & & & & & & & & & \\
\hline & $5 \times D C A$ & 0.04 & & & & & & & & & & & & & \\
\hline
\end{tabular}

\subsection{Conclusions}

Firstly, Chapter 2 of this thesis was designed to serve as a detailed handbook on DSSC fabrication.

It provides a comprehensive reference for reliable and reproducible fabrication and testing procedures. Additionally, with the aim of improving DSSC performance and longevity, 14 different dyes and 8 different electrolyte mixtures were tested in DSSCs with the bis-TPA dyes showing the highest efficiency, and impressive efficiencies at low-light intensities. Lastly, one set of DSSCs was tested periodically over the course of a year to determine when performance begins to decrease or fails entirely with no signs of reduction within the observation period.

\subsection{Future Work}

Future work on this project involves testing the best performing dyes, the bis-TPA dyes, with the Co-bpy electrolyte to see if an improvement in efficiency is observed. Additionally, future work includes testing the thiophene functionalized TPA based dyes in Figure 46 with an HTM. These dyes were previously synthesized and tested with iodide electrolyte by Bonnier et al. ${ }^{61}$ with molecule $8 \mathrm{~b}$ having an efficiency of over 6.5\%. 


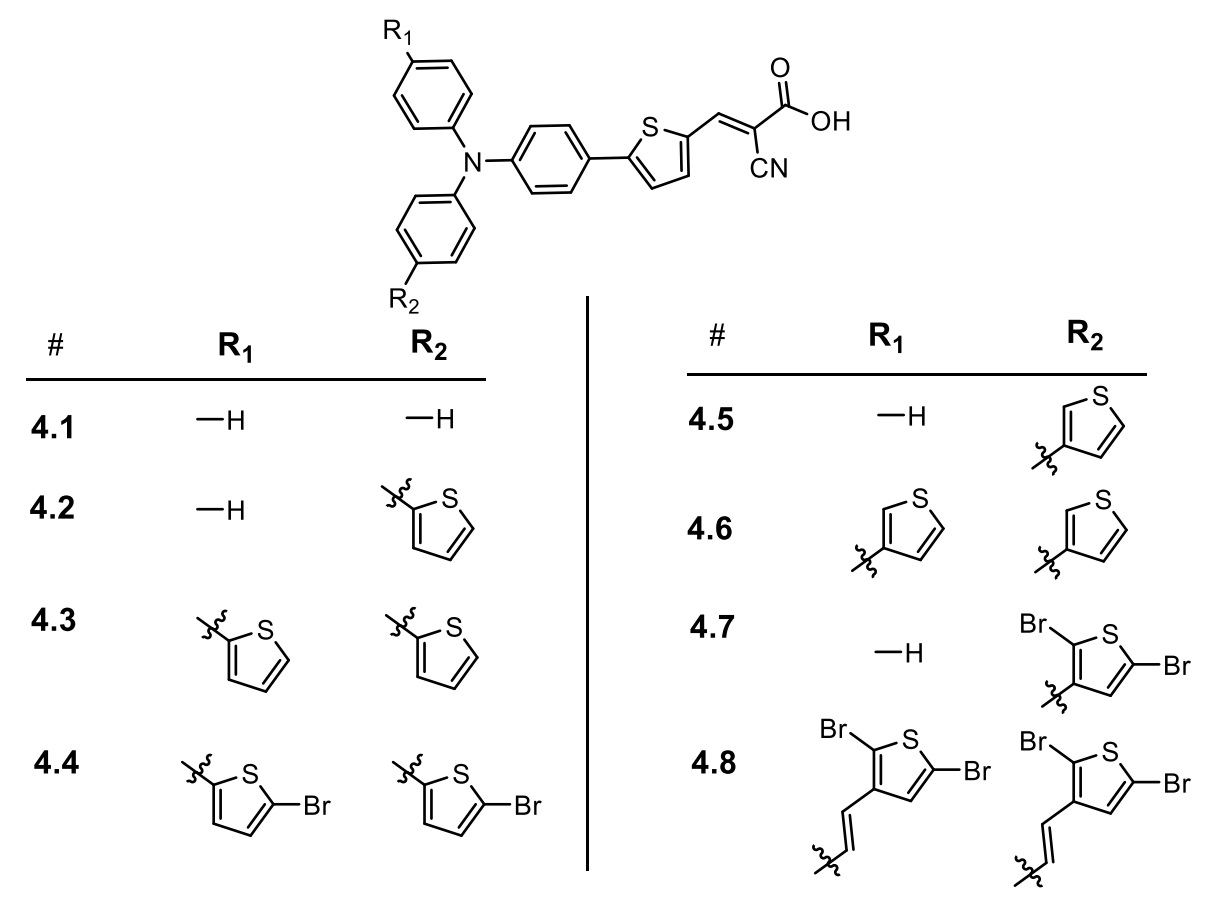

Figure 46 Thiophene functionalized TPA based dyes

New work would see these dyes paired with ethylenedioxythiophene (EDOT) as an HTM in the hopes that EDOT could be polymerized directly onto the thiophenes of the dyes as shown in Figure 47, which would result in much faster regeneration of the dye. This should increase $\mathrm{J}_{\mathrm{sc}}$ resulting in a higher efficiency than observed in previous testing.

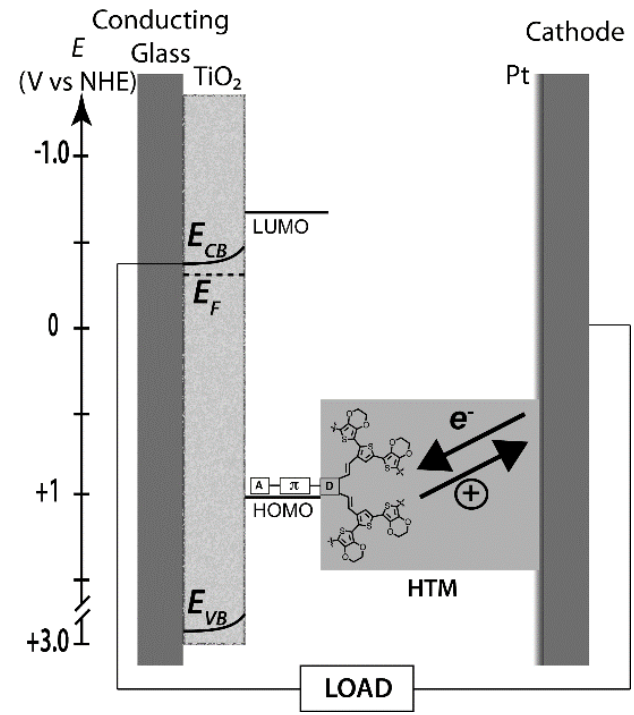

Figure 47 DSSC containing a thiophene functionalized TPA dye paired polymerized with the PEDOT HTM 
As Figure 48 shows, dyes can come in many different colours. This allows for the use of DSSCs as tiles for incorporation into a mosaic type module. As such, future work includes designing and building a DSSC mosaic. This would require wiring of multiple DSSCs together so combined performance could be investigated to determine how modules perform compared to individual DSSCs. Additionally, this mosaic could serve as a display piece to illustrate the potential uses of DSSCs should they become commercially available.

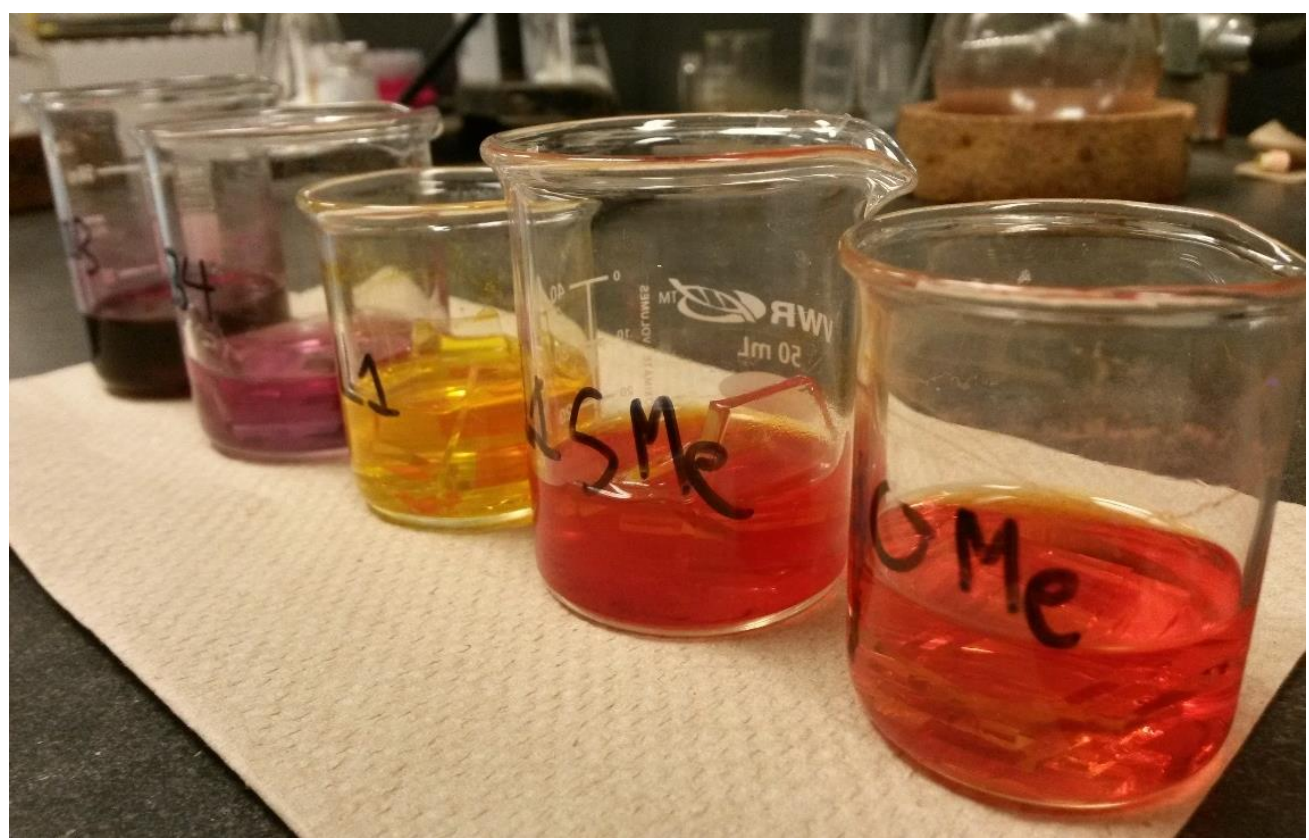

Figure 48 Anodes dipped in various coloured dye solutions used in DSSC fabrication 
Chapter 5: Appendices

6.1 Additional DSSC Stability Data

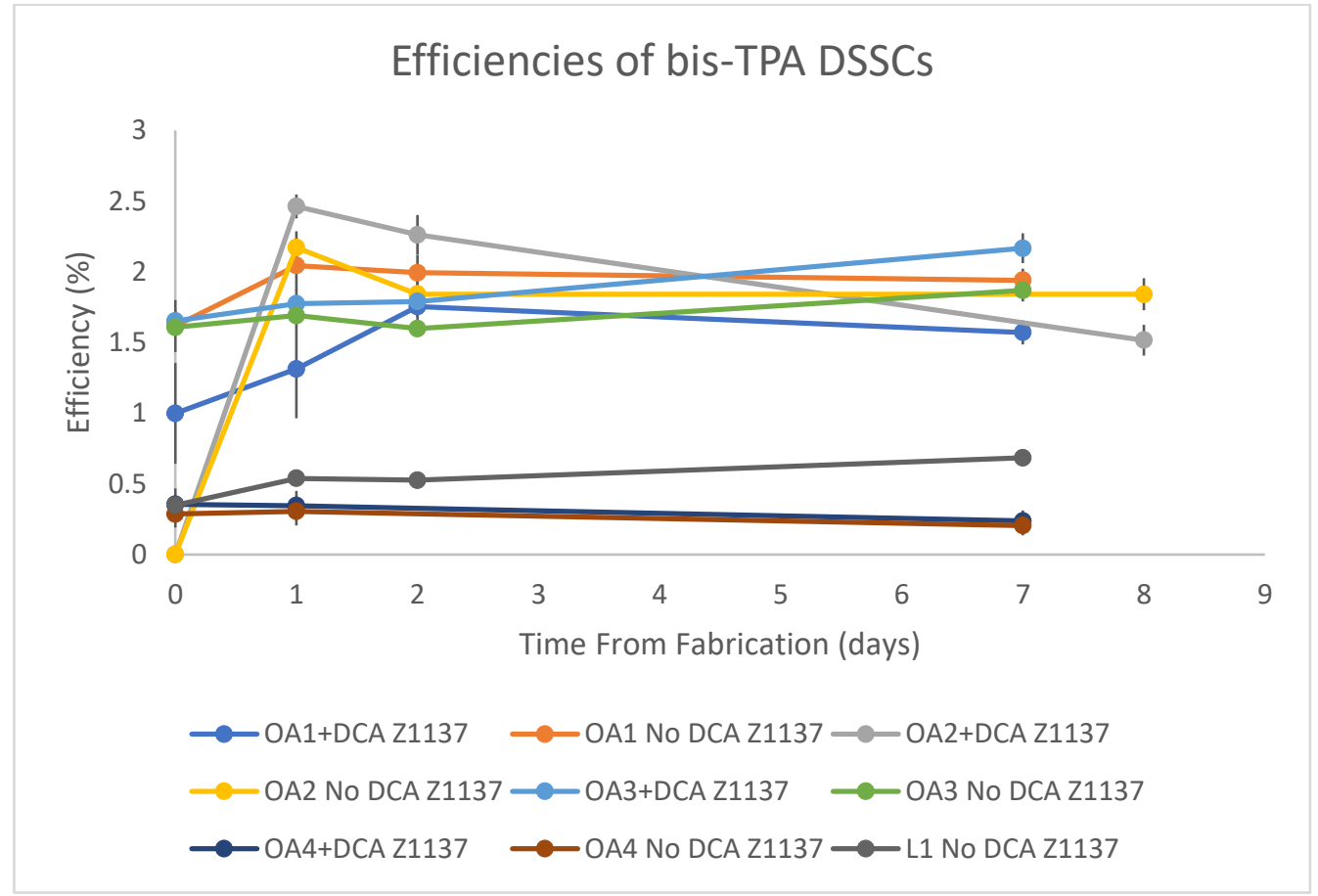

Figure 49 Efficiency data for all bis-TPA dyes with and without DCA

6.2 Electrolyte Mixtures

Z1137 Electrolyte

Name

1,3-dimethylimidazolium iodide

lodine

4-tert-Butylpyridine

Sodium iodide

Guanidinium thiocyanate

Acetonitrile
Short

DMII

$\mathrm{I}_{2}$

4-TBP

$\mathrm{Nal}$

GuNCS

$\mathrm{MeCN}$
Concentration

$0.55 \mathrm{M}$

$60 \mathrm{mM}$

$0.5 \mathrm{M}$

$0.05 \mathrm{M}$

$0.1 \mathrm{M}$

Solvent 
Z1137+Li+ Electrolyte

Name

1,3-dimethylimidazolium iodide

lodine

4-tert-Butylpyridine

Sodium iodide

Guanidinium thiocyanate

Lithium hexafluorophosphate

Acetonitrile
Short

DMII

$\mathrm{I}_{2}$

4-TBP

$\mathrm{Nal}$

GuNCS

$\mathrm{LiPF}_{6}$

$\mathrm{MeCN}$

Solvent

Co-terpy Electrolyte

Name

Short

Concentration

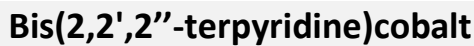

$\left[\mathrm{Co}(\text { terpy })_{2}\right]\left(\mathrm{PF}_{6}\right)_{2}$

$0.22 \mathrm{M}$

(II)bis(hexafluorophosphate)

Bis(2,2',2"'-terpyridine)cobalt

(III)tris(hexafluorophosphate)

$\left[\mathrm{Co}(\text { terpy })_{2}\right]\left(\mathrm{PF}_{6}\right)_{3} \quad 0.033 \mathrm{M}$

4-tert-Butylpyridine

4-TBP

$0.2 \mathrm{M}$

Lithium hexafluorophosphate

$\mathrm{LiPF}_{6}$

$0.1 \mathrm{M}$

Acetonitrile

$\mathrm{MeCN}$

Solvent 
Co-bpy Electrolyte

Name

Short

Concentration

Tris(2,2'-bipyridine)cobalt

(II)bis(hexafluorophosphate)

$\left[\mathrm{Co}(\mathrm{bpy})_{3}\right]\left(\mathrm{PF}_{6}\right)_{2}$

$0.22 \mathrm{M}$

Tris(2,2'-bipyridine)cobalt

$\left[\mathrm{Co}(\mathrm{bpy})_{3}\right]\left(\mathrm{PF}_{6}\right)_{3} \quad 0.033 \mathrm{M}$

(III)tris(hexafluorophosphate)

4-tert-Butylpyridine

4-TBP

$0.2 \mathrm{M}$

Lithium hexafluorophosphate

$\mathrm{LiPF}_{6}$

$0.1 \mathrm{M}$

Acetonitrile

$\mathrm{MeCN}$

Solvent

Co-dmpb Electrolyte

Name

Short

Concentration

Bis(dimethylpyridinebisoxazoline)

cobalt(II)bis(hexafluorophosphate)

$\left[\mathrm{Co}(\mathrm{dmpb})_{2}\right]\left(\mathrm{PF}_{6}\right)_{2}$

$0.22 \mathrm{M}$

4-tert-Butylpyridine

4-TBP

$0.2 \mathrm{M}$

Lithium hexafluorophosphate

$\mathrm{LiPF}_{6}$

$0.1 \mathrm{M}$

Acetonitrile

$\mathrm{MeCN}$

Solvent 
Co-dmpb+NOPF 6 Electrolyte

Name

Short

$$
\left[\mathrm{Co}(\mathrm{dmpb})_{2}\right]\left(\mathrm{PF}_{6}\right)_{2}
$$

$\mathrm{NOPF}_{6}$

4-TBP

$\mathrm{LiPF}_{6}$

$\mathrm{MeCN}$

Acetonitrile

Lithium hexafluorophosphate

HTM Mixture

Name

Short

$\mathbf{N}^{4}, \mathbf{N}^{4}, \mathbf{N}^{4}, \mathbf{N}^{4}$-tetrakis(4-

$((1,1,1,3,5,5,5-$

heptamethyltrisiloxan-3-

yl)oxy)phenyl)-[1,1'-biphenyl]-4,4'-

diamine

4-tert-Butylpyridine

4-TBP

$1.6 \mathrm{M}$

Lithium bis(trifluoromethane)

sulfonimide

$$
\mathrm{CF}_{3} \mathrm{SO}_{2} \mathrm{NLiSO}_{2} \mathrm{CF}_{3}
$$

Dichloromethane
HTM

$0.26 \mathrm{M}$

\section{Concentration}

$0.22 \mathrm{M}$

$0.033 \mathrm{M}$

$0.2 \mathrm{M}$

$0.1 \mathrm{M}$

Solvent

\section{Concentration}


HTM Mixture

Name

$\mathbf{N}^{4}, \mathbf{N}^{4}, \mathbf{N}^{4}, \mathbf{N}^{4}$-tetrakis(4-

$((1,1,1,3,5,5,5-$

heptamethyltrisiloxan-3-

yl)oxy)phenyl)-[1,1'-biphenyl]-4,4'-

diamine

4-tert-Butylpyridine

4-TBP

$1.6 \mathrm{M}$

Lithium bis(trifluoromethane)

sulfonimide

Acetonitrile

$\mathrm{CF}_{3} \mathrm{SO}_{2} \mathrm{NLiSO}_{2} \mathrm{CF}_{3}$

$\mathrm{MeCN}$

Solvent

$\mathrm{HTM}+\mathrm{NOPF}_{6}$ Mixture

Name

Short

HTM

$\mathrm{NOPF}_{6}$

4-TBP

4-tert-Butylpyridine

Lithium bis(trifluoromethane)

sulfonimide

Acetonitrile
$\mathrm{CF}_{3} \mathrm{SO}_{2} \mathrm{NLiSO}_{2} \mathrm{CF}_{3}$

$\mathrm{MeCN}$
$1.6 \mathrm{M}$

\section{Concentration}

$0.26 \mathrm{M}$

$0.026 \mathrm{M}$

$0.1 \mathrm{M}$

Solvent 


\subsection{Synthetic Procedures}

All reagents were purchased from Aldrich or are otherwise noted. Analytical thin-layer chromatography was performed on aluminum-backed sheets precoated with silica 60 F254 adsorbent (0.25 mm thick; Silicycle) and visualized under UV light. Routine ${ }^{1} \mathrm{H}$ and ${ }^{13} \mathrm{C}\{1 \mathrm{H}\} \mathrm{NMR}$ spectra were recorded at 400 and $100 \mathrm{MHz}$ respectively, on a Bruker AV 400 instrument at ambient temperature. Chemical shifts $(\delta)$ are reported in parts per million $(\mathrm{ppm})$ from low to high field and referenced to a residual nondeuterated solvent $\left(\mathrm{CHCl}_{3}\right)$ for ${ }^{1} \mathrm{H}$ and ${ }^{13} \mathrm{C}$ nuclei. Standard abbreviations indicating multiplicity are used as follows: $\mathrm{s}=$ singlet; $\mathrm{d}=$ doublet; $\mathrm{m}=$ multiplet; $\mathrm{br}=$ broad.

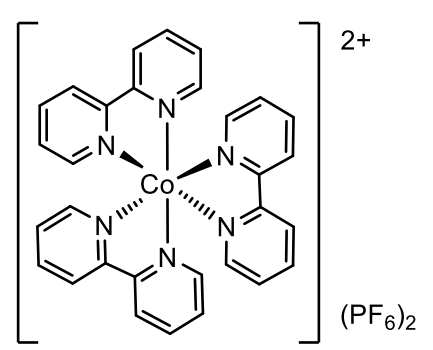

Synthesis of Tris(2,2'-bipyridine)cobalt(II)bis(hexafluorophosphate) : $\left[\mathrm{Co}(\mathrm{bpy})_{3}\right](\mathrm{Cl})_{2}(0.5751 \mathrm{~g}, 0.961 \mathrm{mmol})$ was dissolved in $\mathrm{MeOH}(1.5 \mathrm{~mL})$ at room temperature to make a saturated solution (with any remaining solids filtered out) and 3 equivalents of $\mathrm{NH}_{4} \mathrm{PF}_{6}(0.470 \mathrm{~g}, 2.883 \mathrm{mmol})$ was dissolved in another portion of $\mathrm{MeOH}(1.5 \mathrm{~mL})$ to make a saturated solution and added to the $\mathrm{Co}(\mathrm{bpy})_{3}(\mathrm{Cl})_{2}$ solution. The resulting brown precipitate was filtered out and washed with cold $\mathrm{MeOH}$ before being dried under vacuum to obtain the product $\left[\mathrm{Co}(\mathrm{bpy})_{3}\right]\left(\mathrm{PF}_{6}\right)_{2}(0.5951 \mathrm{~g}, 76 \%)$. NMR data not available because the complex is paramagnetic and does not show on NMR.

\footnotetext{
$\stackrel{N}{\prime} \oplus$ Synthesis of dimethylimidizolium iodide: To a solution of $\mathrm{N}$-methylimidazole $(2.1 \mathrm{~g}, 26 \mathrm{mmol})$

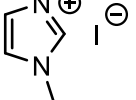
in dry toluene $(6.0 \mathrm{~mL})$, was added 1.5 equivalents of methyl iodide $(5.4 \mathrm{~g}, 38 \mathrm{mmol})$ and the mixture allowed to stir in a capped vial for 12 hours at ambient temperature. A precipitate was observed, which was filtered off and washed with anhydrous diethyl ether and dried under vacuum to yield the desired compound as a brown powder (3.91 g, 68\%). ${ }^{1} \mathrm{H} \mathrm{NMR}\left(400 \mathrm{MHz},\left(\mathrm{CD}_{3}\right)_{2} \mathrm{SO}\right): \delta=9.06(\mathrm{~s}, 1 \mathrm{H}), 7.69$ (s,2H), 3.85 (s, 6H). ${ }^{13} \mathrm{C}\left\{{ }^{1} \mathrm{H}\right\}$ NMR $\left(100 \mathrm{MHz},\left(\mathrm{CD}_{3}\right)_{2} \mathrm{SO}\right): \delta=136.93,123.34,35.73$.
} 
6.4 NMR Spectra

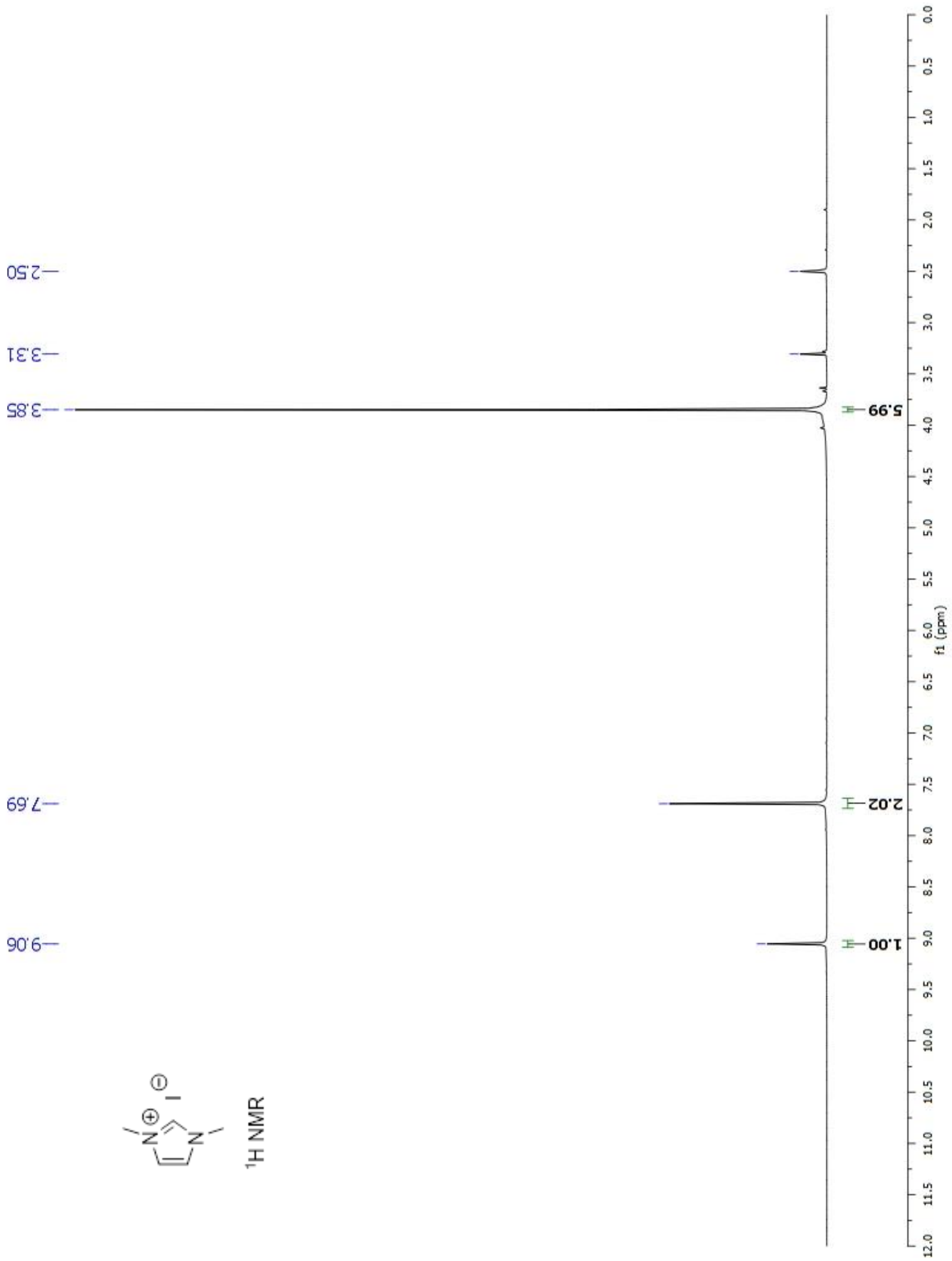




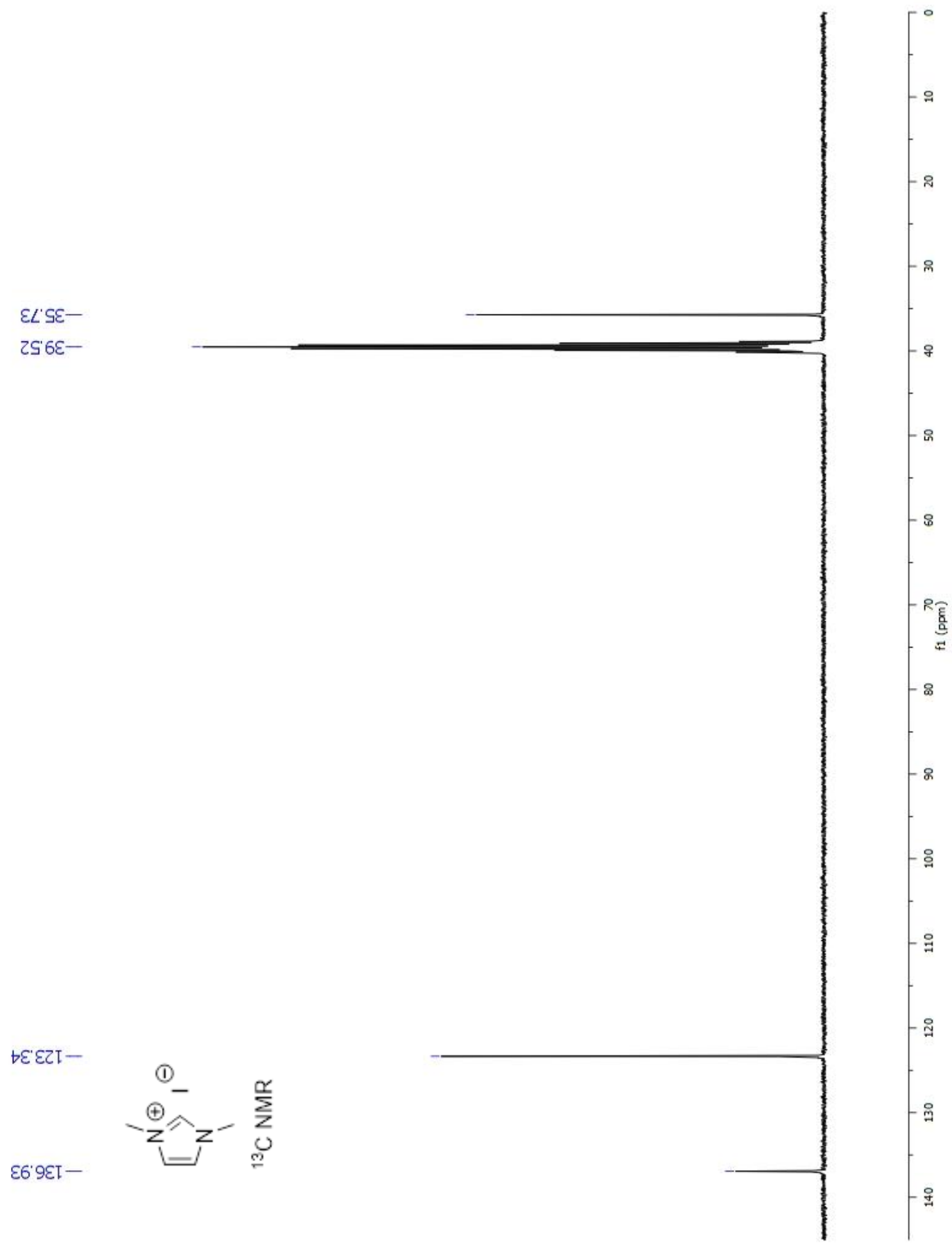




\section{References}

(1) BP. BP Statistical Review of World Energy 2016; London, 2016.

(2) Schiermeier, Q.; Tollefson, J.; Scully, T.; Witze, A.; Morton, O. Nature 2008, 454, 816-823.

(3) IEA. Key World Energy Statistics; Paris, 2016.

(4) Ginley, D. S.; Parilla, P. A. Front. Energy Res. 2013, 1, 1-5.

(5) Callendar, G. S. Q. J. R. Meteorol. Soc. 1938, 64, 223-240.

(6) Antonovsky, M. Y.; Bolin, B.; Bolle, H.-J.; Dickinson, R. E.; Doos, B. R.; Gifford, R. M.; Jager, J.; Jarvis, P. G.; Jones, P. D.; Keepin, W.; Kelly, P. M.; Kristoferson, L.; Mintzer, I.; Parry, M. L.; Robin, G. deQ.; Sandford, A. P.; Seiler, W.; Shugart, H. H.; Tarrant, J. R.; Tucker, C. J.; Warrick, R. A.; Wigley, T. M. L. The Greenhouse Effect, Climate Change, and Ecosystems; 1986.

(7) Houghton, J. T.; Jenkins, G. J.; Ephraums, J. J. Climate Change The IPCC Scientific Assessment; New York, 1990; Vol. 1.

(8) Lashof, D. a; Ahuja, D. R. Nature 1990, 344 (6266), 529-531.

(9) Edenhofer, O.; Pichs-Madruga, R.; Sokona, Y.; Minx, J. C.; Farahani, E.; Susanne, K.; Seyboth, K.; Adler, A.; Baum, I.; Brunner, S.; Eickemeier, P.; Kriemann, B.; Savolainen, J.; Schlomer, S.; von Stechow, C.; Zwickel, T. Climate Change 2014: Mitigation of Climate Change; 2014.

(10) Dincer, I. Renew. Sustain. Energy Rev. 2000, 4 (2), 157-175.

(11) C, L. J. Science (80-. ). 1974, 186 (4162), 427.

(12) El Chaar, L.; Lamont, L. A.; El Zein, N. Renew. Sustain. Energy Rev. 2011, 15 (5), 2165-2175.

(13) Ellabban, O.; Abu-Rub, H.; Blaabjerg, F. Renew. Sustain. Energy Rev. 2014, 39, 748-764. 
(14) Kapooria, R. K.; Kumar, S.; Kasana, K. S. J. Energy South. Africa 2008, 19 (1), 77-83.

(15) Becquerel, A. E. Comptes Rendus L'Academie des Sci. 1839, 9, 145-149.

(16) Telkes, M. J. Appl. Phys. 1947, 18 (12), 1116-1127.

(17) Chapin, D. M.; Fuller, C. S.; Pearson, G. L. J. Appl. Phys. 1954, 25 (5), 676-677.

(18) Green, M. A. Sol. Energy 2003, 74 (3), 181-192.

(19) Saga, T. NPG Asia Mater. 2010, 2 (3), 96-102.

(20) Parida, B.; Iniyan, S.; Goic, R. Renew. Sustain. Energy Rev. 2011, 15 (3), 1625-1636.

(21) Hagfeldt, A.; Boschloo, G.; Sun, L.; Kloo, L.; Pettersson, H. Chem. Rev. 2010, 110 (11), 6595-6663.

(22) Reference Solar Spectral Irradiance: Air Mass 1.5 http://rredc.nrel.gov/solar/spectra/am1.5/ (accessed Jul 5, 2017).

(23) Grätzel, M. Acc. Chem. Res. 2009, 42 (11), 1788-1798.

(24) Balasingam, S. K.; Lee, M.; Kang, M. G.; Jun, Y. Chem. Commun. 2013, 49 (15), 1471-1487.

(25) O’Regan, B.; Grätzel, M. Nature 1991, 353, 737-740.

(26) O’Regan, B. C.; Durrant, J. R. Acc. Chem. Res. 2009, 42 (11), 1799-1808.

(27) Bonnier, C.; Machin, D. D.; Abdi, O.; Koivisto, B. D. Org. Biomol. Chem. 2013, 11 (22), 3756-3760.

(28) Hagberg, D. P.; Edvinsson, T.; Marinado, T.; Boschloo, G.; Hagfeldt, A.; Sun, L. Chem. Commun. 2006, No. 21, 2245-2247.

(29) Hagberg, D. P.; Marinado, T.; Karlsson, K. M.; Nonomura, K.; Qin, P.; Boschloo, G.; Brinck, T.; Hagfeldt, A.; Sun, L. J. Org. Chem. 2007, 72 (25), 9550-9556. 
(30) Feldt, S. M.; Gibson, E. A.; Gabrielsson, E.; Sun, L.; Boschloo, G.; Hagfeldt, A. J. Am. Chem. Soc. 2010, 132 (46), 16714-16724.

(31) Kim, H.; Kim, Y.; Hong, J.; Kim, M.; Seo, H.; Park, J.; Choi, J. J. Electr. Eng. Technol. 2007, 2 (4), 513-517.

(32) Zhao, X.; Li, M.; Song, D.; Cui, P.; Zhang, Z.; Zhao, Y.; Shen, C.; Zhang, Z. Nanoscale Res. Lett. 2014, $9(1), 202$.

(33) Tsai, J. K.; Hsu, W. D.; Wu, T. C.; Meen, T. H.; Chong, W. J. Nanoscale Res. Lett. 2013, 8 (1), 459.

(34) Bella, F.; Gerbaldi, C.; Barolo, C.; Grätzel, M. Chem. Soc. Rev. 2015, 44 (11), 3431-3473.

(35) Bella, F.; Galliano, S.; Gerbaldi, C.; Viscardi, G. Energies 2016, 9 (5), 384.

(36) Selopal, G. S.; Wu, H.-P.; Lu, J.; Chang, Y.-C.; Wang, M.; Vomiero, A.; Concina, I.; Diau, E. W.-G. Sci. Rep. 2016, 6 (August 2015), 18756.

(37) Toyoda, T.; Sano, T.; Nakajima, J.; Doi, S.; Fukumoto, S. J. Photochem. Photobiol. A Chem. 2004, 164, 203-207.

(38) Bandara, T. M. W. J.; Jayasundara, W. J. M. J. S. R.; Fernado, H. D. N. S.; Dissanayake, M. A. K. L.; De Silva, L. A. A.; Albinsson, I.; Furlani, M.; Mellander, B. E. J. Appl. Electrochem. 2015, 45 (4), 289-298.

(39) Liang, M.; Chen, J. Chem. Soc. Rev. 2013, 42 (8), 3453-3488.

(40) Gadisa, A.; Svensson, M.; Andersson, M. R.; Inganas, O. Appl. Phys. Lett. 2004, 84 (9), 1609-1611.

(41) Boschloo, G.; Hagfeldt, A. Acc. Chem. Res. 2009, 42 (11), 1819-1826.

(42) Hardin, B. E.; Snaith, J.; Mcgehee, M. D. Nat. Photonics 2012, 6 (February), 162-169. 
(43) Bai, Y.; Zhang, J.; Wang, Y.; Zhang, M.; Wang, P. Langmuir 2011, 27, 4749-4755.

(44) Olson, C. L.; Nelson, J.; Islam, M. S. J. Phys. Chem. B 2006, 110 (20), 9995-10001.

(45) Miessler, G. L.; Tarr, D. A. Inorganic Chemistry, 4th ed.; Pearson Education: Upper Saddle River, 2011.

(46) Jena, A.; Mohanty, S. P.; Kumar, P.; Naduvath, J.; Lekha, P.; Das, J.; Narula, H. K.; Mallick, S.;

Bhargava, P.; Gondane, V. Trans. Indian Ceram. Soc. 2012, 71 (May 2012), 1-16.

(47) Yang, C.; Liao, S.; Sun, Y.; Chuang, Y.; Wang, T.; Shieh, Y.; Lin, W. Journl Phys. Chem. C 2010, 114, 21786-21794.

(48) Wang, M.; Chamberland, N.; Breau, L.; Moser, J.-E.; Humphry-Baker, R.; Marsan, B.; Zakeeruddin, S. M.; Grätzel, M. Nat. Chem. 2010, 2 (5), 385-389.

(49) Daeneke, T.; Kwon, T.-H.; Holmes, A. B.; Duffy, N. W.; Bach, U.; Spiccia, L. Nat. Chem. 2011, 3 (3), 211-215.

(50) Yanagida, S.; Yu, Y.; Manseki, K. Acc. Chem. Res. 2009, 42 (11), 1827-1838.

(51) Chen, K. Y.; Du, C.; Patrick, B. O.; Berlinguette, C. P. Inorg. Chem. 2017, 56, 2383-2386.

(52) Sepehrifard, A.; Kamino, B. A.; Bender, T. P.; Morin, S. ACS Appl. Mater. Interfaces 2012, 4 (11), 6211-6215.

(53) Liu, X.; Zhang, W.; Uchida, S.; Cai, L.; Liu, B.; Ramakrishna, S. Adv. Mater. 2010, 22 (20), E150E155.

(54) Hug, H.; Bader, M.; Mair, P.; Glatzel, T. Appl. Energy 2014, 115, 216-225.

(55) Nazeeruddin, M. K.; Pechy, P.; Renouard, T.; Zakeeruddin, S. M.; Humphry-baker, R.; Comte, P.; Liska, P.; Cevey, L.; Costa, E.; Shklover, V.; Spiccia, L.; Deacon, G. B.; Bignozzi, C. A.; Grätzel, M. J. 
Am. Chem. Soc. 2001, 123, 1613-1624.

(56) Grätzel, M. Inorg. Chem. 2005, 44, 6841-6851.

(57) Matthew, S.; Yella, A.; Gao, P.; Humphry-Baker, R.; Curchod, B. F. E.; Ashari-Astani, N.; Tavernelli, I.; Rothlisberger, U.; Nazeeruddin, M. K.; Grätzel, M. Nat. Chem. 2014, 6, 242-247.

(58) Yella, A.; Lee, H.-W.; Tsao, H. N.; Yi, C.; Chandiran, A. K.; Nazeeruddin, M. K.; Diau, E. W.-G.; Yeh, C.-Y.; Zakeeruddin, S. M.; Grätzel, M. Science (80-. ). 2011, 334, 629-634.

(59) Wang, Z. Chem. Mater. 2008, 20 (12), 3993-4003.

(60) Abdi, O. K. Multichromic Triphenylamine-based dyes : Designing better interfaces for DSSC applications, Ryerson University, 2015.

(61) Bonnier, C.; Machin, D. D.; Abdi, O. K.; Robson, K. C. D.; Koivisto, B. D. Org. Biomol. Chem. 2013, $11(40), 7011-7015$.

(62) Yu, Q.; Liao, J.; Zhou, S.; Shen, Y.; Liu, J.; Kuang, D.; Su, C. J. Phys. Chem. C 2011, 115, 2200222008.

(63) Robson, K. C. D.; Hu, K.; Meyer, G. J.; Berlinguette, C. P. J. Am. Chem. Soc. 2013, 135, 1961-1971.

(64) Ito, S.; Chen, P.; Comte, P.; Nazeeruddin, M. K.; Liska, P.; Pechy, P.; Grätzel, M. Prog. Photovoltaics Res. Appl. 2007, 15, 603-612.

(65) Hara, K.; Wang, Z. S.; Cui, Y.; Furube, A.; Koumura, N. Energy Environ. Sci. 2009, 2 (10), 1109.

(66) Hussein, B. Towards Novel BODIPY Compounds for Material and Medical Applications, Ryerson University, 2017. 